Florida International University FIU Digital Commons

$11-10-2015$

\title{
An Exploration of Workplace Interventions for Women with Postpartum Depression Symptoms
}

Cyntianna C. Ledesma Ortega

Florida International University, Cyntianna@gmail.com

DOI: 10.25148 /etd.FIDC000175

Follow this and additional works at: https://digitalcommons.fiu.edu/etd

Part of the Other Education Commons, Performance Management Commons, Technology and Innovation Commons, and the Training and Development Commons

\section{Recommended Citation}

Ledesma Ortega, Cyntianna C., "An Exploration of Workplace Interventions for Women with Postpartum Depression Symptoms" (2015). FIU Electronic Theses and Dissertations. 2278.

https://digitalcommons.fiu.edu/etd/2278

This work is brought to you for free and open access by the University Graduate School at FIU Digital Commons. It has been accepted for inclusion in FIU Electronic Theses and Dissertations by an authorized administrator of FIU Digital Commons. For more information, please contact dcc@fiu.edu. 


\section{FLORIDA INTERNATIONAL UNIVERSITY \\ Miami, Florida}

\section{AN EXPLORATION OF WORKPLACE INTERVENTIONS FOR WOMEN WITH POSTPARTUM DEPRESSION SYMPTOMS}

A dissertation submitted in partial fulfillment of

the requirements for the degree of

DOCTOR OF EDUCATION

in

ADULT EDUCATION AND HUMAN RESOURCE DEVELOPMENT

by

Cyntianna C. Ledesma Ortega

2015 
To: Dean Delia C. Garcia

College of Education

This dissertation, written by Cyntianna C. Ledesma Ortega, and entitled An Exploration of Workplace Interventions for Women with Postpartum Depression Symptoms, having been approved in respect to style and intellectual content, is referred to you for judgment.

We have read this dissertation and recommend that it be approved.

Patricia Barbetta

Mido Chang

Valerie Russell

Thomas G. Reio, Jr., Major Professor

Date of Defense: November 10, 2015

The dissertation of Cyntianna C. Ledesma Ortega is approved.

Dean Delia C. Garcia

College of Education

Dean Lakshmi N. Reddi

University Graduate School

Florida International University, 2015 
(C) Copyright 2015 by Cyntianna C. Ledesma Ortega

All rights reserved. 


\section{DEDICATION}

To my beautiful girls, Brielle Mavie and Stella Jude, this dissertation happened because of you and for you. This is my small attempt to make the world a place that is worthy of having you in it. 


\section{ACKNOWLEDGMENTS}

This section could be a dissertation all by itself. There are many people to thank, but teachers make the world go 'round, so I'll start with them.

To Dr. Reio, I am certain that without you this dissertation never would have happened. From your compassion when Stella was born, to the way you supported my topic from its inception, you have played an instrumental role in my success. You have been an exceptional mentor, not only in an academic sense, but also by sharing your own stories of parenting highs and lows, life lessons, and most important of all, the best places in the neighborhood to enjoy a nice meal. I feel privileged to have had the opportunity to learn from you, write with you, and have a friendship with you. THANK YOU!

To Dr. Chang, I told you that you would never get me to like statistics and I was wrong. Thank you for trying AND succeeding. You are the most patient professor I've ever had and the only one who has ever been able to get me to like math.

To Dr. Barbetta and Dr. Russell, thank you for joining my committee. Dr. Barbetta, your curiosity and feedback about the topic helped me recognize areas of weakness and consider angles that had never occurred to me. Thank you for your candor because it made me a better researcher. Dr. Russell, you were the one who finally made me realize that I needed to focus on who I wanted to help and how, so that I could stop running around in circles with regard to my research question. I needed that. Thank you!

To Dr. Bliss, your feedback throughout this process has been extraordinarily valuable. I always looked forward to it because it was so evident that you really read my work and wanted me to be successful. I am grateful to have been able to learn from you. 
And, finally, thank you every teacher who encouraged my love of reading, writing, and learning, but especially to my first teacher, Ms. Evelyn. Thank you for listening during the most desperate times and for catalyzing the idea for this dissertation by reminding me that if I don't like something, I have the power to change it.

To my parents, thank you for always supporting my writing from the plays I would write and have Joanna and Wesley act in, to the days of Y.O., funding my own newspaper, writing for the high school newspaper, TV production days, journalism school, masters, and doctorate, and for giving me practice by having me edit your own works. I wouldn't be me if it hadn't been for parents like you who saw the value in allowing a child to express herself in her own way. Thank you!

To my siblings, Joanna, Wesley, Vincent, and Arianna, my life would have been utterly boring growing up without you. Thanks for keeping it interesting. Special thanks to Vincent for reading and editing 64 pages of this dissertation.

To Nancy and Roberto, thank you for being supportive of my education from day one and for feeding and babysitting my children (and husband) so that I could write.

I have saved the very best for last. To my husband Humberto, all the people listed before you have helped me while I was in the classroom, but YOU helped me get to the door. If it weren't for you I never would have stepped into the first master's class, much less have finished a dissertation. Thank you for always trying to make me see myself the way you see me and for putting my education first. You are the greatest teammate, friend, husband, and father I could ever have dreamed up. You have always cheered for me even when I felt like a loser and that support has meant everything. And as promised, now it's my turn to cheer for you. Get up and make it happen, baby. Love you! 
ABSTRACT OF THE DISSERTATION

AN EXPLORATION OF WORKPLACE INTERVENTIONS FOR WOMEN WITH POSTPARTUM DEPRESSION SYMPTOMS

\author{
by
}

Cyntianna C. Ledesma Ortega

Florida International University, 2015

Miami, Florida

Professor Thomas G. Reio, Jr., Major Professor

The overarching purpose of this collected papers dissertation was to explore the best practices used by Human Resource Development (HRD) professionals to help working mothers who are experiencing postpartum depression symptoms after maternity leave. The first paper in this dissertation was an integrative literature review. The second paper in this dissertation investigated whether participation in online support groups served to moderate the effect of postpartum depression symptoms on work impairment (measured in terms of absenteeism and presenteeism). Both studies were undergirded by the stress-buffering hypothesis, which posits that social support can moderate the effect of experiencing a stressful event. Study \#2 also included the self-labeling theory, which explains how a person with mental illness seeks voluntary support.

Study \#1 reviews studies that examine how to support women experiencing postpartum depression symptoms in the workplace. No studies were found in HRD literature. The stress-buffering hypothesis held weight in informing HRD professionals to help women experiencing postpartum depression symptoms. The majority of the studies 
pointed to social support, especially from coworkers and supervisors, as having a positive effect on postpartum depression symptom scores.

Study \#2 explores the effect of participation in online support groups on the work impairment of women experiencing postpartum depression symptoms. This study surveyed working mothers with children under the age of one from online support groups. The survey consisted of three measures: The Edinburg Postnatal Depression Scale (Cox, Holden, \& Sagovsky, 1987); the Work Productivity and Activity Impairment (WPAI; Reilly, Zbrozek, \& Dukes, 1993); and the Online Social Support for Smoking Cessation survey (OS4; Graham, Papandonatos, Kang, Moreno, \& Abrams, 2011). This study did not support the hypothesis that online support group participation would moderate the effect of postpartum depression symptoms on work impairment.

Overall, the findings of these studies are entry points into the HRD literature about how working women who are experiencing postpartum depression symptoms can be supported by their employers. Further research is necessary to examine the type of social support that is effective at helping working mothers. 


\section{TABLE OF CONTENTS}

CHAPTER

PAGE

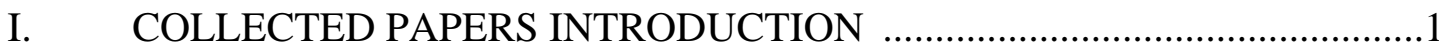

Background to the Problem ..........................................................................

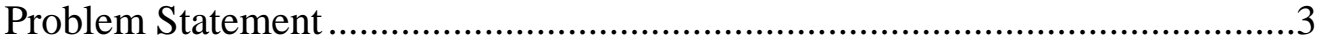

Purpose of Collected Papers .........................................................................6

Conceptual Background for Collected Papers ......................................................6

Empirical Research on Women with Postpartum Depression Symptoms at

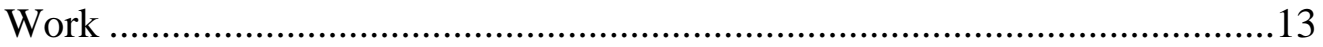

Description of Collected Papers.......................................................................14

Potential Implications of Collected Papers Research .......................................22

Structure of Collected Papers Dissertation .........................................................22

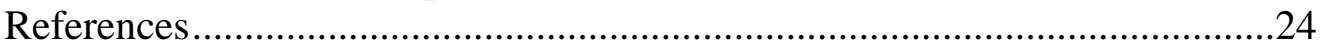

II. STUDY \#1, INTERVENTIONS FOR WOMEN WITH POSTPARTUM

DEPRESSION SYMPTOMS: AN INTEGRATIVE LITERATURE

REVIEW FOR HUMAN RESOURCE DEVELOPMENT

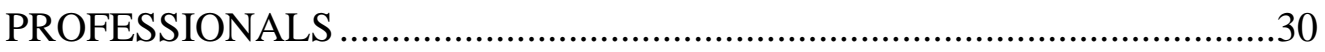

Purpose and Research Question.....................................................................32

Theoretical Framework ...............................................................................33

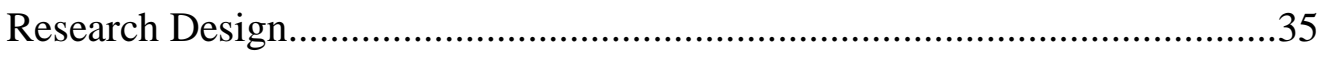

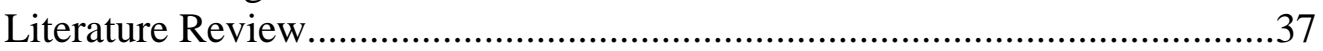

HRD Professionals and Maternal Mental Health...............................................48

Further Research …………...................................................................5

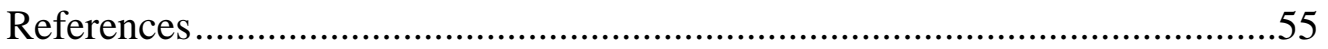

III. STUDY \#2, THE IMPACT OF ONLINE SOCIAL SUPPORT ON WORK IMPAIRMENT IN WOMEN WITH POSTPARTUM DEPRESSION

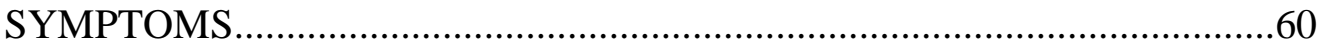

Purpose of the Study ..................................................................................64

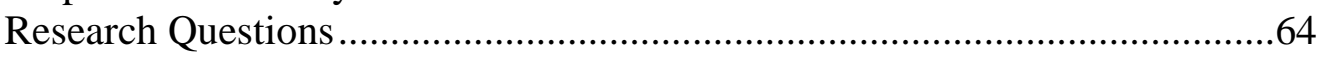

Conceptual Framework ...................................................................................64

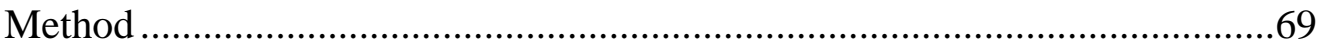

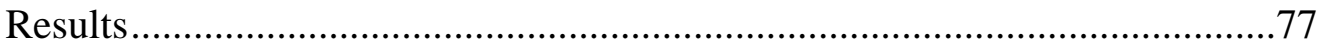

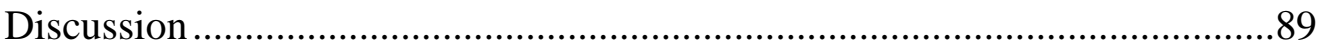

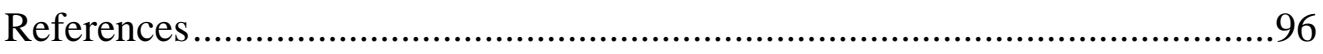

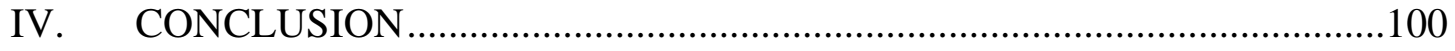

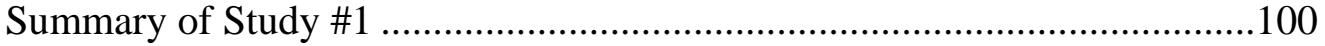

Summary of Study \#2 .................................................................................102

Findings Related to Overall Purpose Collected Papers Dissertation ...............104

Implications for Theory, Research, and Practice ...........................................105

References........................................................................................110 


\section{COLLECTED PAPERS INTRODUCTION}

This collected papers dissertation used measures of absenteeism (the time taken off from work related to illness) and presenteeism (the ability to produce effectively) to determine whether online social support moderates the effect of postpartum depression symptoms on work impairment. The background to the problem, problem statement, purpose, conceptual background, prior empirical research, description of the collected papers, brief overview of potential implications, and the structure of the collected papers are presented below.

\section{Background to the Problem}

Postpartum depression symptoms pose a health concern for working mothers, as well as for the health of the organization with which she is employed. In addition to the physical toll of pregnancy and birth, expectant and new mothers experience the added stress of having to leave work for a period of time (maternity leave), which can affect household income or can cause job loss if the Family and Medical Leave Act (2006) does not apply. Compounding an already stressful situation, some new mothers may experience peripartum depression symptoms. Peripartum depression symptoms is an umbrella term for a major or minor depressive episode beginning during pregnancy or after the birth of a child (American Psychiatry Association, 2013). To be diagnosed with peripartum depression symptoms, women must exhibit either a depressed mood or loss of interest or pleasure along with three or more of the following symptoms: significant weight loss or gain; insomnia or hypersomnia; psychomotor agitation or delay; fatigue or loss of energy; feelings of worthlessness or guilt nearly every day; diminished ability to think or concentrate; or recurrent thoughts of death or suicide (with or without a specific 
plan; American Psychiatric Association, 2013). The American Psychiatric Association (2013) has bundled postpartum depression symptoms (specifically depression “occurring after childbirth, with reference to the mother"; Postpartum, 2003) into the same classification as peripartum depression symptoms. However, the researcher is especially interested in the effects of postpartum depression symptoms on work impairment and therefore will attempt to disaggregate the literature on peripartum depression symptoms from that specifically about postpartum depression symptoms. Additionally, the phrase postpartum depression symptoms will be used throughout this paper to describe symptoms of a depression occurring after the birth of a child.

Although the workplace cost directly associated with postpartum depression symptoms is not evident in the literature, based on the clinical designation of postpartum depression symptomatology as a major or minor depression with postpartum onset (American Psychiatric Association, 2013), the literature on depression can be used to estimate the effects of postpartum depression symptoms in the workplace. Depression affects an employee's ability to function and accounts for a higher incidence of absenteeism (time taken off from work) and lack of presenteeism (ability to produce effectively; Greenberg et al., 2003; Lerner et al., 2012). It is vital to the job organization that the effects of depression on work impairment be mitigated. Women who are experiencing postpartum depression symptoms upon their return to work may require support to overcome their depression and once again become productive employees. Empirical studies have estimated that $5 \%$ to $25 \%$ of pregnant and postpartum women experience depression symptoms (Bennett, Einarson, Taddio, Koren, \& Einarson, 2004; Centers for Disease Control and Prevention, 2008; Klein \& Essex, 1994; O'Hara \& 
Swain, 1996). The variation in the prevalence estimate is affected by several factors beginning with a lack of diagnosis. A lack of diagnosis is often attributed to the fact that postpartum depression symptoms mirror those of general postpartum discomfort (Klein \& Essex, 1994; O’Hara, Neunaber, \& Zekoski, 1984). Another fact is that there is a lack of consensus on the time frame of the postpartum period. The DSM-V informs that the onset of postpartum depression symptoms is within the first four weeks after the birth of a child (American Psychiatric Association, 2013). However, several studies have found the highest risk for the onset of depression is within the first three months after delivery (Andrews-Fike, 1999; Horowitz \& Goodman, 2004; Stowe, Hostetter, \& Newport, 2005). Other researchers found that the onset risk is elevated through the first six months after delivery (Beeghly et al., 2002; Stuart, Couser, Schilder, O'Hara, \& Gorman, 1998). This discrepancy makes it difficult to fully understand when postpartum depression symptoms begin and what triggers the onset. One thing is very clear in the literature; a woman who is left untreated is likely to be depressed well into and, in some cases, after her child's first year of life (Carpiniello, Parante, Serri, Costa, \& Carta, 1997; O’Hara \& Zekoski, 1988). To cover the breadth of the postpartum depression period established in the literature, the researcher will consider the time after the birth of a child through that child's first birthday the postpartum period. It has been well established in the literature that $62.4 \%$ of new mothers return to work during their child's first year (Laughlin, 2011).

\section{Problem Statement}

Human Resource Development (HRD) "is a process for developing and unleashing human expertise through organization development and personnel training and development for the purpose of improving performance” (Swanson \& Holton, 2001, 
p. 4). If improving performance is the ultimate goal of HRD professionals, then it is crucial that HRD professional consider the impact of postpartum depression symptoms on work impairment of new mothers. Experiencing postpartum depression symptoms causes a risk, not only to the health of the employee herself, but also to the organization in loss of productivity. To understand what information HRD professionals have about postpartum depression symptoms in the workplace, a search of three major databases (Academic OneFile, Academic Search Complete, and ProQuest) was conducted. The searches (which included anything published through February 17, 2015) combined the term "postpartum depression” and each of the following terms individually: "workplace”, “job”, “employee”, and "human resources” and returned a total of 81 articles. Of the 81 articles returned, about half were repeated. In total, eight were deemed relevant or somewhat-relevant to this study, but none explicitly addressed postpartum depression symptoms and workplace interventions and none was found in journals or resources specifically addressed to HRD professionals. The eight studies were grouped into the following categories: risks of depression related to income and job security (Dagher, McGovern, Dowd, \& Gjerdingen, 2012; Miyake, Tanaka, Sasaki, \& Hirota, 2011); maternal mental health in relation to the work-related stress setting (Dagher, 2007; Dagher et al., 2009; Perry-Jenkins, Smith, Goldberg, \& Logan, 2011); postpartum depression symptoms in relation to job quality (Cooklin, Canterford, Strazdins, \& Nicholson, 2011); depression related to maternal postpartum employment choices and expectations (Hock \& DeMeis, 1990); and employer-employee contact during maternity leave and implications concerning a new mother's return to work (Stomp-van den Berg et 
al., 2007). It appears that there is no relevant literature around helping women with postpartum depression symptoms at work that is directed to HRD professionals.

In an effort to begin a conversation around what HRD professionals can do to help an employee who is dealing with postpartum depression, this researcher is interested in how HRD professionals can offer social support to the employee. Studies have shown that social support has been found to be a major defense against postpartum depression symptoms (Beck, 2001; Gjerdingen \& Chaloner, 1994; Gjerdingen, McGovern, Attanasio, Johnson, \& Kozhimannil, 2014). One study found that women with postpartum depression symptoms who sought out support in online forums found relief and comfort in exchanging their stories with others (Evans, Donelle, \& Hume-Loveland, 2012). The ability to freely express oneself with others appears to serve an important function for women with postpartum depression symptoms who often feel the need to disguise their distress and shame related to their perceived inability to be a good mother (Evans et al., 2012). Promoting the use of online discussion groups as an intervention strategy is an excellent opportunity for HRD professionals to take part in the well-being of their postpartum employees. Studies surrounding the use of online support groups for postpartum depression symptoms and in other women's issues (e.g., menopause, child loss, premature births, and infertility) have shown that online support groups are not only abundant sources of information and support for participants, but also are associated with positive outcomes for participants (Bochatin, 2014; Evans et al., 2012; Malik \& Coulson, 2010; Pector, 2012). The ultimate goal of online support groups is to promote "successful reintegration" into society and also to avoid negative consequences like depression, isolation and suicide (Pector, 2012, p.22). By encouraging mothers to be exposed to the 
experiences of other mothers, especially experiences that also conflict with the norm, HRD professionals may be able to help in creating a social support system for women with postpartum depression.

\section{Purpose of Collected Papers}

The purpose of this collected papers dissertation is to investigate whether participation in online support groups is related to less work impairment for women with postpartum depression. Data about online support groups and the impact on work impairment collected in the form of a survey. The survey consisted of questions from the Edinburg Postnatal Depression Scale (EPDS; Cox, Holden, \& Sagovsky, 1987) to determine if the participant is experiencing postpartum depression, the Work Productivity and Activity Impairment (WPAI; Reilly, Zbrozek, \& Dukes, 1993) to determine the participant's absenteeism and presenteeism, and the online social support for smoking cessation (OS4; Graham, Papandonatos, Kang, Moreno, \& Abrams, 2011) to measure perceived online social support.

\section{Conceptual Background for Collected Papers}

This collected papers dissertation employs two theories for its conceptual framework, each of which will be explained in this section. The first theory is the selflabeling theory introduced by Thoits (1985) to explain why mental health patients voluntarily seek treatment. The second is the stress-buffering hypothesis proposed by Cohen and Wills (1985), which aims to explain how a potentially stressful event can lead to illness or illness behavior. The illness or illness behavior (e.g., depressed mood, loss of interest, or diminished ability to think or concentrate) then contributes to work impairment. 


\section{The Self-Labeling Theory}

The self-labeling theory was introduced as an explanation for voluntary treatment seeking in mental health patients (Thoits, 1985). Self-labeling does not require, public, official labeling from peers for a woman with postpartum depression symptoms to apply a negative label to herself (Thoits, 1985). In fact, the self-labeling process happens in private. For example, women often describe the feeling of falling instantly in love with their newborn child upon his or her birth. A mother who is suffering from postpartum depression symptoms may label herself a bad mother if she did not feel immediately connected with her child. She compares herself to what other mothers feel - what society deems to be normal - and decides she does not meet the expectation. The concept of needing to meet normative expectations is further supported by Hochschild’s (2012) studies that demonstrate that individuals notice when they have inappropriate feelings or inappropriately display their feelings and work to bring them in line with the social expectation.

There are three major assumptions that underlie the theory of self-labeling (Thoits, 1985). First, that the individual who is self-labeling is a well-socialized individual who can identify when rules or normative expectations have been broken. Next, that there are known categories of normative behaviors that carry cultural labels for individuals who violate them. Last, it theorizes that individuals are motivated to conform to social expectations. Thoits explains that when an internal conflict occurs between the societal expectations of emotions for a given situation and the actual emotions experienced by a person, the self-labeling process takes place. When a new mother experiences feelings that deviate from the societally indoctrinated norm of a blissful 
motherhood, she may begin to label herself as a bad mother, as supported in a study by Taylor (1996). It is her own recognition of these feelings, which are contrary to societal norms, that catalyzes her to seek treatment voluntarily (Taylor, 1996). These feelings of inadequacy, if not mitigated, will ultimately lead to depressive symptoms that contribute to work impairment.

\section{The Working Mother Dilemma}

Numerous studies have linked return-to-work events - such as child-care related stressors, shorter maternity leaves, and socio-economic status - as risk factors for postpartum depression symptoms (Beck, 2001; O’Hara \& Swain, 1996; Robertson, Grace, Wallington, \& Stewart, 2004). Additionally, one study found that even women who were self-perceived to be well-adjusted to early motherhood did not feel ready to return to work at 18 weeks postpartum (Vujinović, 2014). Therefore, we can assume that in women with postpartum depression symptoms the stress of returning to work is likely exacerbated by their condition and may play a role in work impairment.

In addition to physiological and psychological factors, mothers face the dilemma of deciding whether they want to be working mothers or if they want to be (or can afford to be) stay-at-home mothers. There has been ample research around this dilemma and it serves to emphasize the point that making the decision to return to work after the birth of

a child is not only a matter of physical, psychological, and economic well-being, but also one that is deeply intertwined with the socially-constructed identity labels applied to different types of mothers (e.g. the working mother versus the stay-at-home mother; Crowley, 2015; Elgar \& Chester, 2007; Mudry, Kushner, \& Neufeld, 2010; Pedersen \& Kilzer, 2014). Balancing these issues can be difficult for a mother who is well-adjusted, 
such as the women in the previously cited studies, yet for women with postpartum depression, there is an amplified stress response due to poor coping abilities including fatigue, difficulties in soothing and caring for baby, and debilitating sense of incompetence (Knudson-Martin \& Silverstein, 2009).

\section{Seeking Social Support Online}

Social support is defined as the functions performed for an individual by others (Thoits, 2011). Thoits borrowed from Sullivan (1953) to classify these others into two groups: primary and secondary. Primary group members are people who are close to the individual to with whom the individual feels emotionally tied such as significant others and family members. The secondary group members tend to be larger and one where members' knowledge of one another is less personal. Secondary members may enter and leave their common group (such as religious group, workplace, and volunteer groups) at their own discretion therefore the length of membership will vary (2011). Thoits has asserted that both groups - primary and secondary - can serve equally important functions in social support.

Online support group members generally fall into the secondary group category.

One study found that individuals lacking social support in the real world were more likely to engage in online social support (Turner, Grube, \& Meyers, 2001). When an individual seeks support online, the individual is expanding his or her network of potential similar others. This can lead to higher levels of social support (Cohen \& Wills, 1985). Online social support has been shown to be effective for matching the user to his or her needs (Vayreda, \& Antaki, 2009). In a study about online support groups for people with bipolar disorder, Vayreda and Antaki (2009) found that a person must be comfortable 
with his or her identity (in the case for postpartum depression, the self-assigned label) to find a support group that adequately addresses his or her needs. This further illustrates not only the psychological function of self-labeling, but also the practical need for it as it applies to support seeking behavior.

The four main functions of social support include: emotional, instrumental, informational, and, within informational, appraisal. Emotional support refers to offerings of love, caring, esteem, encouragement, and sympathy. Instrumental support refers to helping others with practical tasks or problem or offering material assistance. Informational support is the provision of facts or advice that helps an individual solve problems. Encompassed within informational support is appraisal support. Appraisal support is feedback about an individual's situation and giving guidance about possible courses of action (Cohen \& McKay, 1984; Thoits, 2011). Cohen and McKay (1984) proposed that when an individual decides that an event is in fact harmful, a stress response will occur. The researchers argued that social support can enter at the moment of appraisal to help an individual make a decision about whether the stressor is in fact harmful. Social support can also enter at the moment of a stress response to help an individual make a decision about his or her coping abilities. Helping an individual to redefine the situation as non-threatening is the ultimate goal of appraisal support. The proposed model posits that when an individual is able to cope with a stressful situation the negative effects related to work impairment are mitigated.

Appraisal support is best offered by individuals deemed as similar others; people who have or are experiencing the same or a similar situation (Cohen \& McKay, 1984). In this case, women with postpartum depression symptoms would seek support from other 
women with postpartum depression. A way to quickly connect with a community of similar others is through using the Internet to find online support groups (Fox \& Duggan, 2013). Approximately $80 \%$ of Internet users have reported posting a healthcare-related question or shared their own health experience online (Fox \& Duggan, 2013). Of those $59 \%$ who posted comments, questions or stories about their own health, $78 \%$ reported that they posted their question to a general audience of friends or other Internet users. This means that people who are seeking support are doing so more from their peers rather than healthcare professionals (Fox \& Duggan, 2013).

\section{The Stress-Buffering Hypothesis}

The stress-buffering hypothesis proposed by Cohen and Wills (1985) has five parts, which begins with the occurrence of a potentially stressful event. A stressful event refers to a situation that has the potential to elicit a negative effect, physiological response, and behavioral adaptation (Cohen \& McKay, 1984). In this study, the potentially stressful event is returning to work after the birth of a child. If the stress of the event is not mitigated, this could lead to work impairment as posited by the conceptual model.

The next stage of the stress-buffering hypothesis is appraisal of the stressful event. If there is an intervention at this point, either before there is a reaction to the stress related to the event or during the anticipation of said event, then there is a possibility that a stress appraisal response can be avoided (Cohen \& Willis, 1985). In other words, if a new mother is anticipating that returning to work will be a stressful event; then, before the event occurs, others can intervene to help her change her perception. Presumably, the 
social support would moderate not only the appraisal of the event, but also the selflabeling attributed to it, and its effects on work impairment.

In the third step, when social support from others does not intervene, the event is appraised as stressful. Continuing with the subject of this study, this could mean that the new mother has decided that returning to work will have negative outcomes for her and her child. This is followed by an emotionally linked physiological response or behavioral adaptation such as anxiety or sadness. At this point, social support from others could help the mother reappraise the stressful event, the resulting self-labeling, and also her response to it. However, without social support, the emotional response is followed by the illness or illness behavior (depression), which can ultimately lead to work impairment.

The conceptual model undergirding this study combines the stress-buffering hypothesis and the self-labeling hypothesis. The self-labeling hypothesis posits why women with postpartum depression symptoms seek social support. The stress-buffering hypothesis postulates how returning to work can catalyze a series of stress responses that eventually lead to work impairment if social support is not sought.

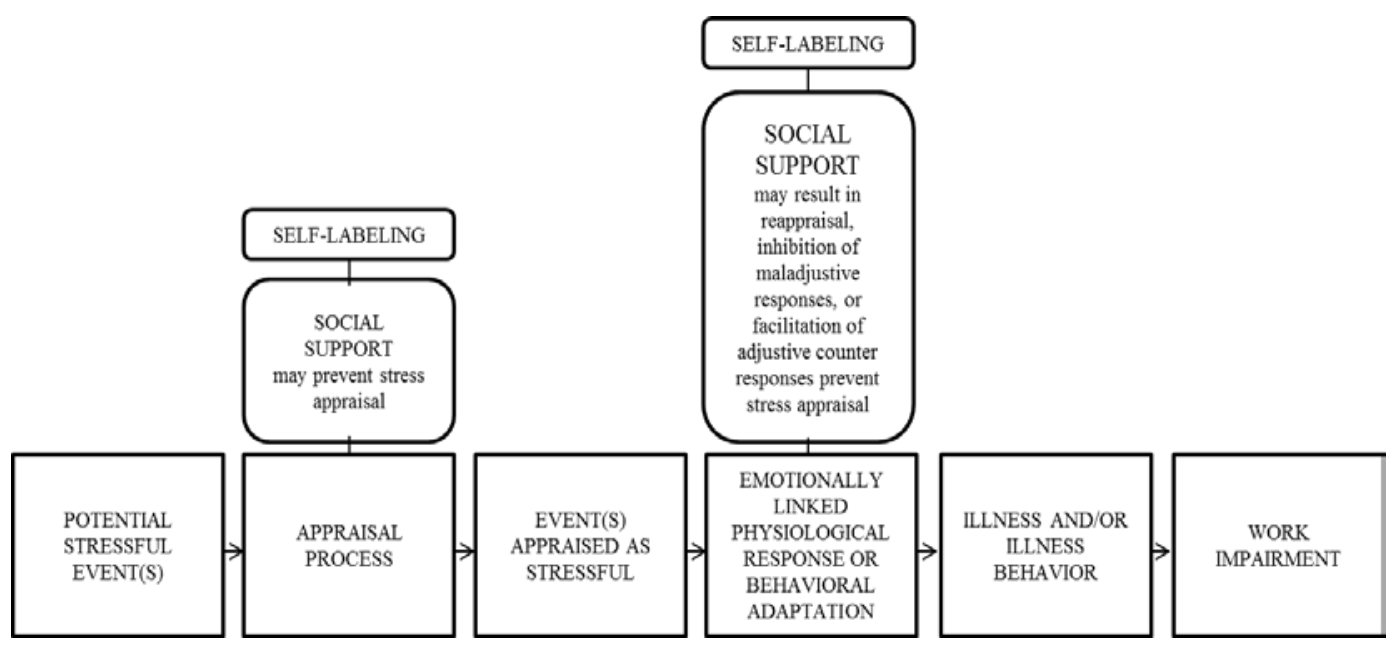


Figure 1. The conceptual model for this study combines the self-labeling theory and the stress-buffering hypothesis to predict work impairment measured by absenteeism and presenteeism.

\section{Empirical Research on Women with Postpartum Depression Symptoms at Work}

Although there is limited research focused on women's experiences with

postpartum depression symptoms at work, one large study by Dagher et al. (2009) found that psychological job demands were positively associated with postpartum depression symptom scores. That study was conducted in three hospitals in Minneapolis-Saint Paul, Minnesota and included 638 participants. The participants were primarily White (87\%), married (76\%), first time mothers (46\%) averaging around 30 years old, and had incomes above the state poverty level (86\%). The women were surveyed by perinatal nurses at the hospital for enrollment, and then were interviewed over the telephone by university researchers.

The findings of that study related to psychological job demands are supported by studies that suggest that stressful life events (such as those related to returning to work such as finding child-care, shorter maternity leaves, and socio-economic status) and lack of social support are major risk factors in postpartum depression symptoms (Beck, 2001; O’Hara \& Swain, 1996; Robertson, Grace, Wallington, \& Stewart, 2004). Dagher et al.’s (2009) study also found that workplace social support had a buffering effect on postpartum depression. That finding is supported by studies on postpartum depression symptom interventions that list social support as an effective intervention (Beck, 2001;

Gjerdingen \& Chaloner, 1994; Gjerdingen et al., 2014).

There is a significant financial impact to organizations with depressed employees. While there are no data directly related to the cost-effects of postpartum depression 
symptoms in the workplace, the literature on general depression reveals that there is a $20 \%$ loss of productivity per depressed individual per day and there was an estimated $\$ 51.5$ billion lost in work impairment, such as absenteeism and presenteeism (the ability to produce effectively) in the year (Beck et al., 2011; Greenberg et al., 2003; Lerner et al., 2012).

The absence of empirical research addressing the needs of depressed individuals in the workplace has been acknowledged (Dietrich, Deckert, Ceynowa, Hegerl, \& Stengler, 2012). There is also little research on interventions for postpartum depression symptoms in the workplace as evidenced by a review of three major databases (Academic OneFile, Academic Search Complete, and ProQuest). However, as previously discussed, research indicates that social support and, specifically, online support groups can mitigate the negative effects of postpartum depression symptoms. To close the gap in knowledge about what particular events related to returning-to work cause stress to women with postpartum depression symptoms and to subsequently create interventions, two studies were conducted.

\section{Description of Collected Papers}

The fulfillment of this collected papers dissertation took take place across two studies related to the workplace experiences of women experiencing postpartum depression symptoms. The first of the studies was a literature review and the second an empirical study.

Table 1 presents the running title, method, and intended publication outlet for each of the two studies in this proposed collected papers dissertation. These studies are further described in the sections that follow. 
Table 1

Title, Method, and Intended Publication Outlet for Collected Papers

\begin{tabular}{lll}
\hline Running Title & Method & Intended Publication Outlet \\
\hline STUDY \#1. Interventions & Literature review & $\begin{array}{l}\text { Human Resource } \\
\text { for Women with Postpartum }\end{array}$ \\
$\begin{array}{l}\text { Depression Symptoms: An } \\
\text { Integrative Literature }\end{array}$ & \\
Review for Human & & \\
Resource Development & & \\
Professionals & &
\end{tabular}

STUDY \#2. The Impact of Online Social Support on Workplace Absenteeism and Presenteeism in Women with Postpartum Depression
Survey (Babbie, 1990 as

cited by Creswell, 2012).
Human Resource

Development Quarterly

\section{Study \#1: Interventions for Women with Postpartum Depression Symptoms: An}

\section{Integrative Literature Review for Human Resource Development Professionals}

There is substantial research in the public health, medical, psychology, and psychiatry fields about the experiences of women with postpartum depression, the effect on their families, and some of the risk factors (Beck, 2001; O'Hara \& Swain, 1996;

Knudson-Martin \& Silverstein, 2009; Robertson, Grace, Wallington, \& Stewart, 2004).

However, there is a need for research that explores how experiencing postpartum depression symptoms can lead to work impairment and how HRD professionals might intervene. The overall purpose of this literature review was to examine the research in the previously mentioned fields to inform the practice of HRD concerning how to help employees with postpartum depression. 
Purpose and research question. The purpose of this literature review was to examine the HRD literature on postpartum depression, depression in the workplace, and the workplace repercussions to determine where there are informational gaps at the crosssection of mental health research and work impairment (measured in absenteeism and presenteeism). This review will be guided by the research questions: (a) How is postpartum depression symptoms discussed in the context of the workplace in the HRD literature in the United States? (b) Does there exist a set of best practices in the HRD literature to guide HRD professionals in helping employees with postpartum depression symptoms in the United States?

Method. A structured literature review was conducted to collect all the research conducted in the United States about postpartum depression symptoms and work impairment to the date of the study. This structured literature will be guided by the practices in Fink (2013) regarding inclusion and exclusion criteria for literature reviews. Fink offers a two-screening approach. The first screening requires a broad range of criteria be established and the second screening will be for methodological quality, which is how well a study has been designed and implemented (Fink, 2013).Three major databases (Academic OneFile, Academic Search Complete, ProQuest) were searched for terms which combined "postpartum depression" and each of the following terms individually: “workplace,” “job,” “employee,” and "human resources.” Publications must be peer-reviewed. The search will be limited to studies conducted in the United States when attempting to answer the research question.

Publication submission and formatting. This study will be submitted to Human Resource Development Review (HRDR). HRDR submissions must be prepared according 
the APA $6^{\text {th }}$ Edition. Manuscripts should not exceed 30 double-spaced pages, excluding figures and references.

\section{Study \#2: The Impact of Online Social Support on Workplace Absenteeism and Presenteeism in Women with Postpartum Depression}

This quantitative study used measures of presenteeism and absenteeism to understand if having online social support makes a positive impact on the work impairment of women with postpartum depression. In accordance with the model, a woman participating in this study will have already returned to work and may be experiencing emotional or physiological response to this event. By comparing women who do not participate in online support groups with women who do, we can better understand whether participating in online support groups by postpartum women is linked to work impairment, and to what degree.

Purpose and research question. This survey study investigated whether participation in online support groups was associated with higher presenteeism and lower absenteeism, which are the measures of work impairment. Psychological job demands were found in one study to be positively associated with postpartum depression symptoms (Dagher et al., 2009). Online support groups have been shown to help women with postpartum depression symptoms by providing “important meeting places for postpartum women to network and augment their care through emotional, informational, and instrumental support” (Evans et al., 2012, p. 409).

This study was conducted to answer the following question for employed women with postpartum depression symptoms who engage in in online support groups: To what 
degree is participation in online postpartum depression support groups related to work impairment?

Method. This study will rely on a convenience sample. The survey was distributed in a digital format using Survey Monkey. The researcher recruited participants through clinical professionals who were personally known to the researcher; via online support forums; and also through Facebook and other social media outlets where the researcher connected with organizations that supported women with postpartum depression. In most cases, gatekeepers of the support groups shared the survey link with community members. Participant recruitment using social media has been used successfully in several studies (Beck, 2004; Malik \& Coulson, 2008; Yuan, Bare, Johnson, \& Saberi, 2014). The researcher followed Dillman et al.’s (2009) data-collection scheduling framework for administration of online surveys. The framework includes: a) sending an invitation of pre-notification to the participants and/or the forum administrators inviting them to participate, b) sending the survey link 3 days after the invitation pre-notification, c) sending an e-mail reminder one week after the initial survey e-mail, d) sending an e-mail reminder two weeks after the initial survey email, and e) sending a thank you e-mail to the participants at the conclusion of the study.

A sample size of at least five and up to 50 participants per variable was recommended for a correlation analysis (Green, 1991). This study has three main research variables: participation in online support groups, work impairment, and postpartum depression symptom score. Therefore, according to Green (1991), the researcher should recruit between 15 and 150 women. However, for the purpose of statistical power, the researcher recruited 153 participants. The participants were 
employed full-time or part-time and had returned to work within 12 months or less of giving birth. The rationale for this time frame lies in the findings of previous research. The American Psychiatry Association (2013) diagnoses postpartum depression symptoms as depressive symptoms that begin within the first four weeks after the birth of a child; however, researchers have found that the onset of risk is elevated through the first six months after delivery (Beeghly et al., 2002; Stuart, Couser, Schilder, O'Hara, \& Gorman, 1998). Additionally, research has shown that $55 \%$ of employed women return to work during the first five month of their child's life and another 7.4\% return within the first six to 11 months (Laughlin, 2011). This information substantiates this time period as a time of critical need for social support.

The participants of the study were divided into two groups: those who had participated in online support groups after the birth of their child and those who had not. Participation can be described in two terms: participant (a person who posts and interacts with the group) and lurker (a person who does not post, but does read the postings). There will be a question on the survey addressing the level of participation.

Data about online support groups and the relation to work impairment were collected in the form of a survey. The survey consisted of questions related to postpartum depression symptoms, work impairment (including absenteeism and presenteeism), and perceived social support given on a Likert-scale. In similar studies, the following measures have been used: The Edinburg Postnatal Depression Scale, which consists of 10 short statements related to events in the past seven days such as "I have been able to laugh and see the funny side of things” (Cox et al., 1987). This measure has been found to have satisfactory validity in identifying women with postpartum depression symptoms 
(Dagher, McGovern, \& Dowd, 2014). For work impairment, the Work Productivity and Activity Impairment (WPAI) has been used to compute absences from work due to health issues and presenteeism (Beck, 2011). Questions such as:

During the past seven days, how many hours did you miss from work because of problems associated with [your PROBLEM]? Include hours you missed on sick days, times you went in late, left early, etc., because of [your PROBLEM]. Do not include time you missed to participate in this study. (Reilly, Zbrozek, \& Dukes, 1993)

Both measures survey events within the past seven days, thereby offering data about events that occur within the same time period. For example, the researcher will be able to collect data about a woman's depressive state within a seven day period and correlate that to her work impairment within that same seven day period.

For online social support, a survey was adapted from a previous study on online social support for smoking cessation (Graham, Papandonatos, Kang, Moreno, \& Abrams, 2011). This survey includes questions such as "I never posted messages on [name of website].” Items cover the main functions of social support discussed previously: emotional, informational, instrumental, and appraisal support (Cohen \& McKay, 1984; Thoits, 2011). The online social support survey has shown to be a valid and reliable research instrument (Graham et al., 2011).

In addition to the above mentioned survey items, the survey included questions about the employee's workplace organizations such as maternity leave policies, benefits, and industry similarities to compare factors that may influence stress-levels beyond those linked with returning to work such as childcare factors, maternity leave timeframe, and 
socio-economic status (Beck, 2001; O’Hara \& Swain, 1996; Robertson, Grace, Wallington, \& Stewart, 2004). It also included questions about how the participant was recruited for the survey (i.e., an online forum, Facebook, through a clinician etc.). The survey had a total of 49 questions.

The hypotheses were: (a) there is a positive correlation between postpartum depression symptoms and work impairment, (b) there is a group difference between the participants who are experiencing postpartum depression symptoms and those who are not experiencing postpartum depression symptoms in terms of online support group participation, and that (c) participation in online support groups will moderate the association of postpartum depression symptoms on work impairment. The first hypothesis was tested by running a zero-order correlation between the two groups (possibly depressed and non-depressed) and overall work impairment. The second hypothesis was tested by running a $\chi^{2}$ analysis of the two groups versus whether or not the group members had read messages in a postpartum depression support group. Another $\chi^{2}$ analysis was run of the two groups versus whether or not the group members had posted messages in a postpartum depression support group. The last hypothesis tested whether participation in online support groups moderated the effect of postpartum depression symptoms on work impairment. To test this hypothesis overall work impairment was regressed on depression group, readership group, and the interaction between the two, then overall work impairment was regressed on depression group, posting group, and the interaction between the two.

Publication submission and formatting. This study will be submitted to Human Resource Development Quarterly (HRDQ). HRDQ submissions must be prepared 
according the APA $6^{\text {th }}$ Edition. Manuscript page total should be limited to approximately 30 double-spaced pages, including all of the text, tables, figures, and references.

\section{Potential Implications of Collected Papers Research}

This research brings to light a problematic gap at the cross-section of HRD and mental health research. The literature review exposes areas where intervention research may be necessary surrounding the topic of postpartum depression symptoms in the workplace. The literature review also reveals best practices to guide HRD professionals in helping employees with postpartum depression. These revelations could potentially change the way women with postpartum depression symptoms experience back-to-work transitions.

The empirical study examined whether online social support was related to work impairment. Online support groups have been shown in previous research to be equally as effective as in-person social support in terms of helping depressed individuals (Cohen \& Wills, 1985).

\section{Structure of Collected Papers Dissertation}

This doctoral dissertation will follow the FIU College of Education's guidelines for the "Collected Papers" dissertation format. It will consist of an introductory chapters and a closing chapter written solely for the dissertation, as well as the two related studies outlined above to be submitted to peer-reviewed journals. Dissertation chapters will be as follows:

Chapter 1: Introduction, related literature review, research rationale

Chapter 2: Examination of HRD literature related to postpartum depression symptoms and work impairment 
Chapter 3: Survey research undertaken to investigate the relation between online social support and work impairment

Chapter 4: Conclusions, implications, and directions for future research 


\section{REFERENCES}

American Psychiatric Association. (2013). Diagnostic and statistical manual of mental disorders (5th ed.). Washington, DC: Author.

Andrews-Fike, C. (1999). Primary care companion. Journal of Clinical Psychiatry, 1, 914

Beck, A., Crain, A. L., Solberg, L. I., Unützer, J., Glasgow, R. E., Maciosek, M. V., \& Whitebird, R. (2011). Severity of depression and magnitude of productivity loss. The Annals of Family Medicine, 9, 305-311.

Beck, C. T. (2001). Predictors of postpartum depression: An update. Nursing Research, 50, 275-285.

Beck, C. T. (2004). Birth trauma: in the eye of the beholder. Nursing Research, 53, 2835.

Beeghly, M., Weinberg, M., Olson, K., Kernan, H., Riley, J., \& Tronick, E. (2002). Stability and change in level of maternal depressive symptomatology during the first postpartum year. Journal of Affective Disorders, 71, 169-180.

Bennett, H. A., Einarson, A., Taddio, A., Koren, G., \& Einarson, T. R. (2004). Prevalence of depression during pregnancy: Systematic review. Obstetrics \& Gynecology, 103, 698-709.

Bochantin, J. (2014). Long live the mensi-mob: Communicating support online with regards to experiencing menopause in the workplace. Communication Studies, 65, 260-280.

Carpiniello, B., Parante, C.M., Serri, F., Costa, G., \& Carta, M.G. (1997). Validation of the Edinburgh postnatal depression scale in Italy. Journal of Psychosomatic Obstetrics \& Gynecology, 18, 280-285.

Centers for Disease Control and Prevention (CDC). (2008). Prevalence of self-reported postpartum depressive symptoms--17 states, 2004-2005. Morbidity and Mortality Weekly Report, 57(14), 361.

Cohen, S., \& McKay, G. (1984). Social support, stress and the buffering hypothesis: A theoretical analysis. In A. Baum, S.E. Taylor, J.E. Singer (Eds.), Handbook of psychology and health, pp. 253-267. Hillsdale, NJ: Psychology Press.

Cohen, S., \& Wills, T. A. (1985). Stress, social support, and the buffering hypothesis. Psychological Bulletin, 98, 310. 
Cooklin, A. R., Canterford, L., Strazdins, L., \& Nicholson, J. M. (2011). Employment conditions and maternal postpartum mental health: Results from the longitudinal study of Australian children. Archives of Women's Mental Health, 14, 217-225.

Cox, J. L., Holden, J. M., \& Sagovsky, R. (1987). Detection of postnatal depression: Development of the 10-item Edinburgh Postnatal Depression Scale. The British Journal of Psychiatry, 150, 782-786.

Crowley, J. E. (2015). Unpacking the power of the mommy wars. Sociological Inquiry. 85.

Dagher, R. K. (2007). A longitudinal analysis of postpartum depression among employed women (Doctoral dissertation). ProQuest Dissertations and Theses database. (UMI No. 3273123).

Dagher, R. K., McGovern, P. M., Alexander, B. H., Dowd, B. E., Ukestad, L. K., \& McCaffrey, D. J. (2009). The psychosocial work environment and maternal postpartum depression. International Journal of Behavioral Medicine, 16, 339346.

Dagher, R. K., McGovern, P. M., \& Dowd, B. E. (2014). Maternity leave duration and postpartum mental and physical health: Implications for leave policies. Journal of Health Politics, Policy and Law, 39, 369-416.

Dagher, R. K., McGovern, P. M., Dowd, B. E., \& Gjerdingen, D. K. (2012). Postpartum depression and health services expenditures among employed women. Journal of Occupational and Environmental Medicine, 54, 210-215.

Dietrich, S., Deckert, S., Ceynowa, M., Hegerl, U., \& Stengler, K. (2012). Depression in the workplace: A systematic review of evidence-based prevention strategies. International Archives of Occupational and Environmental Health, 85, 1-11.

Dillman, D. A., Smyth, J. D., \& Chrstian, L. M. (2009). Internet, mail, and mixed-mode survey: The tailored design method. Hoboken, NJ: John Wiley \& Sons.

Elgar, K., \& Chester, A. (2007). The mental health implications of maternal employment: Working versus at-home mothering identities. Australian e-Journal for the Advancement of Mental Health, 6, 47-55.

Evans, M., Donelle, L., \& Hume-Loveland, L. (2012). Social support and online postpartum depression discussion groups: A content analysis. Patient Education and Counseling, 87, 405-410.

Family and Medical Leave Act of 1993, 29 U.S.C. §§ 2601-2654 (2006). 
Farr, S. L., Bitsko, R. H., Hayes, D. K., \& Dietz, P. M. (2010). Mental health and access to services among US women of reproductive age. American Journal of Obstetrics and Gynecology, 203, 542.

Fink, A. (2013). Conducting research literature reviews: From the Internet to paper. Thousand Oaks, CA: Sage Publications.

Fox, S. \& Duggan, M. Peer-to-Peer Health Care. (2013, January 14). Retrieved February 21, 2015, from http://www.pewinternet.org/2013/01/15/peer-to-peer-health-care/

Gjerdingen, D. K., \& Chaloner, K. M. (1994). The relationship of women's postpartum mental health to employment, childbirth, and social support. The Journal of Family Practice, 38, 465-472.

Gjerdingen, D., McGovern, P., Attanasio, L., Johnson, P. J., \& Kozhimannil, K. B. (2014). Maternal depressive symptoms, employment, and social support. The Journal of the American Board of Family Medicine, 27, 87-96.

Graham, A. L., Papandonatos, G. D., Kang, H., Moreno, J. L., \& Abrams, D. B. (2011). Development and validation of the online social support for smokers scale. Journal of Medical Internet Research, 13(3).

Green, S. B. (1991). How many subjects does it take to do a regression analysis? Multivariate Behavioral Research, 26, 449-510.

Greenberg, P. E., Kessler, R. C., Birnbaum, H. G., Leong, S. A., Lowe, S. W., Berglund, P. A., \& Corey-Lisle, P. K. (2003). The economic burden of depression in the United States: how did it change between 1990 and 2000?. Journal of Clinical Psychiatry, 64, 1465-1475.

Hochschild, A. R. (2012). The managed heart: Commercialization of human feeling. Berkeley, CA: University of California Press.

Hock, E. \& DeMeis, D. K. (1990). Depression in mothers of infants: The role of maternal employment. Developmental Psychology, 26, 285.

Horowitz, J. A., \& Goodman, J. (2004). A longitudinal study of maternal postpartum depression symptoms. Research and Theory for Nursing Practice, 18, 149-163.

Klein, M. H., \& Essex, M. J. (1994). Pregnant or depressed? The effect of overlap between symptoms of depression and somatic complaints of pregnancy on rates of major depression in the second trimester. Depression, 2, 308-314. 
Knudson-Martin, C., \& Silverstein, R. (2009). Suffering in silence: A qualitative metadata-analysis of postpartum depression. Journal of Marital and Family Therapy, $35,145-158$.

Laughlin, L. L. (2011). Maternity leave and employment patterns of first-time mothers: 1961-2008. US Department of Commerce, Economics and Statistics Administration, US Census Bureau. Retrieved February 21, 2015, from https://www.census.gov/prod/2011pubs/p70-128.pdf

Lerner, D., Adler, D., Hermann, R. C., Chang, H., Ludman, E. J., Greenhill, A., \& Rogers, W. H. (2012). Impact of a work-focused intervention on the productivity and symptoms of employees with depression. Journal of Occupational and Environmental Medicine, 54, 128.

Malik, S. H., \& Coulson, N. S. (2010). Coping with infertility online: An examination of self-help mechanisms in an online infertility support group. Patient Education and Counseling, 81, 315-318.

Miyake, Y., Tanaka, K., Sasaki, S., \& Hirota, Y. (2011). Employment, income, and education and risk of postpartum depression: The Osaka maternal and child health study. Journal of Affective Disorders, 130, 133-137.

Mudry, T., Kushner, K. E., \& Neufeld, A. (2010). Employed mothers' worker ideology and social support network composition. Qualitative Health Research, 20, 905921.

O'Hara, M. W., Neunaber, D. J., \& Zekoski, E. M. (1984). Prospective study of postpartum depression: prevalence, course, and predictive factors. Journal of Abnormal Psychology, 93, 158-171.

O'Hara, M. W., \& Swain, A. M. (1996). Rates and risk of postpartum depression: A meta-analysis. International Review of Psychiatry, 8, 37-54.

O'Hara , M. W. Zekoski , E. M. (1988). Postpartum depression: A comprehensive review. In R. Kumar \& I. F. Brockington (Eds.), Motherhood and mental illness: Vol. 2. Causes and consequences (pp. 17-63). London, UK: Wright.

Pascoe, J. M., \& French, J. (1989). The reliability and validity of the maternal social support index for primiparous mothers: A brief report. Family Medicine, 22, 228230.

Pector, E. A. (2012). Sharing losses online: Do internet support groups benefit the bereaved? International Journal of Childbirth Education, 27, 19-25. 
Pedersen, D. E., \& Kilzer, G. (2014). Work-to-family conflict and the maternal gatekeeping of dual-earner mothers with young children. Journal of Family and Economic Issues, 35, 251-262.

Perry-Jenkins, M., Smith, J. Z., Goldberg, A. E., \& Logan, J. (2011). Working-class jobs and new parents' mental health. Journal of Marriage and Family, 73, 1117-1132.

Postpartum. (n.d.) In Miller-Keane Encyclopedia and dictionary of medicine, nursing, and allied health, Seventh Edition. (2003), Retrieved February 102015 from http://medical-dictionary.thefreedictionary.com/postpartum

Robertson, E., Grace, S., Wallington, T., \& Stewart, D. E. (2004). Antenatal risk factors for postpartum depression: A synthesis of recent literature. General Hospital Psychiatry, 26, 289-295.

Reilly, M. C., Zbrozek, A. S., \& Dukes, E. M. (1993). The validity and reproducibility of a work productivity and activity impairment instrument. Pharmacoeconomics, 4, 353-365.

Stomp-van den Berg, S. G., Van Poppel, M. N. M., Hendriksen, I. J., Bruinvels, D. J., Uegaki, K., De Bruijne, M. C., \& Van Mechelen, W. (2007). Improving return-towork after childbirth: design of the Mom@Work study: A randomised controlled trial and cohort study. BMC Public Health, 7, 43.

Stowe, Z. N., Hostetter, A. L., \& Newport, D. J. (2005). The onset of postpartum depression: Implications for clinical screening in obstetrical and primary care. American Journal of Obstetrics \& Gynecology, 192, 522-526.

Stuart, S., Couser, G., Schilder, K., O'Hara, M., \& Gorman, L. (1998). Postpartum anxiety and depression: Onset and comorbidity in a community sample. Journal of Nervous and Mental Disease, 186, 420-424.

Sullivan, H. S. (1953). The interpersonal theory of psychiatry. New York, NY: Norton.

Swanson, R.A. \& Holton, E.F. (2009). Foundations of human resource development $\left(2^{\text {nd }}\right.$ ed.). San Francisco, CA: Berrett-Koehler.

Taylor, V. A. (1996). Rock-a-by baby: Feminism, self help, and postpartum depression. New York: Routledge.

Thoits, P. A. (1985). Self-labeling processes in mental illness: The role of emotional deviance. American Journal of Sociology, 9, 221-249.

Thoits, P. A. (2011). Mechanisms linking social ties and support to physical and mental health. Journal of Health and Social Behavior, 52, 145-161. 
Turner, J. W., Grube, J. A., \& Meyers, J. (2001). Developing an optimal match within online communities: An exploration of CMC support communities and traditional support. Journal of Communication, 51, 231-251.

Van Lerberghe, W., Manuel, A., Matthews, Z., \& Cathy, W. (2005). The world health report 2005-make every mother and child count. World Health Organization. Geneva.

Vayreda, A., \& Antaki, C. (2009). Social support and unsolicited advice in a bipolar disorder online forum. Qualitative Health Research, 19, 931-942.

Vujinović, N. (2014). '...There’s no substituting actual time with your child’: Understanding first-time mothers' readiness to return to work. Journal of Industrial Relations, 56, 488-507.

Yuan, P., Bare, M. G., Johnson, M. O., \& Saberi, P. (2014). Using online social media for recruitment of human immunodeficiency virus-positive participants: A crosssectional survey. Journal of Medical Internet Research, 16. 


\section{CHAPTER II}

\section{STUDY \#1, INTERVENTIONS FOR WOMEN WITH POSTPARTUM}

\section{DEPRESSION SYMPTOMS: AN INTEGRATIVE LITERATURE REVIEW FOR}

HUMAN RESOURCE DEVELOPMENT PROFESSIONALS

Postpartum depression symptoms can occur in new mothers after the birth of a child. Women who experience postpartum depression symptoms exhibit a depressed mood or loss of interest or pleasure along with three or more of the following symptoms: significant weight loss or gain; lack of sleep or too much sleeping; overstimulation or delay in reactions; fatigue or loss of energy; feelings of worthlessness or guilt nearly every day; diminished ability to think or concentrate; or recurrent thoughts of death or suicide (with or without a plan; American Psychiatric Association, 2013). Postpartum depression symptoms pose a health concern for working mothers and the organization with which they are employed. Although there are no figures to estimate the direct cost of depression with postpartum onset, depression accounts for a higher incidence of absenteeism (time taken off from work) and a lack of presenteeism (ability to produce effectively; Greenberg et al., 2003; Lerner et al., 2012). The lack of productivity and time taken off from work accounts for \$51.5 billion lost in wage-based value (Beck et al., 2011).

Women make up 57.7\% of the labor force (U.S. Bureau of Labor Statistics, 2013). Of these women, $60.7 \%$ have children under 3 years old, $64.7 \%$ have children under 6 years old, and 76.01\% have children between ages 6 and 17 (U.S. Bureau of Labor Statistics, 2013). Because women, especially mothers, make up a large part of the workforce, HRD professionals should be prepared to help women with postpartum 
depression symptoms, not only for their own health, but also because of its effect on employee productivity.

At 6 weeks postpartum, women usually obtain medical clearance from their doctors and are able to resume normal activities, including work (McGovern et al., 1997). Even so, this does not mean a woman is necessarily free of postpartum depression symptoms. The DSM-V (American Psychiatric Association, 2013) informs that the onset of postpartum depression symptoms is within the first four weeks after the birth of a child, however, several studies have found that the highest risk for the onset of depression is within the first three months after delivery (Andrews-Fike, 1999; Horowitz \& Goodman, 2004; Stowe, Hostetter, \& Newport, 2005). Other researchers have found that the risk of onset is elevated through the first six months after delivery (Beeghly et al., 2002; Stuart, Couser, Schilder, O’Hara, \& Gorman, 1998). These discrepancies make it difficult to fully understand when postpartum depression symptoms begin and what triggers the onset. However, one thing is very clear; a woman who is left untreated is likely to be depressed well into, and in some case, after, her child's first year of life (Carpiniello, Parante, Serri, Costa, \& Carta, 1997; O’Hara \& Zekoski, 1988).

According to a 2011 report, $28.3 \%$ of women return to work within three months of having a child, $26.7 \%$ return within three to five months, $7.4 \%$ return within six to eleven months, and 37.6\% never return to their previous employers (Laughlin, 2011). Although the majority of women are returning to work well past the four-week onset period described by the DSM-V (American Psychiatric Association, 2013), many women are still returning to work well within the period identified by researchers as high risk for postpartum onset (Andrews-Fike, 1999; Beeghly et al., 2002, Horowitz \& Goodman, 
2004; Stowe et al., 2005; Stuart et al., 1998). For human resource development (HRD) professionals, this means that of the two out of every three new mothers who return to work, each new mother has a $25 \%$ chance of developing postpartum depression symptoms (O’Hara \& Swain, 1996).

Work leave programs allow women to recover from childbirth and bond with their new baby, but what happens once it is time to go back to work? The literature surrounding the maternity leave and subsequent return-to-work transition focuses on the following areas: breastfeeding cessation (Baxter, 2008; Chuang et al., 2010; Skafida, 2012; Wells, 2012); reduced earning capacity after leave (Aisenbrey, Evertsson, \& Grunow, 2009; Baker, 2011); work-life balance for new mothers (Alstveit, Severinsson, \& Karlsen, 2011; Buzzanell et al., 2005; Feldman, Sussman, \& Zigler, 2004; Spiteri \& Xuereb, 2012); likelihood of returning to work after the birth of a child (Baxter, 2009; Coulson, Skouteris, Milgrom, Noblet, \& Dissanayake, 2010; Stomp-van den Berg, et al., 2007) and policy issues (Buzzanell \& Liu, 2005; Hofferth \& Curtin, 2006; Wiese \& Ritter, 2012). A gap exists in the literature in reference to how to support women with postpartum depression symptoms, or women who are within the six month period of high onset risk, in transitioning back into their role of employee. Understanding the needs of women returning to work with postpartum depression symptoms is an urgent human resource development (HRD) problem.

\section{Purpose and Research Question}

In an effort to enter a conversation around what HRD professionals can do to help an employee who is dealing with postpartum depression symptoms, this research aims to discover how postpartum depression interventions are being discussed in the HRD 
literature, if at all. This review focuses on studies conducted in the United States because the researcher is interested in uncovering gaps in the way HRD professionals and organizations support new mothers in the United States. It is widely criticized that the United States is lacking in supporting new working mothers when other industrialized nations do (e.g., paid maternity leave; Appelbaum \& Milkman, 2015). This review will be directed by Torraco's (2005) guide for conducting integrative literature reviews and the following research questions: (a) How are postpartum depression symptoms discussed in the context of the workplace in HRD literature in the United States? (b) Does there exist a set of best practices in HRD literature to guide HRD professionals in helping employees with postpartum depression symptoms in the United States?

\section{Theoretical Framework}

The major risk factors for postpartum depression symptoms include: depression and anxiety while pregnant; an unplanned or unwanted pregnancy; poor marital relationship; lack of social support, socio-economic status, and stressful life events including child care factors (Beck, 2001; O’Hara \& Swain, 1996; Robertson, Grace, Wallington, \& Stewart, 2004). The last two factors are directly related to the workplace and therefore it is important to understand the decisions women make about work and work leave while they are pregnant, and especially after a child is born. If a mother chooses to take time off of work during her pregnancy or after the birth of her child, her income will likely be affected (a risk factor) as only $39 \%$ of male and female workers report having access to paid leave (The Council of Economic Advisers, 2014). If she does return to work, she will have to decide who will care for her child while she works (another risk factor; Beck, 2001; O’Hara \& Swain, 1996; Robertson et. al, 2004). 
This study is guided by the stress-buffering hypothesis. The stress-buffering hypothesis proposed by Cohen and Wills (1985) has five parts, which begin with the occurrence of a potentially stressful event. A stressful event refers to a situation that has the potential to elicit a negative effect, physiological response, and behavioral adaptation (Cohen \& McKay, 1984). In this study, the first potentially stressful event is returning to work after the birth of a child.

The next stage of the stress-buffering hypothesis is appraisal of the stressful event. If there is an intervention at this point, either before there is a reaction to the stress reaction to the event or during the anticipation of said event, then there is a possibility that a stress appraisal response can be avoided (Cohen \& Willis, 1985). In other words, if a new mother is anticipating that returning to work will be a stressful event then, before the event occurs, others can intervene to help her change her perception.

In the third step, when social support from others does not intervene, the event is appraised as stressful. Continuing with the subject of this study, this could mean that the new mother has decided that returning to work will have negative outcomes for her and her child. This is followed by an emotionally linked physiological response or behavioral adaptation such as anxiety or sadness. At this point, social support from others could help the mother reappraise the stressful event and also her response to it. However, without social support, the emotional response is followed by the illness or illness behavior (depression), and, this researcher posits, it can ultimately lead to work impairment (i.e., increased absenteeism and decreased presenteeism).

This theory supports the notion that HRD professionals have two opportunities in the return-to-work transition of new mothers to help them. The first opportunity is just 
before the new mother is returning to work after leave. The theory postulates that at this point offering social support could help ease the stress of returning to work, which could therefore mitigate any further negative outcomes. The second point where an HRD professional could help is once the new mother has already returned to work. This is another opportunity where the HRD professional could offer social support to help the new mother reappraise the situation. If the social support is successful in resulting in a positive reappraisal, illness or illness behaviors and posited subsequent work impairment may be inhibited.

\section{Research Design}

Because the issues related to human resource development span multiple disciplines (e.g., business, psychology, education and social sciences) the following large databases were searched: Academic One File, Academic Search Complete, ProQuest, PsychInfo, and Social Sciences Citation Index. The search term "postpartum depression or postnatal depression" was combined with each of the following terms individually to search each database: workplace, job, employee, employee assistance program, and human resources. The literature search was not delimited necessarily by a time frame; however, this article only includes empirical studies available through July 23, 2015. The search was limited to peer-reviewed articles, published in English in the United States. After removing 300 duplicates, 124 articles were available for selection. Table 2 represents the number of available articles for the aforementioned descriptors in each of the five databases. 
Table 2

Findings of Research Databases

\begin{tabular}{ll}
\hline Database & Results \\
\hline Academic One File & 37 \\
Academic Search Complete & 20 \\
PsychInfo & 95 \\
ProQuest & 250 \\
Social Science Citation Index & 22 \\
\hline SUBTOTAL & 424 \\
\hline REPEATED ARTICLES & 300 \\
\hline TOTAL & 124 \\
\hline
\end{tabular}

The second stage of this review consisted of a staged review (Torraco, 2005) wherein the researcher did an initial review of the abstracts of each of the 124 studies. The studies were narrowed based on whether they were directly related to HRD practices, work, employment status and postpartum depression in women. For example, an article about men’s peripartum mental health was excluded (Singley, 2015) as well as several articles investigating clinical treatments and procedures (D’Angelo, Williams, Harrison, \& Ahluwalia, 2012; Leddy, Haaga, Gray, \& Schulkin, 2011; Stube, Grewen, Pedersen, Propper, Meltzer-Brody, 2012). This narrowed the number of relevant articles to 22. An in-depth review of the remaining 22 studies brought the sample down to 12 articles. No articles were directly related to HRD practices, nor were any published in HRD journals. However, the remaining 12 articles were selected because they discussed postpartum maternal mental health in the context of the workplace. Table 3 gives an overview of the fields where the 12 selected articles were published. 
Table 3

Findings by Field of Publication

\begin{tabular}{ll}
\hline Field & Results \\
\hline Medicine & 2 \\
Psychology & 4 \\
Public Health & 6 \\
\hline TOTAL & 12 \\
\hline
\end{tabular}

The 12 articles reviewed for this study spanned in publication date from 1990-2013. Nine articles were published at the rate of at least one per year from 2007-2013, except for 2010. While there is little movement in this research area, these findings seem to indicate that there is beginning to be some interest in the topic of maternal employment and postpartum mental health.

\section{Literature Review}

Due to the lack of findings within the HRD literature, it appears that postpartum depression has been largely overlooked in the context of the U.S. workplace. Therefore, in answer to the second research question, there does not seem to exist a set of best practices in the HRD literature to guide HRD professionals in helping employees with postpartum depression symptoms. Notwithstanding, the articles reviewed for this paper were grouped into four main areas of interest with relation to postpartum maternal mental health and work: leave time, role congruence and role quality, physical and personal stressors, and work-related stressors. This section will explain the findings of the research studies in each group in an attempt to isolate factors that may contribute to a working mother's overall postpartum mental health. 


\section{Maternity Leave Length and Maternal Mental Health}

The Family and Medical Leave Act (FMLA; 2006) prevents parents from losing their jobs when they take time off to care for a new child. To be protected by FMLA, the parent must work for a covered employer. That is, an employer that meets the following criteria: the employer must be a private-sector employer (with 50 or more employees); a public agency; or a private or public elementary or secondary school. Parents' jobs are secured for up to 12 weeks through FMLA; however, it is an unpaid leave. Only about $60 \%$ of workers report having access to FMLA leave (Jorgensen \& Appelbaum 2014; The Council of Economic Advisors, 2014). Of those, 20\% were new mothers (The Council of Economic Advisors, 2014).

McGovern et al. (1997) evaluated the effect of maternal leave on mental health. The researchers found that time off from work had a positive effect on vitality when a new mother had more than 12 weeks off, which surpasses the current FMLA regulation. More than 15 weeks off from work had a positive effect on maternal mental health and more than 20 weeks had a positive effect on role function. For this study, 854 women were identified from birth records obtained from the Minnesota Department of Health from October 1991 through February 1992. Eligibility criteria consisted of: having had a live birth, keeping the infant versus putting up for adoption, being an English speaker, living in the Twin Cities, and working continuously for one year prior to the child's birth for a minimum of 20 hours per week. Women who were deemed higher risk for postpartum depression symptoms based on neonatal complications, medical risk factors, and single mothers were over sampled to gain sufficient subjects for this group. At five months after childbirth, 654 women were identified for this study. Data for the study was obtained through telephone interviews conducted 
between six and nine months after birth. The most interesting finding in this study suggests that new mothers experience the lowest levels of general well-being at seven months postpartum. Researchers suggest that this decrease in well-being may have been due to the cumulative effect of several infectious and non-infectious symptoms being experienced by the majority of the mothers around this time. Those symptoms included things like: stiff joins, back and neck pain, colds, and flus. This creates a cause for concern because the postpartum recovery period is generally considered to last only six weeks, and as previously mentioned, FMLA only protects mothers from job loss up to 12 weeks. These findings suggest that a follow-up well after the six-week traditional recovery period may be needed.

A similar study by Chatterji and Markowitz (2012) used secondary data obtained from the Early Childhood Longitudinal Study - Birth Cohort (ECLS-B) to examine the association between family leave length (leave taken by mothers and fathers after childbirth) and mental and overall health among new mothers. The data included a nationally representative sample of 14,000 children born in 2001 who were followed until they began kindergarten. The survey used in this measured depressive symptoms within the week just before the survey response, along with other self-reported health data. The study was narrowed down to 2,200 mothers after applying the following criteria: mother must (a) be the biological or adoptive mother, (b) have worked full- or part-time during pregnancy, and (c) have returned to work either part-time or full-time within nine months. The findings of this study indicated that mothers who worked prior to childbirth and who returned to work in the first year had higher depression scores when they had less than 12 weeks of maternity leave. Mothers' overall health had a "statistically 
significant, detrimental” decline if they had less than 8 weeks of paid maternity leave (Chatterji \& Markowitz, 2012, p. 70).

The Study of Early Child Care and Youth Development (SECCYD) is a longitudinal study conducted by the National Institute of Child Health and Human Development of 1,127 children and their families. Beginning in 1991, birth records from Arkansas, California, Kansas, Massachusetts, North Carolina, Pennsylvania, Virginia, Washington, and Wisconsin were used to select potential participants. Those mothers were then screened at the hospital within 48 hours of childbirth. Two weeks later, families received a phone call for consent to participate and at one month, they were interviewed in person. Participants were then interviewed again at 6, 15, 24, and 36 months.

Researchers used this secondary data to examine the relationship of maternal employment on maternal mental and overall health, self-reported parenting stress, and parenting quality at three and six months postpartum (Chatterji, Markowitz, \& BrooksGunn, 2013). They found that longer work hours were positively associated with depressive symptoms and parenting stress at three months postpartum. Parenting stress was affected by any number of work hours, while depressive symptoms were exacerbated in mothers who work full time. A small decline in overall health was present in full-time working mothers at six months postpartum. The findings led the researchers to conclude that transitioning back to work was difficult for the average new mother, especially if she was returning full time.

These studies indicate that a maternity leave over 12 weeks, especially around the 15-week mark, is beneficial to a maternal mental health (Chatterji \& Markowitz, 2012; 
Chatterji et al., 2013; McGovern et al., 1997). Eight weeks of paid maternity leave or more has a positive effect on maternal depression scores (Chatterji \& Markowitz, 2012), whereas at six months postpartum, new mothers may experience a decline in overall health (Chatterji et al., 2013). Further, around seven months postpartum, physicians should follow-up with new mothers, especially those who have returned to work, to make sure they have returned to previous levels of function (McGovern et al., 1997).

Another study selected for this review found that length of maternity leave did not have any effect on mental health (measured using The Center for Epidemiologic Studies Depression Scale) at 12-weeks postpartum (Klein, Hyde, Essex, \& Clark, 1998). The study used data from the Wisconsin Maternity Leave and Health Project, which included 570 participants who were recruited from obstetrics and family practice clinics in two Midwestern clinics. Potential participants were identified in their second semester and were required to meet the following criteria: (a) older than 18; (b) not disabled in any way that could change functioning as a parent; (c) living with the father, though not necessarily married; (d) one parent must be employed; and (e) mother was either employed or a full-time homemaker (i.e., not self-reported as unemployed or student). The women were interviewed in person during their second trimester, then again at one month, four months, and one year after delivery. In addition to a lack of findings of that related maternity leave to mental health decline at 12 -weeks postpartum, the study also indicated that there were no differences among homemakers and women employed parttime and full-time. Instead, the researchers pointed to the importance of role quality (i.e., the difference between a job that offers opportunity for advancement and recognition versus one that does not; Usdansky, Gordon, Wang, \& Gluzman, 2012) as being the main 
influence on a working mother's mental health (Klein et al., 1998). This was in contrast to simply having a job or not, which was not nearly as important.

\section{Maternal Role Congruence and Role Quality}

Role congruence refers to a woman's preference for working or staying at home and her actual status (Klein et al., 1998). Some women may feel that they prefer one role (to be employed), but feel they must fulfill the traditional role of being the "stay at home" mother (Hock \& DeMeis, 1990). The literature in this section examines this potential conflict and its role in maternal mental health.

Hock and DeMeis (1990) examined role congruence in two longitudinal studies. The first study consisted of 209 first-time mothers who were recruited from three large metropolitan hospitals. The new mothers were contacted in the maternity ward 48 hours after the birth of their child. Researchers obtained their consent to participate and collected demographic information. The women were then were contacted to complete a survey at 12-months postpartum and divided into four groups based on their employment status and employment preference. Group 1 consisted of women who were employment preferring/employed status, group 2 were employment preferring/home status, group 3 were home preferring/employed status, and group 4 were home preferring/home status. The survey consisted of measures of maternal separation anxiety, stress, and depression. The findings of this study indicated that women who preferred to be at home and were at home were significantly more anxious about separating from their children than employment preferring/employed mothers. Only the group 2 women (preferred employment, but were home) reported significantly higher symptoms of depression reported higher symptoms of depression than the other groups. 
A second study was conducted to replicate the first and consisted of 164 first-time mothers. In addition to the measures from study 1 , this study included a measure for maternal role investment and another for career salience. As in the first study, the new mothers were contacted in the maternity ward 48 hours after the birth of their child. Researchers collected demographic information and, in addition in study 2, administered the two new measures. The new mothers then received the same survey as study 1 , but when they were 8-months postpartum instead of 12-months postpartum. The findings of this study were similar to those of study 1 . The members of group 2 (preferred employment, but were home) also reported higher symptoms of depression than the other groups. Groups 1 and 4 (employment preference/employed and home preference/home, respectively) were similar in terms of levels of stress and depression.

Usdansky et al. (2012) also used the secondary data from the SECCYD to examine how maternal mental health is affected by the interaction between employment status, job quality, and preferred employment status. Like the previous study, researchers found that women who were not employed, but preferred to be, had elevated depression scores. They also found that high quality jobs benefitted maternal mental health regardless of whether or not a mother prefers to be employed. Mothers who were employed in low-quality jobs experienced higher depressive symptoms regardless of their employment preferences. This study was the first to examine how job quality benefits mothers irrespective of their employment preferences. It also offers the important perspective of repeated measures of mental health, job status, and job quality longitudinally. 
The results of these studies are significant to HRD professionals because they shed light on the importance of acknowledging women's preferences and psychological differences when discussing maternal employment. In other words, no assumptions should be made about what mothers prefer in terms of maternity leave, childcare, or employment. Each mother should be able to choose the path that fits her psychological needs and well-being.

\section{Working Mother's Physical and Personal Stressors}

An 817-participant cohort study conducted in Minnesota offered the data used in the following three studies in this section (Dagher, McGovern, Dowd, \& Lundberg, 2012; McGovern et al., 2007; McGovern et al., 2011). A fourth study using this data (Dagher et al., 2009) will be discussed in the next section of this paper. The participants were recruited at the hospital and then interviewed at 5 weeks, 11 weeks, 6 months and 12 months postpartum. All mothers selected were 18 or older, gave birth to a healthy singleton infant, spoke English, were employed and planned to return to the same employer.

The first study published from this data evaluated the personal and work-related factors associated with postpartum health at 5 and 11 weeks postpartum (McGovern et al., 2007). Of the 817 participants selected for the study, 716 agreed to participate at 5weeks postpartum. That number went down to 638 at the time of the 11 week postpartum interview.

The study found that better preconception health, higher level of coworker support during pregnancy, having a vaginal delivery, and not breastfeeding each contributed to better physical health. The effects for better preconception health were 
seen at both 5 and 11 weeks, while the effects for vaginal delivery and no breast feeding tapered off before 11 weeks. Higher level of coworker support influenced better physical health at 11 weeks postpartum. Better mental health was attributed at 5 and 11 weeks to better preconception health, absence of perinatal mood problems, social support from family and friends, and perceived control over home and work. The effects of lower job stress were only seen at the 11 week mark. Postpartum depression symptoms were mitigated by better preconception health, absence of perinatal mood problems, and having an infant without colic issues at both the 5 and 11 week marks. At the 11 week mark, additional positive influences were attributed to being married or partnered and being non-white.

An examination into total workload alongside the previously mentioned factors was the focus of the second study from this data set (Dagher et al., 2012). Total workload was described as the total hours spent on paid and unpaid duties (i.e., working for pay and domestic chores). The second study also expanded the time frame to include data from 6-months postpartum. Total workload was seen to increase over the 6 month postpartum period. Women were working more hours, while their unpaid hours decreased. Worse depression scores were associated with higher total workload, lower job flexibility, lower social support, an infant with sleep problems, and breastfeeding. At 12-months postpartum, the total daily workload increased a statistically significant amount (McGovern et al., 2011). The third study using this data set included the 12-month postpartum data and found that (consistent with the other studies) total workload, available social support, perceived control over work and home activities and infant care-giving, influence maternal mental health. 
In essence, when it comes to physical and personal stressors that influence maternal health, researchers may need to be looking at factors that can be moderated such as total workload, social support of family and friends, and job stress to best assist new mothers.

\section{Work-Related Stressors}

The last study from the cohort study previously mentioned focuses on examining the correlates of postpartum depression symptoms (measured by the Edinburg Postnatal Depression Scale) at 11 weeks postpartum (Dagher et al., 2008) by applying the job demand-control-support model of workplace stress. This model suggests that women under high psychological job demands and limited degree of control can experience negative effects in their health. Consistent with findings in the previous studies, job demands were positively associated with higher depression scores. Decision latitude (degree of control over work tasks) was not associated with postpartum depression symptom scores and did not moderate the effect of job demand. Under conditions of low psychological demands, coworker support and decision latitude were contributing factors in reduced depression scores. Schedule autonomy and coworker support were positively associated with perceived control over work and family. This study was the first to examine the application of demand-control-support model to postpartum depression symptoms. Researchers concluded that in comparison to perceptions of control over work and family, the job-demand-control model did not explain postpartum depression symptoms.

Shift working has been applied by new parents as a strategy for avoiding child care costs (Perry-Jenkins et al., 2007). Dual-earning parents take on schedules that are 
opposite and non-overlapping of each other so that one parent is always available to care for the child. Researchers examined whether shift work was related to depressive symptoms and relationship conflict.

Data for this study came from a longitudinal study of 132 working couples recruited from prenatal classes in a hospital in western New England. Participants were interviewed five times as they transitioned into new parenthood. The first interview occurred during the third trimester of pregnancy, then one month after the baby’s birth, and one month after the mother's return to work. At 6-months postpartum, participants received a mailed survey; a final face-to-face interview was conducted when the baby was one-year-old. All couples met the following eligibility criteria: (a) both parents were employed full time, (b) both members of the couple planned to return to full time within 6 months of the child's birth, (c) both members were employed in an unskilled or semiskilled job and had no higher than an associate's degree, (d) both members of the couple were expecting their first child, and (e) the couple was married or living together.

On average, the mothers in this study experienced a decrease in depressive symptoms immediately after the baby's birth, but then they increased as the year progressed. The fathers experienced no statistically significant change in depressive symptoms. Both mothers and fathers reported significant increases in relationship conflict across the first year; however, for mothers only, the conflict began to level out near the end of the first year.

Higher levels of depressive symptoms were predicted by working evening or night shifts in both mothers and fathers and also by higher levels of relationship conflict. Depression symptom scores for individuals were unaffected by the shifts their partners 
worked. The researchers found that workplace stress and overload were not factors of shift work that contributed to depressive symptoms. This left the researchers puzzled as to what could be the factor of shift work that causes the depressive symptomatology to increase.

The same group of researchers, using the same data collection method, published a study that tested individual responses to working class job conditions and relationship between job conditions and new parents' mental health (Perry-Jenkins et al., 2011). This study found that some workers in low-status occupations reported higher levels of autonomy, which in turn created positive perceptions about job conditions. High job urgency and low coworker support contributed to an increase in depressive symptoms in fathers. Higher coworker support in a high job urgency setting created a decrease in fathers' depressive symptoms. For mothers, low urgency jobs were linked to declines in depressive symptoms, however, having supportive coworkers in a high urgency setting served to benefit their mental health. Supportive work settings appear to have a mitigating effect on urgent and stressful job conditions. Supportive work settings included reports of general feelings of emotional support, which included receiving offerings of love, caring, esteem, encouragement, and sympathy (Cohen \& McKay, 1984; Thoits, 2011) and instrumental support, which included receiving help from others with practical tasks or problems or offering material assistance (Cohen \& McKay, 1984; Thoits, 2011).

\section{HRD Professionals and Maternal Mental Health}

HRD professionals may find it difficult to understand where they fit in helping employees with postpartum depression symptoms. After all they are not counselors or 
therapists; yet, these studies present some areas where HRD professionals can make a meaningful difference in the way women handle their depression at work. One possible solution could be to develop a training program that would alert supervisors and managers to the issue of postpartum depression symptoms in working women, its potential human and organizational negative effects, and how to avoid potential loss of employee productivity.

First, HRD professionals should study the signs and symptoms of postpartum depression symptoms. It may be necessary to check in regularly with new mothers who are transitioning back to work to see if some of these signs have emerged, especially at six- and seven-months postpartum when new mothers may begin to experience a decline in overall health (Chatterji et al., 2013; McGovern et al., 1997). If HRD professionals sense that an employee could be experiencing postpartum depression symptoms, they can suggest vesting their physician or refer them to their organization's employee assistance program, if one exists.

HRD professionals should encourage women to take as much or as little maternity leave as they feel comfortable with. The studies presented in this review indicated that maternity leave over 12 weeks, especially around 15 weeks was associated with an increase in maternal mental health (Chatterji \& Markowitz, 2012; Chatterji et al., 2013; McGovern et al., 1997). However, studies on role quality emphasized that maternity leave length had little to no effect on maternal mental health when compared to role congruence (Dagher, et al., 2008; McGovern et al., 2007). HRD professionals may think that promoting longer maternity leaves will be helpful to all women, but studies show that longer leaves can have adverse effects on women who prefer to be working. 
Discussions with employees about maternity leave length and how they use their FMLA benefits should be supportive of each individual woman's post-childbirth employment preference.

Having a higher level of coworker support influenced better physical health (Dagher, et al., 2008; McGovern et al., 2007), especially in high urgency jobs (PerryJenkins et al., 2011). HRD professionals can begin to foster this social support in the workplace by being supportive of individual decisions with respect to maternity leave. HRD professionals can also foster social support in the workplace by helping new mothers connect with each other.

HRD professionals can also encourage supervisors to allow new mothers to have some control over their workload while they transition back to work. Better mental health was attributed at 5 and 11 weeks to perceived control over home and work (Dagher et al., 2012; Klein et al., 1998). The flexibility offered could also mitigate the effects of job stress (McGovern et al., 2007).

\section{Further Research}

Based on the findings related to social support and its impact on maternal mental health, it appears that the stress-buffering hypothesis (Cohen \& Willis, 1985) may have some empirical support in its application in helping women with postpartum depression symptoms at work. The studies examined in this literature review offered support for returning to work as a potential stressor in the lives of new mothers (Chatterji \& Markowitz, 2012; Chatterji et al., 2013; McGovern et al., 1997). The stress-buffering hypothesis dictates that this is the catalyzing event in a series that will lead to work impairment in women with postpartum depression symptoms if social support is not 
available. Social support has been shown to have positive effects on overall maternal mental health (Dagher, et al., 2009; McGovern et al., 2007; Perry-Jenkins et al., 2007). This an lead to a reappraisal of returning to work as a non-stressful event, in turn inhibiting physiological and emotional consequences in new mothers, which can eventually lead to work impairment. The four types of social support cited in the social support literature are: emotional, instrumental, informational, and appraisal support (Cohen \& McKay, 1984; Thoits, 2011). Further research into the applications of the stress-buffering hypothesis should be modeled around the most effective types of social support co-workers, supervisors, and organizations can offer new mothers and how each affects overall work impairment.

Several questions remain after reviewing the literature presented in this paper. Studies found that breastfeeding caused an increase in depressive symptomatology in working women (Dagher et al., 2012; McGovern et al., 2007). The reasons for this are not assessed in the studies and, therefore, as suggested by McGovern et al. (2007), further research is necessary in this topic. Breastfeeding mothers could be facing a higher level of stress because of the physical and time commitments of breastfeeding. This may be contributing to their overall total workload, which contributes to higher depression scores. Another reason could be that although employers are mandated to have a private location for breastfeeding mothers to express breast milk, the mothers may not feel this benefit is adequate (McGovern et al., 2007). Some possible scenarios could include: negative comments from supervisors about taking the time to pump, stress related to taking time off for pumping, the designated area is not kept clean, or the designated area is not truly private. 
The studies that examine role quality (Hock \& DeMeis, 1990; Klein et al., 1998; Usdansky et al., 2011) clearly indicated that women who desire employment and remain unemployed are likely to suffer a decline in mental health. In each of these studies, the women surveyed were employed prior to giving birth. Barring job loss during to maternity leave, the question remains as to why they would not go back to work if they had an employment opportunity? Perhaps some women felt a strong psychological conflict between traditional motherhood roles and their desire to work (Hock \& DeMeis, 1990). This conflict should be examined in further research studies.

The last remaining question with respect to this literature review comes from the studies on shift work (Perry-Jenkins et al., 2007; Perry-Jenkins et al., 2011). The studies were unable to come up with a reason for the decline in mental health of parents who work opposite schedules, as it could not be attributed to job stress or job overload. More research in this area could determine if shift work is a viable option for new parents that are looking to have parent caregivers, versus other family members or daycare, while one or the other parent is working.

No studies in this literature review were found using the term "employee assistance program” coupled with "postpartum depression.” This suggests that there is no research with regard to what employee assistance programs (EAPs) are doing for women with postpartum depression symptoms. It is possible that postpartum depression symptoms are being addressed in the same way as depression by employee assistance programs; however, there are complex issues experienced by new mothers that are not experienced by employees with depression. For example, this literature review found that new moms who struggled with managing their total workload could have higher 
depression scores (Dagher et al., 2012). Additionally, infant-care giving was a source of stress for some new mothers (McGovern et al., 2011). EAPs may need to focus not only on helping new mothers get treatment for the depression symptoms, but also in helping them address some of the return-to-work transitioning factors that contribute to the elevated depression symptoms.

A review of international studies and policies are also needed to assess what findings may be generalizable to new mothers in the United States. It is widely criticized that the United States is lacking in providing mandated paid leave for new mothers when other industrialized nations do (Appelbaum \& Milkman, 2015). How does maternal mental health compare to that of competing nations? Do the United States policies of unpaid maternity influence the maternal mental health of American women?

\section{Conclusion}

There is a clear need for HRD professionals to investigate the implications of postpartum depression symptoms, and its interventions, in the workplace. The literature reviewed throughout this article points to factors in the transition back to work after maternity, role quality, role congruency, and work-stressors as points of concern. HRD professionals are in a position to facilitate change in the way women experience returning to work after a baby, and should especially be interested in facilitating a smooth transition for women who are experiencing postpartum depression symptoms.

The next step for this field of study relies heavily on HRD researchers and professionals to recognize maternal mental health as an important factor in the work impairment of new mothers. As evidenced by this literature review, the field of HRD has work to do in finding viable interventions for new mothers with postpartum depression 
symptoms. Additionally, in continuing to ignore the issue of maternal mental health at work; as consequence, we may burden their partners who are also in the workforce with new worries, in turn causing their own work impairment. Maternal mental health is an issue that not only affects women, but also their partners, families, and especially, their children. Mothers are the biggest population of our current workforce (U.S. Bureau of Labor Statistics, 2013). As HRD professionals, it is a disservice to ALL of our employees and organizations to ignore an issue that could potentially affect the vast majority of our workforce. 


\section{REFERENCES}

Aisenbrey, S., Evertsson, M., \& Grunow, D. (2009). Is there a career penalty for mothers' time out? A comparison of Germany, Sweden and the United States. Social Forces, 88, 573-605.

Alstveit, M., Severinsson, E., \& Karlsen, B. (2011). Readjusting one’s life in the tension inherent in work and motherhood. Journal of Advanced Nursing, 67, 2151-2160.

American Psychiatric Association. (2013). Diagnostic and statistical manual of mental disorders, (DSM-5®). American Psychiatric Pub.

Andrews-Fike, C. (1999). Primary Care Companion, Journal of Clinical Psychiatry, 1, 914

Appelbaum, E., \& Milkman, R. (2015). Leaves that pay: Employer and worker experiences with paid family leave in California. Leaves that Pay. Employment Policy Research Network. Retrieved from http://50.87.169.168/OJS/ojs-2.4.41/index.php/EPRN/article/viewFile/1909/1906

Baker, D. (2011). Maternity leave and reduced future earning capacity. Family Matters, 89, 82-89.

Beck, C. T. (2001). Predictors of postpartum depression: an update. Nursing Research, 50, 275-285.

Beck, A., Crain, A. L., Solberg, L. I., Unützer, J., Glasgow, R. E., Maciosek, M. V., \& Whitebird, R. (2011). Severity of depression and magnitude of productivity loss. The Annals of Family Medicine, 9, 305-311.

Beeghly, M., Weinberg, M., Olson, K., Kernan, H., Riley, J., \& Tronick, E. (2002). Stability and change in level of maternal depressive symptomatology during the first postpartum year. Journal of Affective Disorders, 71, 169-180.

Buzzanell, P. M., \& Liu, M. (2005). Struggling with maternity leave policies and practices: A poststructuralist feminist analysis of gendered organizing. Journal of Applied Communication Research, 33(1), 1-25

Buzzanell, P. M., Meisenbach, R., Remke, R., Liu, M., Bowers, V., \& Conn, C. (2005). The good working mother: Managerial Women's sensemaking and feelings about work-family issues. Communication Studies, 56, 261-285.

Carpiniello, B., Parante, C.M., Serri, F., Costa, G., \& Carta, M.G. (1997). Validation of the Edinburgh postnatal depression scale in Italy. Journal of Psychosomatic Obstetrics \& Gynaecology, 18, 280-285. 
Chatterji, P., \& Markowitz, S. (2013). Family leave after childbirth and the health of new mothers. Journal of Mental Health Policy and Economics, 15, 61-76.

Chatterji, P., Markowitz, S., \& Brooks-Gunn, J. (2013). Effects of early maternal employment on maternal health and well-being. Journal of Population Economics, 26, 285-301.

Chuang, C. H., Chang, P. J., Chen, Y. C., Hsieh, W. S., Hurng, B. S., Lin, S. J., \& Chen, P. C. (2010). Maternal return to work and breastfeeding: A population-based cohort study. International Journal of Nursing Studies, 47, 461-474.

Cohen, S., \& McKay, G. (1984). Social support, stress and the buffering hypothesis: A theoretical analysis. In A. Baum, S.E. Taylor, J.E. Singer (Eds.), Handbook of psychology and health, (pp. 253-267). Hillsdale, NJ: 1984.

Cohen, S., \& Wills, T. A. (1985). Stress, social support, and the buffering hypothesis. Psychological Bulletin, 98, 310.

Coulson, M., Skouteris, H., Milgrom, J., Noblet, A., \& Dissanayake, C. (2010). Factors influencing the planning undertaken by women during pregnancy for their return to work after maternity leave. The Australian and New Zealand Journal of Organisational Psychology, 3, 1-12.

Dagher, R. K., McGovern, P. M., Dowd, B. E., \& Lundberg, U. (2011). Postpartum depressive symptoms and the combined load of paid and unpaid work: A longitudinal analysis. International Archives of Occupational and Environmental Health, 84, 735-743.

Dagher, R. K., McGovern, P. M., Alexander, B. H., Dowd, B. E., Ukestad, L. K., \& McCaffrey, D. J. (2009). The psychosocial work environment and maternal postpartum depression. International Journal of Behavioral Medicine, 16, 339-346.

Dietrich, S., Deckert, S., Ceynowa, M., Hegerl, U., \& Stengler, K. (2012). Depression in the workplace: a systematic review of evidence-based prevention strategies. International Archives of Occupational and Environmental Health, 85, 1-11.

Family and Medical Leave Act of 1993, 29 U.S.C. §§ 2601-2654 (2006).

Feldman, R., Sussman, A. L., \& Zigler, E. (2004). Parental leave and work adaptation at the transition to parenthood: Individual, marital, and social correlates. Journal of Applied Developmental Psychology, 25, 459-479. 
Greenberg, P. E., Kessler, R. C., Birnbaum, H. G., Leong, S. A., Lowe, S. W., Berglund, P. A., \& Corey-Lisle, P. K. (2003). The economic burden of depression in the United States: how did it change between 1990 and 2000?. Journal of Clinical Psychiatry, 64, 1465-1475.

Hock, E., Colleges, W. S., \& Demeis, D. K. (1990). Depression in mothers of infants: The role of maternal employment. 26, 285-291.

Hofferth, S. L., \& Curtin, S. C. (2006). Parental leave statutes and maternal return to work after childbirth in the United States. Work and Occupations, 33, 73-105.

Horowitz, J. A., \& Goodman, J. (2004). A longitudinal study of maternal postpartum depression symptoms. Research and Theory for Nursing Practice, 18, 149-163.

Jorgensen, H., \& Appelbaum, E. (2014). Documenting the need for a national paid family and medical leave program: Evidence from the 2012 FMLA Survey (No. 2014-10). Center for Economic and Policy Research (CEPR). Retrieved from http://www.cepr.net/index.php/publications/reports/documenting-the-need-for-anational-paid-family-and-medical-leave-program-evidence-from-the-2012-fmlasurvey

Klein, M. H., Hyde, J. S., Essex, M. J., \& Clark, R. (1998). Maternity leave, role quality, work involvement, and mental health one year after delivery. Psychology of Women Quarterly, 22, 239-266.

Laughlin, L. (2010). Who's minding the kids?: Child care arrangements, Spring 2005/Summer 2006. US Department of Commerce, Bureau of the Census. Retrieved from http://www.census.gov/prod/2013pubs/p70-135.pdf

Lerner, D., Adler, D., Hermann, R. C., Chang, H., Ludman, E. J., Greenhill, A., \& Rogers, W. H. (2012). Impact of a work-focused intervention on the productivity and symptoms of employees with depression. Journal of Occupational and Environmental Medicine, 54, 128.

McGovern, P., Dowd, B., Gjerdingen, D., Moscovice, I., Kochevar, L., \& Lohman, W. (1997). Time off work and the postpartum health of employed women. Medical Care, 35, 507- 521.

McGovern, P., Dowd, B., Gjerdingen, D., Dagher, R., Ukestad, L., McCaffrey, D., \& Lundberg, U. (2007). Mothers' health and work-related factors at 11 weeks postpartum. Annals of Family Medicine, 5, 519-527. 
McGovern, P., Dagher, R. K., Rice, H. R., Gjerdingen, D., Dowd, B., Ukestad, L. K., \& Lundberg, U. (2011). A longitudinal analysis of total workload and women's health after childbirth. Journal of Occupational and Environmental Medicine / American College of Occupational and Environmental Medicine, 53, 497-505.

O'Hara, M. W., \& Swain, A. M. (1996). Rates and risk of postpartum depression- a metaanalysis. International Review of Psychiatry, 8, 37-54.

O'Hara , M. W., \& Zekoski , E. M. (1988). Postpartum depression: A comprehensive review. In R. Kumar \& I. F. Brockington (Eds.), Motherhood and mental illness: Vol. 2. Causes and consequences (pp. 17-63). London: Wright.

Perry-Jenkins, M. (2011). Working-class jobs and new parents’ mental health. The Journal of Industrial Economics, 59, 1117-1132.

Perry-Jenkins, M., Goldberg, A. E., Pierce, C. P., \& Sayer, A. G. (2007). Shift work, role overload, and the transition to parenthood. Journal of Marriage and the Family, 69, 123-138.

Robertson, E., Grace, S., Wallington, T., \& Stewart, D. E. (2004). Antenatal risk factors for postpartum depression: a synthesis of recent literature. General Hospital Psychiatry, 26, 289-295.

Singley, D. B. (2015). And daddy makes three: Spotlight on men's peripartum mental health. International Journal of Childbirth, 30, 19-24.

Skafida, V. (2012). Juggling work and motherhood: the impact of employment and maternity leave on breastfeeding duration: a survival analysis on growing up in Scotland data. Maternal and Child Health Journal, 16, 519-527.

Spiteri, G., \& Xuereb, R. B. (2012). Going back to work after childbirth: Women’s lived experiences. Journal of Reproductive and Infant Psychology, 30, 201-216.

Stomp-van den Berg, S. G., Van Poppel, M. N. M., Hendriksen, I. J., Bruinvels, D. J., Uegaki, K., De Bruijne, M. C., \& Van Mechelen, W. (2007). Improving return-towork after childbirth: design of the Mom@Work study, a randomised controlled trial and cohort study. BMC Public Health, 7, 43.

Stowe, Z. N., Hostetter, A. L., \& Newport, D. J. (2005). The onset of postpartum depression: Implications for clinical screening in obstetrical and primary care. American Journal of Obstetrics \& Gynecology, 19, 522-526.

Stuart, S., Couser, G., Schilder, K., O'Hara, M., \& Gorman, L. (1998). Postpartum anxiety and depression: Onset and comorbidity in a community sample. Journal of Nervous and Mental Disease, 186, 420-424. 
The Council of Economic Advisors (2014). Economic Report of the President. Washington, DC: US GPO, Annual. US Council of Economic Advisers. Economic report of the President.

Thoits, P. A. (2011). Mechanisms linking social ties and support to physical and mental health. Journal of Health and Social Behavior, 52, 145-161.

Torraco, R. J. (2005). Writing integrative literature reviews: Guidelines and examples. Human Resource Development Review, 4, 356-367.

Usdansky, M. L., Gordon, R. A., Wang, X., \& Gluzman, A. (2012). Depression risk among mothers of young children: The role of employment preferences, labor force status and job quality. Journal of Family and Economic Issues, 33, 83-94.

Wells, C. A. (2012). Breast milk down the drain. The American Journal of Nursing, 112, 11.

Wiese, B. S., \& Ritter, J. O. (2012). Timing matters: Length of leave and working mothers' daily reentry regrets. Developmental Psychology, 48, 1797. 


\section{CHAPTER III}

\section{STUDY \#2, THE IMPACT OF ONLINE SOCIAL SUPPORT ON WORKPLACE ABSENTEEISM AND PRESENTEEISM IN WOMEN WITH POSTPARTUM DEPRESSION SYMPTOMS}

The birth of a child causes a major disruption in the lives and careers of women. In addition to the physical toll of pregnancy and birth, expectant and new mothers experience the added stress of having to leave work for a period of time (maternity leave), which can affect household income, or possible job loss, if the Family and Medical Leave Act (2006) does not apply. Compounding an already stressful situation, some expectant and new mothers also experience peripartum depression, an umbrella term for a major or minor depressive episode beginning during pregnancy or during the postpartum period (American Psychiatry Association, 2013). Approximately 5\% to 25\% of women are affected by depression within the first four weeks to one year after the birth of a child (American Psychiatry Association, 2013; Bennett et al., 2004; Centers for Disease Control and Prevention, 2008; Klein \& Essex, 1994; O'Hara and Swain, 1996). Postpartum depression symptoms directly affect a women’s normal functioning, including symptoms of depressed mood or loss of interest or pleasure, and significant weight loss or gain; insomnia or hypersomnia; psychomotor agitation or retardation; fatigue or loss of energy; feelings of worthlessness or guilt nearly every day; diminished ability to think or concentrate; or recurrent thoughts of death or suicide (with or without a specific plan) (American Psychiatric Association, 2013). Postpartum depression symptoms can affect a woman not only psychologically and physiologically, but it can 
also cause work impairment upon her return to work after the birth of a child (Dagher et al., 2009).

There is a significant financial impact to organizations with depressed employees. While there is no data directly related to the cost-effects of postpartum depression symptoms in the workplace, the literature on general depression reveals that there is a $20 \%$ loss of productivity per depressed individual per day and there was an estimated $\$ 51.5$ billion lost in absenteeism (time missed from work) and presenteeism (the ability to produce effectively) in the year (Beck et al., 2011; Greenberg et al., 2003; Lerner et al., 2012). This suggests that there are financial implications for organizations that have employees experiencing postpartum depression symptoms, especially when considering that $60.7 \%$ of the female workforce has children under the age of 3 years old (U.S. Bureau of Labor Statistics, 2013). In other words, the majority of the U.S. workforce is made up of women (U.S. Bureau of Labor Statistics, 2013) who are also new mothers. It stands to reason then that human resource development (HRD) professionals should help new mothers transition back to work after maternity leave, especially when they are experiencing postpartum depression symptoms.

Public health, medical, psychology, and psychiatry researchers have studied the experiences of women with postpartum depression, the adverse effects on their families, and have reported some of the risk factors (Beck, 2001; Knudson-Martin \& Silverstein, 2009; O'Hara \& Swain, 1996; Robertson, Grace, Wallington, \& Stewart, 2004). However, a review of five major research databases (Academic One File, Academic Search Complete, ProQuest, PsychInfo, and Social Sciences Citation Index) found no studies published in the field of HRD around helping new mothers who are experiencing 
postpartum depression symptoms at work. This study suggests borrowing from other fields' research to begin a conversation around the best practices that HRD professionals might follow in helping women transition back to work after childbirth. HRD professionals' support in transitioning back to work can influence the impact of postpartum depression symptoms to absenteeism and presenteeism.

Studies that investigated maternal mental health in the workplace were divided into four groups: length of maternity leave, role congruence and quality, physical and personal stressors, and work-related stressors. The major findings of these studies included some evidence that maternity leave length is less important in influencing maternal mental health than a women's perception of control over her workload and her preference for her role status (Klein, Hyde, Essex, \& Clark, 1998; Hock \& DeMeis, 1990; Usdansky et al., 2011). For example, a woman who took 8 weeks of maternity leave, but has a flexible schedule and prefers to be a working mother, is likely to have better mental health scores than a woman who took 12 weeks of maternity leave, but has a job that offers no flexibility and prefers to be stay at home.

In addition, research studies have found that mothers face a dilemma when deciding whether they want to be working mothers or (can afford to be) stay-at-home mothers. Role incongruence in such situations has been shown to have a negative impact on the depression scores of new mothers (Hock \& DeMeis, 1990; Klein, Hyde, Essex, \& Clark, 1998; Usdansky, Gordon, Wang, \& Gluzman, 2012). These studies indicate that the decision to return to work is not only financial, but also one that carries psychological consequences, perhaps because of the socially-constructed connotations that have been applied to the labels of working mother versus the stay-at-home mother. 
A finding that was echoed across several studies was that social support from friends, family, and coworkers can be attributed to better maternal health (Dagher et al., 2009; McGovern et al., 2007). Coworker support is especially important if the new mother is in a high urgency job (degree of time stress and pressure, for example an emergency room doctor; Perry-Jenkins et al., 2011). These findings are consistent with literature that shows that lack of social support is a risk factor associated with postpartum depression symptoms (Beck, 2001; Gjerdingen \& Chaloner, 1994; Gjerdingen, McGovern, Attanasio, Johnson, \& Kozhimannil, 2014).

One study about online social support found that women with postpartum depression symptoms found relief and comfort in exchanging their stories with others (Evans, Donelle, \& Hume-Loveland, 2012). Having the ability to speak freely to other women served an important function, as women tend to disguise their distress and shame related to their perceived inability to be a good mother (Evans et al., 2012). Studies about online support groups for postpartum depression symptoms and other women's issues (e.g. menopause, child loss, premature births, and female infertility) have shown positive outcomes for participants (Bochatin, 2014; Evans et al., 2012; Malik \& Coulson, 2010, Pector, 2012). Thus, participation in online support groups could mitigate the effects of postpartum depression symptoms on work impairment. For HRD professionals, this means that they could encourage the use of online support groups to help their employees with postpartum depression symptoms. Online support groups could also be established exclusive to the organization, if the organization is large enough to merit this, to foster social support in the workplace. 


\section{Purpose of the Study}

The purpose of this study is to examine whether participation in online social support groups is associated with the presenteeism and absenteeism of women with postpartum depression symptoms. The research questions guiding this study will be clarified below, followed by an explanation of the conceptual framework for this paper. Then, an explanation of the data collection methods used to obtain participants and description of the sample population will follow. Last, the findings will be discussed, with some attention to how they might apply in an HRD context.

\section{Research Questions}

This study will be conducted to answer the following question for employed women with postpartum depression symptoms who engage in online support groups: To what degree is participation in online support groups related to work impairment? The researcher expects to find an association between postpartum depression symptoms and work impairment, which will be moderated by participation in online support groups. A positive correlation is expected between postpartum depression symptoms and online support group participation.

\section{Conceptual Framework}

The conceptual framework for this study is based on a combination of two theories: the self-labeling theory and the stress-buffering hypothesis. Thus, the conceptual framework uses self-labeling theory (Thoits, 1985) in combination with the stressbuffering hypothesis (Cohen \& Willis, 1985) to predict how participation in online support groups can mitigate the effects of postpartum depression symptoms on work impairment. 


\section{Self-Labeling Theory}

Self-labeling theory was introduced by Thoits (1985) as a way to explain why mental health patients sought treatment voluntarily. Self-labeling is the act by which an individual assesses his or her actions in relation to social norms and then labels him or herself accordingly. For example, women often describe the feeling of falling instantly in love with their newborn child upon his or her birth. A mother who is suffering from postpartum depression symptoms may label herself a bad mother if she did not feel immediately connected with her child. She compares herself to what other mothers describe as normal and decides she does not meet that expectation. The act of selflabeling is a private act that does not require public or official labeling by others (Thoits, 1985).

Three major assumptions underlie the theory of self-labeling (Thoits, 1985). First, the individual who is self-labeling is a well-socialized individual who understands rules and when normative expectations have been broken. Next, that there are known categories of normal and expected behaviors that carry cultural labels for individuals who violate them. Last, there is an assumption that individuals are motivated to conform to societal expectations. When an internal conflict occurs between the societal expectations of emotions for a given situation and the actual emotions experienced by a person, the self-labeling process takes place. The self-labeling process is therefore the impetus for voluntary help-seeking behaviors.

\section{Seeking Social Support Online}

Social support is defined as the functions performed for an individual by others (Thoits, 2011). Thoits borrowed from Sullivan (1953) to classify these others into two 
groups: primary and secondary. Primary group members are people who are close to the individual to whom the individual feels emotionally tied, such as significant others and family members. The secondary group members tend to be larger and one where members' knowledge of one another is less personal. Secondary members may enter and leave their common group (such as religious group, workplace, and volunteer groups) at their own discretion; therefore, the length of membership will vary (2011). Thoits (2011) has asserted that both groups - primary and secondary - can serve equally important functions in social support.

Online support group members generally fall into the secondary group category. One study found that individuals lacking social support in the real world were more likely to engage in online social support (Turner, Grube, \& Meyers, 2001). When an individual seeks support online, the individual is expanding his or her network of potential similar others. This can lead to higher levels of social support (Cohen \& Wills, 1985). Online social support has been shown to be effective for matching the user to his or her needs (Vayreda \& Antaki, 2009). In a study about online support groups for people with bipolar disorder, Vayreda and Antaki (2009) found that a person must be comfortable with his or her identity (in the case for postpartum depression, the self-assigned label)to find a support group that adequately addresses his or her needs. This further illustrates not only the psychological function of self-labeling, but also the practical need for it as it applies to support seeking behavior.

The four main functions of social support include: emotional, instrumental, informational and, within informational, appraisal. Emotional support refers to offerings of love, caring, esteem, encouragement, and sympathy. Instrumental support refers to 
helping others with practical tasks or problem or offering material assistance.

Informational support is the provision of facts or advice that helps an individual solve problems; encompassed within informational support is appraisal support. Appraisal support is feedback about an individual's situation and giving guidance about possible courses of action (Cohen \& McKay, 1984; Thoits, 2011). Cohen and McKay (1984) proposed that when an individual decides that an event is in fact harmful, a stress response will occur. The researchers argued that social support can enter at the moment of appraisal to help an individual make a decision about whether the stressor is in fact harmful. Social support can also enter at the moment of a stress response to help an individual make a decision about his or her coping abilities. Helping an individual to redefine the situation as non-threatening is the ultimate goal of appraisal support, according to Cohen \& McKay (1984). The proposed model posits that when an individual is able to cope with a stressful situation the negative effects related to work impairment are mitigated.

Appraisal support is best offered by individuals deemed as similar others - others who have or are experiencing the same or a similar situation (Cohen \& McKay, 1984). In this case, women with postpartum depression symptoms would seek support from other women with postpartum depression. A way to quickly connect with a community of similar others is use the Internet to find online support groups (Fox \& Duggan, 2013). Approximately $80 \%$ of Internet users have reported posting a healthcare-related question or shared their own health experience online (Fox \& Duggan, 2013). Of those 59\% posted comments, questions or stories about their own health, $78 \%$ of those individuals reported that they posted their question to a general audience of friends or other Internet 
users. This means that people who are seeking support are doing so from their peers more likely than from their healthcare professionals (Fox \& Duggan, 2013).

\section{Stress-Buffering Hypothesis}

The stress-buffering hypothesis proposed by Cohen and Wills (1985) has five parts, which begins with the occurrence of a potentially stressful event. A stressful event refers to a situation that has the potential to elicit a negative effect, physiological response, and behavioral adaptation (Cohen \& McKay, 1984). In this study, the

potentially stressful event is returning to work after the birth of a child. If the stress of the event is not mitigated, this could lead to work impairment as posited by the conceptual model.

The next stage of the stress-buffering hypothesis is appraisal of the stressful event. If there is an intervention at this point, either before there is a reaction to the stress reaction to the event or during the anticipation of said event, then there is a possibility that a stress appraisal response can be avoided (Cohen \& Willis, 1985). In other words, if a new mother is anticipating that returning to work will be a stressful event; then, before the event occurs, others can intervene to help her change her perception. Presumably, the social support would moderate not only the appraisal of the event, but also the selflabeling attributed to it, and its effects on work impairment.

In the third step, when social support from others does not intervene, the event is appraised as stressful. Continuing with the subject of our study, this could mean that the new mother has decided that returning to work will have negative outcomes for her and her child. This is followed by an emotionally linked physiological response or behavioral adaptation such as anxiety or sadness. At this point, social support from others could help 
the mother re-appraise the stressful event, the resulting self-labeling, and also her response to it. However, without social support, the emotional response is followed by the illness or illness behavior (depression), which can ultimately lead to work impairment.

The conceptual model undergirding this study combines self-labeling theory and the stress-buffering hypothesis. Self-labeling theory posits why women with postpartum depression symptoms seek social support. The stress-buffering hypothesis posits how returning to work can catalyze a series of stress responses that eventually lead to work impairment if social support is not sought.

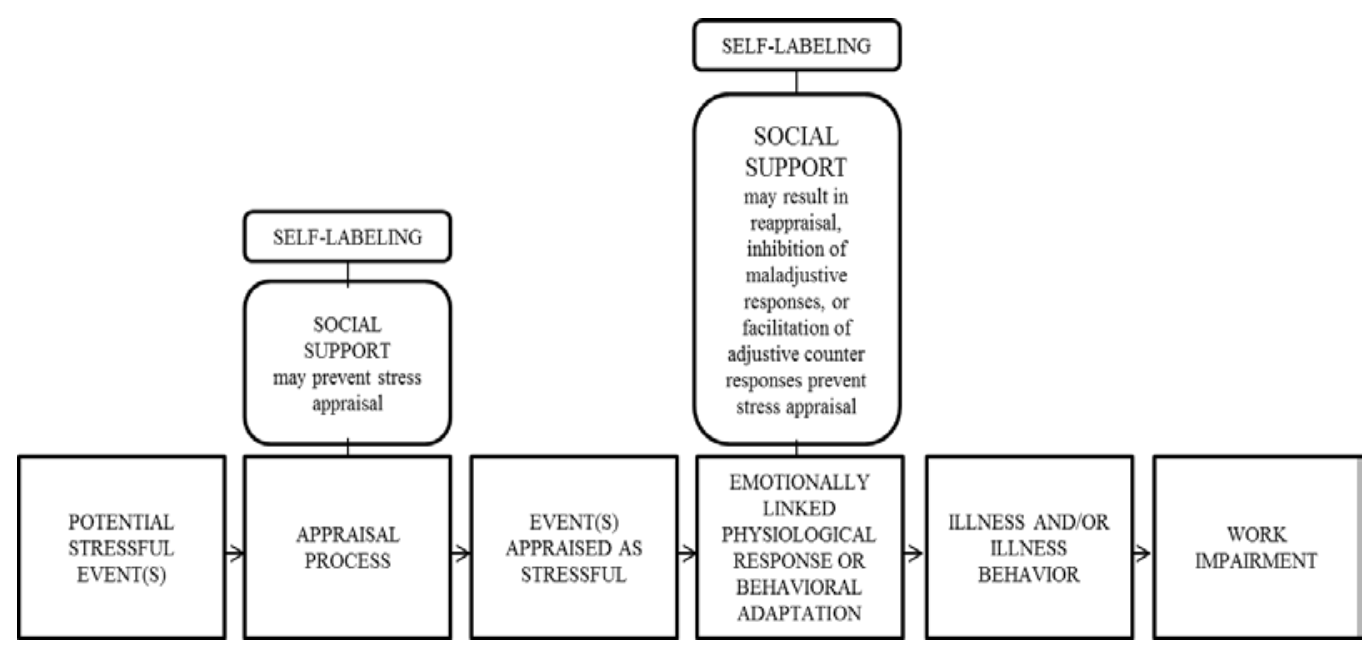

Figure 1. The conceptual model for this study combines the self-labeling theory and the stress-buffering hypothesis to predict work impairment measured by absenteeism and presenteeism.

\section{Method}

Data about online support groups and the relationship to presenteeism and absenteeism will be collected in the form of an online survey. The survey will consist of questions related to postpartum depression symptomology, work impairment (measured by absenteeism and presenteeism), and perceived social support given on a Likert-scale. 
In similar studies, the following measures have been used: The Edinburg Postnatal Depression Scale which consists of 10 short statements related to events in the past seven days such as "I have been able to laugh and see the funny side of things" (Cox, Holden, \& Sagovsky, 1987). This measure has been found to have satisfactory validity in identifying women with postpartum depression symptoms (Dagher, McGovern, \& Dowd, 2014). For work impairment, the Work Productivity and Activity Impairment (WPAI) has been used to compute absences from work due to health issues and presenteeism (Beck, 2011). Questions such as:

During the past seven days, how many hours did you miss from work because of problems associated with [your PROBLEM]? Include hours you missed on sick days, times you went in late, left early, etc., because of [your PROBLEM]. Do not include time you missed to participate in this study. (Reilly, Zbrozek, \& Dukes, 1993)

Both measures survey events within the past seven days, thereby offering data about events that occur within the same time period. For example, the researcher will be able to collect data about a woman's depressive state within a 7-day period and correlate that to her work impairment within that same seven day period.

For online social support, a survey will be adapted from a previous study on online social support for smoking cessation (Graham, Papandonatos, Kang, Moreno, \& Abrams, 2011). This survey includes questions such as "I never posted messages on [name of website].” Items cover the main functions of social support discussed previously: emotional, informational, instrumental, and appraisal support (Cohen \& 
McKay, 1984; Thoits, 2011). The online social support survey has shown to be a valid and reliable instrument (Graham et al., 2011).

In addition to the above mentioned survey items, the survey will include questions about the employee's workplace organizations, such as: maternity leave policies and industry, maternity leave timeframe, and socio-economic status. It will also include questions about how the participant was recruited for the survey (i.e., an online forum, Facebook, through a clinician etc.). The survey had a total of 49 questions.

\section{Sampling Procedures and Sample Size}

A sample size of at least 5 and up to 50 participants per variable was recommended for a correlation analysis (Green, 1991). This study has three main research variables: participation in online support groups, work impairment, and postpartum depression symptoms score. Therefore, according to Green (1991), the researcher should recruit between 15 and 150 women. However, for the purpose of statistical power, the researcher recruited 153 participants. Participants were recruited on the basis that they were working mothers with a child under the age of one. The rationale for this time frame lies in the findings of previous research. The American Psychiatry Association (2013) diagnoses postpartum depression symptoms as depression that begins within the first four weeks after the birth of a child; however, researchers have found that the onset of risk is elevated through the first six months after delivery (Beeghly et al., 2002; Stuart, Couser, Schilder, O'Hara, \& Gorman, 1998). Additionally, research has shown that $55 \%$ of employed women return to work during the first five month of their child's life, and another 7.4\% return within the first six to 11 months (Laughlin, 2011). This information substantiates this time period as a time of critical need for social 
support. A pre-screening survey filtered out participants who did not meet these qualifications. Data collected using the Edinburg Postnatal Depression Scale (Cox, Holden, \& Sagovsky, 1987) will give a score for depression symptoms, which will be used to determine if the participant is experiencing postpartum depression symptoms.

The majority of the participants for this study were recruited through online support groups hosted through public websites, Facebook, and Twitter. Additional participants were recruited by clinical professionals personally known to the researcher and through referrals. The recruitment took place for three consecutive weeks from August to September 2015.

Participant recruitment using social media has been used successfully in several studies (Beck, 2004; Malik \& Coulson, 2008; Yuan, Bare, Johnson, \& Saberi, 2014). Dillman et al. (2009) developed a scheduling framework for administration of online surveys. The framework includes: 1) sending an invitation of pre-notification to the participants and/or the forum administrators inviting them to participate, 2) sending the survey link 3 days after the invitation pre-notification, 3) sending an e-mail reminder one week after the initial survey e-mail, 4) sending an e-mail reminder two weeks after the initial survey email, and 5) sending a thank you e-mail to the participants at the conclusion of the study. This framework was slightly altered to fit the recruitment of this study using social media.

The first step was to select online support groups in which to post the study. A Facebook account was created for the sole purpose of this study. A search for groups containing "postpartum depression" in their title was conducted. The search resulted in a list of 169 groups. Due to Facebook limitations on how many groups user can add, only 
25 groups were selected for posting. The groups were selected based on the member count, that it was not limited to a geographical location, and that the group did not specifically ban advertisements or research postings in their group rules. Messages were posted to these groups either by the researcher or through the group administrator (depending on how the group was set up), a week after the initial post was made, and again two weeks after the initial post was made.

On Twitter, a search was done for "postpartum depression," “\#postpartumdepression”, and “\#PPD”. Tweets asking for participation went out to women whose profiles fit the profile of working mother with a child under a year old. Tweets also went out for a request to retweet to individuals whose profiles indicated that they are advocates for maternal mental health (e.g., the Founder/CEO of Postpartum Progress Inc., Co-Founder of the Postpartum Resource Center of New York, Founder of Postnatal Depression Chat, etc.). The aim of these tweets was to reach the followers of these individuals and organizations (presumably sufferers of postpartum depression). A total of 513 original tweets were sent out. There is no clear way to estimate the number of those that were retweeted, but nearly every tweet sent out was re-tweeted at least once by the account owner. A second request for retweets was sent out a week later, and then again during the final week of recruitment.

Parenting websites (found by searching postpartum online support on Google) were also scanned for active communities in which to post the recruitment announcement. This resulted in posts in 12 postpartum depression support forums and working mother support forums across 5 websites. Others were found, but had strict rules 
that did not allow posting of research studies. These websites were also re-posted to at the one week, two week, and three week marks.

\section{Participant Characteristics}

As a requirement for participation in this study, all participants were working mothers with children under the age of one year old. This was established in a prescreening questionnaire before potential participants had access to the full survey. The ages of the 153 participants ranged from 21 to 43 years old with an average of 31.70

years old. The participants were asked for the age of their youngest child in months; this average was 7.08 months. The majority of the participants were from the United States (133 or 86.9\%) and 13 (8.5\%) were from Australia. One participant represented each of the following countries: Egypt, Mexico, New Zealand, Pakistan, South Africa and the United Kingdom. The participants identified themselves as $62.7 \%$ White, $25.5 \%$ Hispanic, 2.6\% Black, 3.3\% Asian, and 5.9\% other. The majority of the women in this study were college educated. Forty-one percent held a graduate degree and $30.7 \%$ held a bachelor's degree. Twenty-two percent had some college education and 5.2\% held a high school diploma or GED.

Household income was reported in the following ranges: $58.8 \%$ were making $\$ 70,001$ or more; $7.8 \%$ were making $\$ 60,001-\$ 70,000$; $7.8 \%$ were making $\$ 50,001$ $\$ 60,000 ; 7.8 \%$ were making $\$ 40,001-\$ 50,000 ; 7.8 \%$ were making $30,001-\$ 40,000 ; 9.2 \%$ were making $\$ 20,001-\$ 30,000$; and $2 \%$ were making less than $\$ 20,000$. The women in this sample were most commonly employed in organizations that were hospital or medical facilities, professional services (e.g., architect, police officer, lawyer), and forprofit services not including retail or restaurants (e.g., a bank). Ten percent of the women 
reported working 50 or more hours per week (more than full-time). Forty-eight percent of the women reported working between 40 and 49 hours per week; 21.6\% worked 30-39 hours; $12.4 \%$ worked 20-29 hours; and 7.2\% worked 1-19 hours per week. The women in this sample took 12.75 weeks of maternity leave on average (range 1 week to 52 weeks).

Table 4 provides a frequency table of all demographic variables described above.

Table 4

Frequency Table of Demographic Variables

\begin{tabular}{|c|c|c|c|}
\hline Category & Variable & $f$ & Percent \\
\hline \multirow[t]{6}{*}{ Age } & $21-25$ & 13 & 8.5 \\
\hline & $26-30$ & 47 & 30.7 \\
\hline & $31-35$ & 66 & 43.1 \\
\hline & $36-40$ & 24 & 15.7 \\
\hline & $41-43$ & 3 & 2.0 \\
\hline & Total & 153 & 100 \\
\hline \multirow{5}{*}{$\begin{array}{l}\text { Age of Youngest Child (in } \\
\text { months) }\end{array}$} & $0-3$ & 30 & 19.6 \\
\hline & $4-6$ & 35 & 22.9 \\
\hline & $7-9$ & 40 & 26.1 \\
\hline & $10-12$ & 48 & 31.4 \\
\hline & Total & 153 & 100 \\
\hline \multirow{6}{*}{$\begin{array}{l}\text { Maternity Leave Length (in } \\
\text { weeks) }\end{array}$} & $0-12$ & 107 & 69.9 \\
\hline & $13-24$ & 33 & 21.6 \\
\hline & $25-36$ & 10 & 6.5 \\
\hline & $37-48$ & 2 & 1.3 \\
\hline & $49-52$ & 1 & .7 \\
\hline & Total & 153 & 100 \\
\hline \multirow{9}{*}{ Country of Residence } & Australia & 13 & 8.5 \\
\hline & Egypt & 1.7 & 1 \\
\hline & Mexico & 1.7 & 1 \\
\hline & New Zealand & 1.7 & 1 \\
\hline & Pakistan & 1.7 & 1 \\
\hline & South Africa & 1.7 & 1 \\
\hline & United Kingdom & 1.7 & 1 \\
\hline & United States & 133 & 86.9 \\
\hline & Total & 153 & 100 \\
\hline
\end{tabular}


Table 4

Frequency Table of Demographic Variables (continued)

\begin{tabular}{|c|c|c|c|}
\hline Category & Variable & $f$ & Percent \\
\hline \multirow{6}{*}{ Race/Ethnicity } & Asian & 5 & 3.3 \\
\hline & Black & 4 & 2.6 \\
\hline & Hispanic & 39 & 25.5 \\
\hline & White & 96 & 62.7 \\
\hline & Other & 9 & 5.9 \\
\hline & Total & 153 & 100 \\
\hline \multirow[t]{8}{*}{ Education } & High school diploma or GED & 8 & 5.2 \\
\hline & Some college & 34 & 22.2 \\
\hline & Bachelor's degree & 47 & 30.7 \\
\hline & Graduate degree & 64 & 41.8 \\
\hline & Total & 153 & 100 \\
\hline & $\$ 60,001-\$ 70,000$ & 12 & 7.8 \\
\hline & greater than $\$ 70,001$ & 90 & 58.8 \\
\hline & Total & 153 & 100 \\
\hline \multirow[t]{11}{*}{ Type of Organization } & $\begin{array}{l}\text { retail (e.g., hardware store, } \\
\text { clothing store) }\end{array}$ & 8 & 5.2 \\
\hline & manufacturing & 3 & 2.0 \\
\hline & government (non-military) & 11 & 7.2 \\
\hline & $\begin{array}{l}\text { non-profit service (non- } \\
\text { government) }\end{array}$ & 14 & 9.2 \\
\hline & college or university & 13 & 8.5 \\
\hline & hospital or medical facility & 37 & 24.2 \\
\hline & restaurant & 3 & 2.0 \\
\hline & $\begin{array}{l}\text { for-profit service (besides retail } \\
\text { or restaurant; e.g., a bank) }\end{array}$ & 17 & 11.1 \\
\hline & $\begin{array}{l}\text { professional service (e.g., } \\
\text { architect, police officer, lawyer) } \\
\text { (please specify) }\end{array}$ & 24 & 15.7 \\
\hline & other & 23 & 15. \\
\hline & Total & 153 & 100 \\
\hline \multirow{6}{*}{$\begin{array}{l}\text { Number of Hours Worked } \\
\text { (in the previous seven days) }\end{array}$} & $1-19$ & 11 & 7.2 \\
\hline & $20-29$ & 19 & 12.4 \\
\hline & 30-39 & 33 & 21.6 \\
\hline & $40-49$ & 74 & 48.4 \\
\hline & $50+$ & 16 & 1.5 \\
\hline & Total & 153 & 100 \\
\hline
\end{tabular}




\section{Results}

The results section of this paper is organized by the variables of this study: postpartum depression symptoms, work impairment, and participation in online support groups. The first section will include a comparative analysis of the group whose scores on the Edinburg Postnatal Depression Scale (Cox, Holden, \& Sagovsky, 1987) indicated that they were experiencing symptoms of postpartum depression against the group that did not show symptoms of postpartum depression. Next, findings related to online support group participation measures will be discussed and findings related to work impairment, measured in terms of absenteeism and presenteeism. Last, the findings related to our research questions.

\section{Postpartum Depression Symptom Scores}

The Edinburg Postnatal Depression Scale (EPDS; Cox, Holden, \& Sagovsky, 1987 ) is a 10-item scale that results in a cumulative score. Participants who score over 10 points on the EPDS are likely to be experiencing depression. Anyone scoring over 13 points is likely to be suffering from a depressive illness. Accordingly, the cumulative scores of the EPDS was divided into two groups, less than or equal to 9 points (nondepressed), greater than or equal to 10 points (likely depressed) for all analyses. The scores of the EPDS should not be interpreted above 13 as degrees of severity (Cox, Holden, \& Sagovsky, 1987). This scale demonstrated good internal consistency, $\alpha=.93$.

According to the EPDS, 55.8\% of the participants in this study were experiencing some type of postpartum depression symptoms; specifically 39.9\% were possibly experiencing a depressive illness (scored 13 points or higher) and 15.9\% scored between 10 and 12 points. Forty-four percent of the participants in this study did not report any 
symptoms of postpartum depression. No statistically significant differences were found between the members of the likely depressed group $(n=85)$ versus the non-depressed group ( $n=68)$ when as a result of the $\chi^{2}$ analyses conducted: age $(p=.798)$, hours worked per week $(p=.780)$, age of child $(p=.305)$, maternity leave length $(p=.543)$, highest level of education $(p=.339)$, income $(p=.368)$, and race $(p=.239)$.

Table 5 details the findings for the seven $\chi^{2}$ analyses run for the demographic variables.

Table 5

Demographic Variable Cross Tabulation

\begin{tabular}{llll}
\hline Variable Combination & $\chi^{2}$ Value & $d f$ & $p$ \\
\hline Depression Score and Age & 1.65 & 4 & .798 \\
Depression Score and Hours Worked per Week & 1.76 & 4 & .780 \\
Depression Score and Age of Baby & 3.62 & 3 & .305 \\
Depression Score and Maternity Leave Length & 3.09 & 4 & .543 \\
Depression Score and Education & 3.35 & 3 & .339 \\
Depression Score and Income & 4.28 & 6 & .638 \\
Depression Score and Race & 5.51 & 4 & .239 \\
\hline
\end{tabular}

\section{Online Support Group Participation}

Online support group participation was determined based on whether the participant had ever read messages in online support groups, posted messages to online support groups, or both. This scale demonstrated good internal consistency, $\alpha=.81$.

A $\chi^{2}$ comparison of likely depressed participants versus non-depressed participants found that each group was equally likely to participate in reading $(p=.143)$ or posting ( $p$ 
$=.615$ ) to online support groups related to postpartum depression. Fifty-two percent of the participants were non-readers of online support groups and $47 \%$ were readers of online support groups. In the likely depressed group $(n=85), 57.1 \%$ were only readers, and $38.1 \%$ were readers and had posted to online support groups related to postpartum depression. In the non-depressed group ( $n=68), 64 \%$ were readers and 32\% had posted to online support groups related to postpartum depression.

The Online Support Scale for Smoking Cessation developed by Graham et al. (2011) was modified to measure online social support in terms of postpartum depression support instead of smoking cessation. "Online support group” and words related to postpartum depression symptoms were substituted for "QuitNet” and related words in any question that mentioned smoking cessation or a smoking cessation support group (e.g., "I felt comfortable sharing private or personal thoughts with other members of QuitNet in the public forums" became "I felt comfortable sharing private or personal thoughts with other members of an online support group in the public forums").

The finding of this survey indicated that the majority of the participants of online support groups related to postpartum depression also connected with group members about topics other than postpartum depression (29.7\% agreed a little, 32.8\% agreed a lot). All members who participated in this section of the survey had read messages in online support groups related to postpartum depression; however, only 20.3\% indicated that they had posted messages in an online support groups. Forty-three percent indicated that they felt comfortable sharing in private or personal thoughts with other members of the group and $64.1 \%$ felt comfortable sharing private or personal thoughts to an individual member through private messages. Anonymity played a role in feeling comfortable sharing 
personal information for $42.2 \%$ of the participants and it played an important role for $32.8 \%$. Some of the factors that did not play an important role in online support group participation were: the type of advice found was not available anywhere else (71.9\% disagreed a lot), knowing you were not alone in the struggle with postpartum depression symptoms (56.3\% disagreed a lot), the round the clock availability of the online support group (71.9\% disagreed a lot), receiving bad information or advice (42.2\% disagreed a little), and receiving advice and support from people in different stages of postpartum depression recovery (35.9\% disagreed a lot). Sixty-four percent of the participants agreed that they felt supported and encouraged by other online support group members. Although members did that they received negative or critical comments from other members, (37.5\% agreed a little and $29.7 \%$ agreed a lot), overall $50.0 \%$ agreed a little that participation in an online support group aided in coping with postpartum depression symptoms; another 32.8\% agreed a lot with the statement. Table 6 shows these results. 
Table 6

Frequencies of Survey Questions Related to Online Social Support

\begin{tabular}{|c|c|c|c|c|c|c|c|c|}
\hline & \multicolumn{2}{|c|}{$1=$ disagree $\mathrm{a}$ lot } & \multicolumn{2}{|c|}{$\begin{array}{l}2 \text { = disagree } \\
\text { a little }\end{array}$} & \multicolumn{2}{|c|}{$\begin{array}{l}3=\text { agree a } \\
\text { little }\end{array}$} & \multicolumn{2}{|c|}{$\begin{array}{l}4=\text { agree a } \\
\text { lot }\end{array}$} \\
\hline & $f$ & Percent & $f$ & Percent & $f$ & Percent & $f$ & Percent \\
\hline $\begin{array}{l}\text { I connected with other } \\
\text { people in an online } \\
\text { support group on } \\
\text { topics other than } \\
\text { postpartum depression. }\end{array}$ & 14 & 9.2 & 5 & 3.3 & 24 & 15.7 & 24 & 15.7 \\
\hline $\begin{array}{l}\text { I never posted } \\
\text { messages in an online } \\
\text { support group. }\end{array}$ & 30 & 19.6 & 13 & 8.5 & 4 & 2.6 & 20 & 13.1 \\
\hline $\begin{array}{l}\text { I felt comfortable } \\
\text { sharing private or } \\
\text { personal thoughts with } \\
\text { other members of an } \\
\text { online support group } \\
\text { in the public forums. }\end{array}$ & 14 & 9.2 & 7 & 4.6 & 26 & 17.0 & 20 & 13.1 \\
\hline $\begin{array}{l}\text { I felt comfortable } \\
\text { sharing private or } \\
\text { personal thoughts } \\
\text { through direct } \\
\text { messages to individual } \\
\text { members of an online } \\
\text { support group. }\end{array}$ & 23 & 15.0 & 8 & 5.2 & 18 & 11.8 & 18 & 11.8 \\
\hline $\begin{array}{l}\text { By giving advice to } \\
\text { other members of in an } \\
\text { online support group, } \\
\text { my own efforts in } \\
\text { getting better were } \\
\text { reinforced. }\end{array}$ & 17 & 11.1 & 7 & 4.6 & 25 & 16.3 & 18 & 11.8 \\
\hline
\end{tabular}


Table 6

Frequencies of Survey Questions Related to Online Social Support (continued)

\begin{tabular}{|c|c|c|c|c|c|c|c|c|}
\hline \multirow[t]{2}{*}{ Topic } & \multicolumn{2}{|c|}{$\begin{array}{l}1 \text { = disagree a } \\
\text { lot }\end{array}$} & \multicolumn{2}{|c|}{$\begin{array}{l}2 \text { = disagree a } \\
\text { little }\end{array}$} & \multicolumn{2}{|c|}{$\begin{array}{l}3 \text { = agree a } \\
\text { little }\end{array}$} & \multicolumn{2}{|c|}{$\begin{array}{l}4=\text { agree a } \\
\text { lot }\end{array}$} \\
\hline & $f$ & Percent & $f$ & Percent & $f$ & Percent & $f$ & Percent \\
\hline $\begin{array}{l}\text { Being anonymous made } \\
\text { it easier to share } \\
\text { personal information } \\
\text { with people in an online } \\
\text { support group. }\end{array}$ & 19 & 12.4 & 7 & 4.6 & 19 & 12.4 & 22 & 14.4 \\
\hline
\end{tabular}

$\begin{array}{lllllllll}\text { Using an online support } & 10 & 6.5 & 8 & 5.2 & 31 & 20.3 & 18 & 11.8 \\ \text { group helped me cope } & & & & & & & & \\ \text { with postpartum } & & & & & & & & \\ \text { depression. }\end{array}$

\begin{tabular}{lllllllll}
\hline I got advice and support & 14 & 9.2 & 9 & 5.9 & 29 & 19.0 & 15 & 9.8 \\
in an online support \\
group that I could not \\
find anywhere else.
\end{tabular}

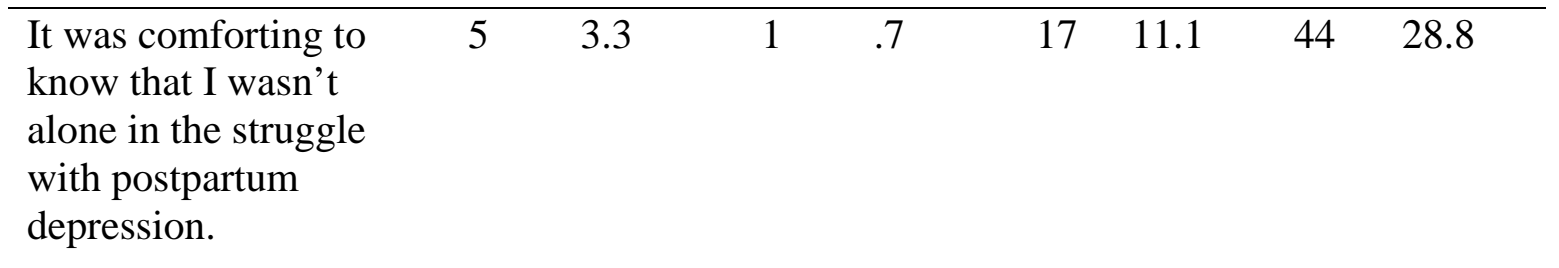

\begin{tabular}{|c|c|c|c|c|c|c|c|c|}
\hline $\begin{array}{l}\text { The fact that an online } \\
\text { support group is } \\
\text { available whenever I } \\
\text { need it, night or day, } \\
\text { was important to me. }\end{array}$ & 6 & 3.9 & 4 & 2.6 & 22 & 14.4 & 35 & 22.9 \\
\hline $\begin{array}{l}\text { I felt supported and } \\
\text { encouraged by other } \\
\text { online support group } \\
\text { members. }\end{array}$ & 7 & 4.6 & 9 & 5.9 & 27 & 17.6 & 24 & 15.7 \\
\hline
\end{tabular}


Table 6

Findings Related to Online Social Support (continued)

\begin{tabular}{|c|c|c|c|c|c|c|c|c|}
\hline \multirow[t]{2}{*}{ Topic } & \multicolumn{2}{|c|}{$\begin{array}{l}1=\text { disagree a } \\
\text { lot }\end{array}$} & \multicolumn{2}{|c|}{$\begin{array}{l}2 \text { = disagree a } \\
\text { little }\end{array}$} & \multicolumn{2}{|c|}{$\begin{array}{l}3 \text { = agree a } \\
\text { little }\end{array}$} & \multicolumn{2}{|c|}{$\begin{array}{l}4=\text { agree a } \\
\text { lot }\end{array}$} \\
\hline & $f$ & Percent & $f$ & Percent & $f$ & Percent & $f$ & Percent \\
\hline $\begin{array}{l}\text { Advice and support } \\
\text { from people in different } \\
\text { stages of postpartum } \\
\text { depression recovery } \\
\text { was helpful to me. }\end{array}$ & 7 & 4.6 & 4 & 2.6 & 32 & 20.9 & 24 & 15.7 \\
\hline $\begin{array}{l}\text { I received negative or } \\
\text { critical comments from } \\
\text { other online support } \\
\text { group members. }\end{array}$ & 49 & 32.0 & 9 & 5.9 & 6 & 3.9 & 3 & 2.0 \\
\hline $\begin{array}{l}\text { I received some bad } \\
\text { information or advice } \\
\text { from someone in an } \\
\text { online support group. }\end{array}$ & 37 & 24.2 & 15 & 9.8 & 13 & 8.5 & 2 & 1.3 \\
\hline $\begin{array}{l}\text { Being in a different } \\
\text { time zone from other } \\
\text { members made it } \\
\text { difficult to get the } \\
\text { support I needed. }\end{array}$ & 61 & 39.9 & 4 & 2.6 & 2 & 1.3 & 0 & 0 \\
\hline
\end{tabular}

\section{Work Impairment}

Work impairment was measured in terms of absenteeism (days missed from work) and presenteeism (how productive an employee is while at work) using the sixitem WPAI (Reilly, Zbrozek, and Dukes, 1993). The survey asked if the participant is currently employed, and in the past seven days (a) how many hours were missed from work because of postpartum depression symptoms, (b) how many hours were missed 
from work for other reason, (c) how many hours were worked in total in the past seven days, (d) how much postpartum depression symptoms affected productivity while at work, and (e) how much postpartum depression symptoms affected other regular activities. This questionnaire allows researchers to calculate the percent of total work impairment due to postpartum depression symptoms based on the following formula: Q2/(Q2+Q4)+[(1-(Q2/(Q2+Q4)))x(Q5/10)]. This scale appears demonstrated good internal consistency, $\alpha=.92$.

Table 7 gives the average and statistical significance of an Independent Samples $t$ test for each question for the likely depressed group versus the non-depressed group, as well as for the total work impairment percentage. 


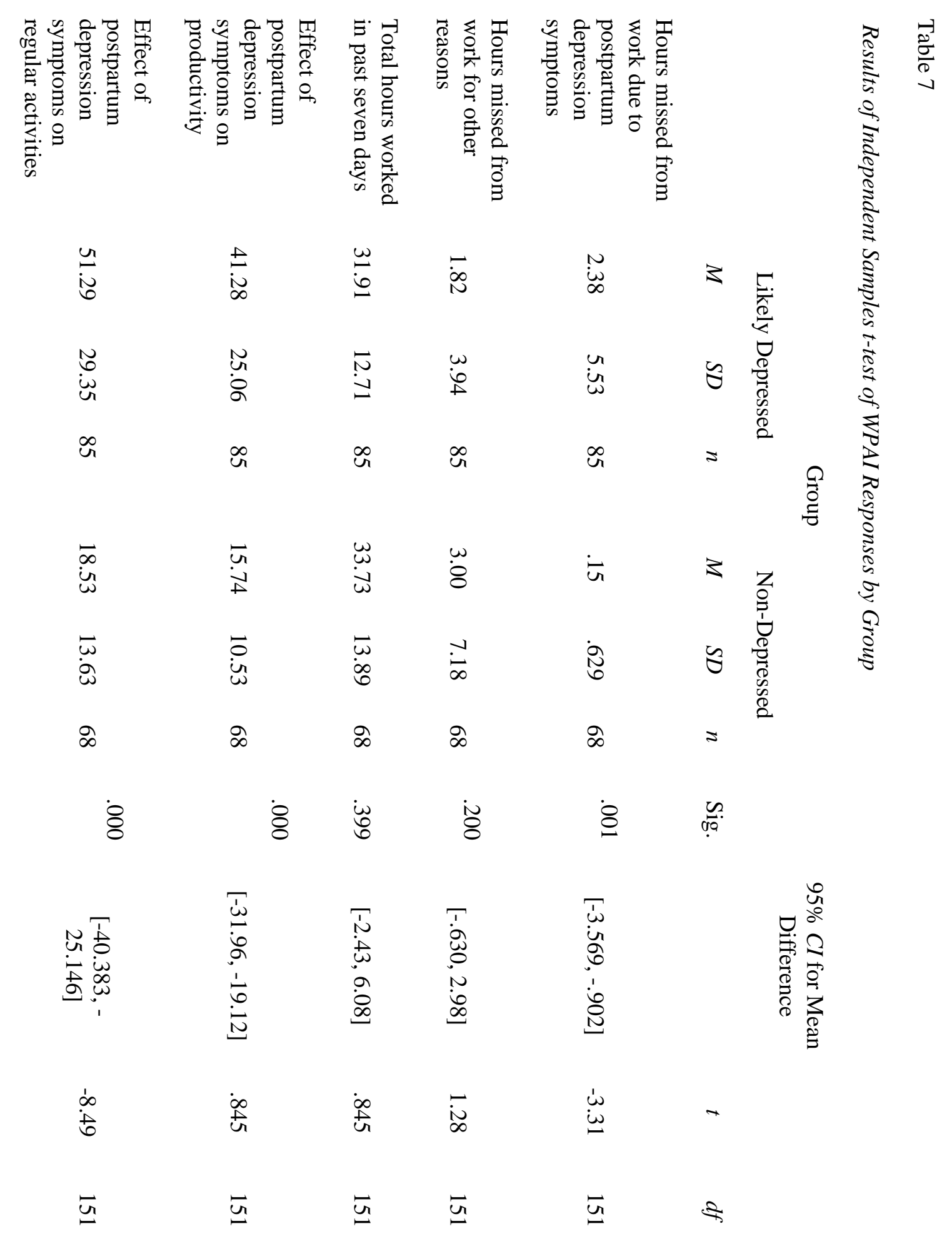


The group that is likely depressed demonstrated higher work impairment scores than the non-depressed group in measures of hours missed from work due to postpartum depression symptoms, effect of postpartum depression symptoms on productivity at work, and the effect of postpartum depression symptoms on regular activities. Hours missed from work for other reasons and total hours worked in the preceding seven days were not statistically different.

\section{Research Question and Hypotheses}

The overarching research question of this study is: To what degree is participation in online support groups related to work impairment? The hypotheses were: (a) there is a positive correlation between postpartum depression symptoms and work impairment, (b) there is a group difference between the participants who are experiencing postpartum depression symptoms and those who are not experiencing postpartum depression symptoms in terms of online support group participation, and (c) that participation in online support groups will moderate the effect of postpartum depression symptoms on work impairment.

To get a preliminary sense of the data, the researcher first ran a zero-order correlation between the variable percent overall working impairment and reading online support groups’ postings related to postpartum depression. Second a zero-order correlation was run between the variable percent overall working impairment and posting in online support groups related to postpartum depression. Reading online support group postings had a statistically significant negative relationship with percent of overall work impairment $(r=-.187, p=.021)$, meaning that participants who read more online postings had lower work impairment scores (i.e., they were absent less frequently and 
more productive during work hours). Posting to online support groups, however, was not statistically significantly when correlated to percent of overall work impairment $(r=.048$, $p=.703)$

To test the first hypothesis, a zero-order correlation analysis of the percent of overall work impairment and postpartum depression symptom scores showed that there was a statistically significant strong, positive correlation between percent of overall work impairment and postpartum depression symptoms $(r=.539, p=.000)$. Increases in postpartum depression symptoms were correlated with increases in the percent of overall work impairment. This means that the more postpartum depression symptoms a woman is experiencing, the more likely she is to self-report diminished productivity at work. In this case, the research hypothesis was supported.

The second hypothesis was tested by running a $\chi^{2}$ analysis of the likely depressed or non-depressed groups versus whether or not the group members had read or posted messages in a postpartum depression support group. This analysis found that members in both the likely depressed group and the non-depressed group were just as likely to participate in reading messages in an online support group for postpartum depression $\left(\chi^{2}(1)=2.14, p=.143\right)$. The same held true for individuals who posted messages in online support groups for postpartum depression. Members of each group were just as likely to post messages in online support groups for postpartum depression $\left(\chi^{2}(1)=.253\right.$, $p=.615)$. The hypothesis that there is a group difference between the participants who are experiencing postpartum depression symptoms and those who are not experiencing postpartum depression symptoms in terms of online support group participation was therefore not supported. 
The last hypothesis tested whether participation in online support groups moderated the effect of postpartum depression symptoms on work impairment. To test this hypothesis a regression analysis was run. The percent of overall work impairment was transformed using the formula $\operatorname{LOG} 10(x+c)$ in order for it to be used as the dependent variable in a regression analysis (Tabachnick \& Fidell, 2001). Overall work impairment was regressed on depression group, readership group, and the interaction between the two, as well as depression group, posting, and interaction between the two. Table 8 gives a summary of the findings of these two analyses.

Table 8

Regression Analyses of Depression Group, Readership, and Posting on Work Impairment

\begin{tabular}{|c|c|c|c|c|c|c|}
\hline & \multicolumn{3}{|c|}{ Model 1 (Readership) } & \multicolumn{3}{|c|}{ Model 2 (Posting) } \\
\hline Variable & $B$ & $S E B$ & $\beta$ & $B$ & $S E B$ & $\beta$ \\
\hline Constant & .074 & .016 & & .092 & .025 & \\
\hline $\begin{array}{c}\text { Depression } \\
\text { Group }\end{array}$ & .119 & $.023 *$ & .465 & .145 & $.033^{*}$ & .552 \\
\hline Readership & .014 & .027 & .055 & & & \\
\hline $\begin{array}{l}\text { Interaction of } \\
\text { Readership and } \\
\text { Depression }\end{array}$ & .039 & .036 & .134 & & & \\
\hline Posting & & & & -.017 & .045 & -.063 \\
\hline $\begin{array}{l}\text { Interaction of } \\
\text { Posting and } \\
\text { Depression }\end{array}$ & & & & .037 & .056 & .124 \\
\hline$R^{2}$ & $.306^{*}$ & & & $.337 *$ & & \\
\hline$F$ & 23.37 & & & 12.18 & & \\
\hline
\end{tabular}


The main effect of depression group (whether or not the participant was depressed) accounted for the significant change in work impairment in both models. Model 1 (readership) accounted for $30.6 \%$ of the change in $R^{2}$ and was statistically significant ( $p=.000$ ). Model 2 (posting) accounted for 33.7\% of the change in $R^{2}$ and was statistically significant $(p=.000)$. The interaction between depression score and reading, and depression score and writing, did not account for any statistically significant effect on work impairment in any of the four models. However, the hypothesis that participation in online support groups would moderate work impairment in women with postpartum depression symptoms could not be supported in this study.

\section{Discussion and Implications to HRD Research}

The findings of this study indicate that postpartum depression symptoms is negatively correlated with overall work impairment. This means that overall work impairment was correlated to loss of productivity and an increase in hours missed from work. This finding is supported by other studies that document the impact of depression in the workplace (Greenberg et al., 2003; Lerner et al., 2012). However, this is the first study in the HRD research realm that associates postpartum depression symptoms (versus general depression) to work impairment.

This study also found that online support group participants who read postings, (versus those who also posted), had lower work impairment scores (i.e., were less likely to be absent from work or have a decrease in productivity while at work). However, posting to online support groups did not have a significant correlation with overall work impairment. This means that it is possible that reading messages in online support groups is more effective at moderating postpartum depression symptoms than posting personal 
messages to online support groups. In her book, Taylor (1996) writes that reading selfhelp literature not only provides concrete information about woman's issues, but also opens up a “new world of possible identities”. Thoits’ (2011) research postulates that having a network of similar others (i.e., other people with whom the depressed individual can identify) can in help the individual feel validated and help her stop worrying about the appropriateness of her feelings and actions. Based on this evidence, perhaps reading online support groups should be treated as self-help literature. Further research needs to be done with respect to the functions of reading personal stories versus sharing personal stories, and whether it is necessary to share one's own stories to gain the most benefits from a social support group.

This study also exposed an interesting dynamic in the online support group participants. Both the likely depressed and non-depressed individuals were equally as likely to read and to post to online support groups related to postpartum depression. This researcher believes that the non-depressed individuals who are reading and posting to online support groups were either curious about whether or not they were experiencing postpartum depression symptoms or, it is also possible, that they were at one time experiencing postpartum depression symptoms and became participants of the online support group, but were not experiencing postpartum depression symptoms at the time that they participated in this survey. Further studies could be conducted to try to determine if the readers of online support groups related to postpartum depression symptoms tend to include readers who are curious about their own feelings. Studies into how long a participant is considered a relevant member should also be conducted. For example, if a participant is no longer experiencing postpartum depression symptoms, is 
she still playing a role in the social support network for the women who are experiencing postpartum depression?

The overall work impairment models further supported that postpartum depression symptoms are related to work impairment. Model 1 (readership) accounted for $30.6 \%$ of the change in $R^{2}$ and was statistically significant $(p=.000)$. Model 2 (posting) accounted for $33.7 \%$ of the change in $R^{2}$ and was statistically significant ( $\left.p=.000\right)$. Additional research should be done on the interaction of reading or posting to online support groups and work impairment during the return-to-work transition, as the proposed model suggests. The questions related to work impairment and depression symptoms required women to answer questions about events in the preceding seven days. On average, the women in this study had been back at work for 3.90 months since the birth of their youngest child. It is possible that these women have fully transitioned into their new roles as mother and employee. Perhaps this same investigation conducted right as women were returning to work, which is a critical period, could yield interaction effects of participation in online support groups.

\section{Implications to HRD Theory}

Prior to this study, the self-labeling theory (Thoits, 1985) and the stress-buffering hypothesis (Cohen \& Willis, 1985) had not been used to explain the effect of postpartum depression symptoms on work impairment. There is evidence to support the conceptual model proposed in this paper, which is undergirded by a combination of the self-labeling theory and the stress-buffering hypothesis. Self-labeling (assessed by the question "In the past seven days, I have blamed myself unnecessarily when things went wrong.”) is correlated with reading postpartum depression support groups’ postings $(r=.258, p=$ 
.001). That means that reading postpartum depression support groups is associated with feelings of blame. This is consistent with self-labeling theory that posits that an individual will first assess his or her actions and then, label him or herself. Subsequently, after labeling themselves (e.g., a mother who thinks she is a bad mother), the individual will then be more likely to seek support (Thoits, 1985). In this case, blame is a function of the labeling process and reading postpartum depression support groups is a mechanism by which a woman may begin to seek support.

The second part of the conceptual model is the stress-buffering hypothesis (Cohen \& Willis, 1985). It posits that after a stressful event, social support can intervene to inhibit the stressor from snowballing into an emotionally-linked physiological response and consequent illness or illness behavior. This illness or illness behavior subsequently affects work impairment. The findings of this study indicate that postpartum depression symptoms are related to overall work impairment (measured in absenteeism and presenteeism). However, this study was not able to support online social support as a moderator for the effect of postpartum depression symptoms on overall work impairment. The researcher believes that these findings are due to other moderator variables not accounted for in this study such as marital status, the number of children in the family, or child care factors. These variables have also been shown to influence postpartum depression symptoms (Beck, 2001; O’Hara \& Swain, 1996; Robertson, Grace, Wallington, \& Stewart, 2004) and may also influence overall work impairment. HRD researchers should conduct further research in to the effect size of postpartum depression symptoms on work impairment and moderating variables. Studies around types of social 
support, especially those in the work place, such as supervisor and coworker support should be examined for moderating effects.

\section{Implications for HRD Practice}

It is important for HRD professionals to understand the implications of postpartum depression symptoms at work. This study found a statistically significant correlation between postpartum depression symptoms and work impairment, which includes more frequent absences from work and a lack of productivity while at work. Before this study, the workplace effects of postpartum depression symptoms could be estimated by looking at research on general depression. However, this correlation further supports the notion that HRD professionals need to understand the impact of postpartum depression symptoms on employees especially because the majority of the U.S.

workforce is made up of women who are also new mothers (57.7\%; U.S. Bureau of Labor Statistics, 2013). The effect of postpartum depression symptoms on the organization is not only limited to work impairment, there may also be effects to voluntary turnover (e.g., if a woman is torn between being a mother and working), organizational commitment (e.g., especially if the organization does not seem to be supportive of her new role as a mother), job satisfaction (e.g., role congruence studies; Dagher, et al., 2008; McGovern et al., 2007), workplace adaptation, and engagement.

A good starting point for HRD professionals would be to learn to recognize the signs of postpartum depression symptoms such as those listed in the DSM-V: depressed mood or loss of interest or pleasure, and significant weight loss or gain; insomnia or hypersomnia; psychomotor agitation or retardation; fatigue or loss of energy; feelings of worthlessness or guilt nearly every day; diminished ability to think or concentrate; or 
recurrent thoughts of death or suicide (with or without a specific plan) (American Psychiatric Association, 2013). HRD professionals can check in with new mothers to make sure they are not experiencing and adverse effects when they return to work.

This study supports that women who are experiencing postpartum depression symptoms will seek social support from similar others to put their feelings and actions into context. Other studies support social support in the work place as a moderator for the effects of postpartum depression symptoms on overall health High levels of coworker support was shown to promote better physical health (Dagher, et al., 2008; McGovern et al., 2007). HRD professionals can use this knowledge to promote social support networking within the organization, for example, facilitating networking opportunities between new mothers or mothers within the organization.

\section{Limitations of the Study}

Selection bias is a potential threat to the internal validity of this study. The majority of the women selected for this study were recruited from online sources. This automatically excludes women who do not have access to the internet or mobile technology. Additionally, the majority of the women in this study had high levels of education and worked in a medical field. It is possible that women who are more educated are more aware of the resources that are available to them, especially if they work in a medical field. This means that the findings of this study may not be generalizable to women with less education and fewer resources.

\section{Conclusions}

This study is ground-breaking because it begins a conversation between HRD professionals and researchers about postpartum depression symptoms in the workplace. 
This study was able to demonstrate a statistically significant relationship between postpartum depression symptoms and work impairment. Work impairment of an employee directly affects the organization in terms of lost wages in lack of productivity and lost time due to absenteeism. This study was also able to illustrate a model that explained just over $30 \%$ of the change in work impairment through postpartum depression symptom scores, readership and posting in online support groups, and the interaction of depression scores and readership and posting separately. This is an important contribution to the literature because it indicates to HRD professionals the serious effects of postpartum depression symptoms on the overall organization. Additionally, HRD professionals should be aware that reading postpartum depression support groups and its effects on work impairment merits further investigation. 


\section{REFERENCES}

American Psychiatric Association. (2013). Diagnostic and statistical manual of mental disorders (5th ed.). Washington, DC: Author.

Beck, C. T. (2001). Predictors of postpartum depression: an update. Nursing Research, 50, 275-285.

Beck, C. T. (2004). Birth trauma: in the eye of the beholder. Nursing Research, 53, 2835.

Beck, A., Crain, A. L., Solberg, L. I., Unützer, J., Glasgow, R. E., Maciosek, M. V., \& Whitebird, R. (2011). Severity of depression and magnitude of productivity loss. The Annals of Family Medicine, 9, 305-311.

Beeghly, M., Weinberg, M., Olson, K., Kernan, H., Riley, J., \& Tronick, E. (2002). Stability and change in level of maternal depressive symptomatology during the first postpartum year. Journal of Affective Disorders, 71, 169-180.

Bennett, H. A., Einarson, A., Taddio, A., Koren, G., \& Einarson, T. R. (2004). Prevalence of depression during pregnancy: Systematic review. Obstetrics \& Gynecology, 103, 698-709.

Bochantin, J. (2014). “Long Live the Mensi-Mob”: Communicating Support Online With Regards to Experiencing Menopause in the Workplace. Communication Studies, 65, 260-280.

Centers for Disease Control and Prevention (CDC. (2008). Prevalence of self-reported postpartum depressive symptoms--17 states, 2004-2005. Morbidity and mortality weekly report, 57, 361.

Cohen, S., \& McKay, G. (1984). Social support, stress and the buffering hypothesis: A theoretical analysis. In A. Baum, S.E. Taylor, J.E. Singer (Eds.), Handbook of Psychology and Health, pp. 253-267. Hillsdale, NJ: Psychology Press.

Cohen, S., \& Wills, T. A. (1985). Stress, social support, and the buffering hypothesis. Psychological Bulletin, 98, 310.

Cox, J. L., Holden, J. M., \& Sagovsky, R. (1987). Detection of postnatal depression: Development of the 10-item Edinburgh Postnatal Depression Scale. The British Journal of Psychiatry, 150, 782-786.

Dagher, R. K., McGovern, P. M., Alexander, B. H., Dowd, B. E., Ukestad, L. K., \& McCaffrey, D. J. (2009). The psychosocial work environment and maternal 
postpartum depression. International Journal of Behavioral Medicine, 16, 339346.

Dagher, R. K., McGovern, P. M., \& Dowd, B. E. (2014). Maternity leave duration and postpartum mental and physical health: Implications for leave policies. Journal of Health Politics, Policy and Law, 39, 369-416.

Dillman, D. A., Smyth, J. D., \& Chrstian, L. M. (2009). Internet, mail, and mixed-mode survey: The tailored design method. Hoboken, NJ: John Wiley \& Sons.

Evans, M., Donelle, L., \& Hume-Loveland, L. (2012). Social support and online postpartum depression discussion groups: A content analysis. Patient Education and Counseling, 87, 405-410.

Family and Medical Leave Act of 1993, 29 U.S.C. §§ 2601-2654 (2006).

Fox, S. \& Duggan, M. Peer-to-Peer Health Care. (2013, January 14). Retrieved February 21, 2015, from http://www.pewinternet.org/2013/01/15/peer-to-peer-health-care/

Gjerdingen, D. K., \& Chaloner, K. M. (1994). The relationship of women's postpartum mental health to employment, childbirth, and social support. The Journal of Family Practice, 38, 465-472.

Gjerdingen, D., McGovern, P., Attanasio, L., Johnson, P. J., \& Kozhimannil, K. B. (2014). Maternal depressive symptoms, employment, and social support. The Journal of the American Board of Family Medicine, 27, 87-96.

Graham, A. L., Papandonatos, G. D., Kang, H., Moreno, J. L., \& Abrams, D. B. (2011). Development and validation of the online social support for smokers scale. Journal of Medical Internet Research, 13(3).

Green, S. B. (1991). How many subjects does it take to do a regression analysis? Multivariate Behavioral Research, 26, 449-510.

Greenberg, P. E., Kessler, R. C., Birnbaum, H. G., Leong, S. A., Lowe, S. W., Berglund, P. A., \& Corey-Lisle, P. K. (2003). The economic burden of depression in the United States: how did it change between 1990 and 2000?. Journal of Clinical Psychiatry, 64, 1465-1475.

Hock, E. \& DeMeis, D. K. (1990). Depression in mothers of infants: the role of maternal employment. Developmental Psychology, 26, 285

Klein, M. H., \& Essex, M. J. (1994). Pregnant or depressed? The effect of overlap between symptoms of depression and somatic complaints of pregnancy on rates of major depression in the second trimester. Depression, 2, 308-314. 
Knudson-Martin, C., \& Silverstein, R. (2009). Suffering in silence: A qualitative metadata-analysis of postpartum depression. Journal of Marital and Family Therapy, $35,145-158$.

Laughlin, L. L. (2011). Maternity leave and employment patterns of first-time mothers: 1961-2008. US Department of Commerce, Economics and Statistics Administration, US Census Bureau. Retrieved February 21, 2015, from https://www.census.gov/prod/2011pubs/p70-128.pdf

Lerner, D., Adler, D., Hermann, R. C., Chang, H., Ludman, E. J., Greenhill, A., \& Rogers, W. H. (2012). Impact of a work-focused intervention on the productivity and symptoms of employees with depression. Journal of Occupational and Environmental Medicine, 54, 128.

Malik, S. H., \& Coulson, N. S. (2010). Coping with infertility online: An examination of self-help mechanisms in an online infertility support group. Patient Education and Counseling, 81, 315-318.

McGovern, P., Dowd, B., Gjerdingen, D., Dagher, R., Ukestad, L., McCaffrey, D., \& Lundberg, U. (2007). Mothers' health and work-related factors at 11 weeks postpartum. Annals of Family Medicine, 5, 519-527.

O'Hara, M. W., \& Swain, A. M. (1996). Rates and risk of postpartum depression: A meta-analysis. International Review of Psychiatry, 8, 37-54.

Robertson, E., Grace, S., Wallington, T., \& Stewart, D. E. (2004). Antenatal risk factors for postpartum depression: A synthesis of recent literature. General Hospital Psychiatry, 26, 289-295.

Pector, E. A. (2012). Sharing losses online: Do internet support groups benefit the bereaved?. International Journal of Childbirth Education, 27, 19-25.

Perry-Jenkins, M., Smith, J. Z., Goldberg, A. E., \& Logan, J. (2011). Working-class jobs and new parents' mental health. Journal of Marriage and Family, 73, 1117-1132.

Stuart, S., Couser, G., Schilder, K., O'Hara, M., \& Gorman, L. (1998). Postpartum anxiety and depression: Onset and comorbidity in a community sample. Journal of Nervous and Mental Disease, 186, 420-424.

Sullivan, H. S. (1953). The interpersonal theory of psychiatry. New York, NY: Norton.

Tabachnick, B. G., \& Fidell, L. S. (2001). Using multivariable statistics (4th ed.). Boston: Allyn \& Bacon.

Thoits, P. A. (1985). Self-labeling processes in mental illness: The role of emotional deviance. American Journal of Sociology, 9, 221-249. 
Thoits, P. A. (2011). Mechanisms linking social ties and support to physical and mental health. Journal of Health and Social Behavior, 52, 145-161. 


\section{CHAPTER IV}

\section{CONCLUSIONS}

This conclusion chapter consists of five parts. The first section is a brief summary of study \#1, which was an integrative literature review. The second section is a brief summary of study \#2, which was an empirical study. The third section discusses findings of each study as they relate to the overall purpose of this collected papers dissertation. The fourth and final section describes the implications of this collected papers dissertation for theory, research, and practice.

\section{Summary of the Study \#1}

The purpose of study \#1 was two-fold. The first aim was to examine how postpartum depression was being discussed in the context of the workplace in HRD literature in the United States. The second aim of this study was to determine if there existed a set of best practices in HRD literature to guide HRD professionals in helping employees with postpartum depression symptoms. This study was guided by the stressbuffering hypothesis (Cohen \& Wills, 1985), which posits that when a person experiences a stressful life event, social support can mitigate the effect before the stress evolves into an illness or illness behavior.

A search was conducted of the following large databases: Academic One File, Academic Search Complete, ProQuest, PsychInfo, and Social Sciences Citation Index, using the term "postpartum depression or postnatal depression” combined with each of the following terms individually: workplace, job, employee, employee assistance program, and human resources. No time delimitation was imposed on the search. The search yielded 124 articles of which none were published in an HRD journal. After 
further examination of the content of the articles, 12 were selected for the literature review. The 12 articles came from medical journals (2), psychology journals (4), and public health journals (6). Four areas of concern around maternal mental health and work emerged: maternal employment status, role congruence and role quality, physical and personal stressors, and work-related stressors.

The lack of literature published in HRD journals points to the fact that HRD professionals may not be aware of the issue of postpartum depression symptoms at work, its potential human and organizational negative effects, and how to avoid potential loss of employee productivity. HRD professionals may need to develop a program to train supervisors and managers on the signs and symptoms of postpartum depression. Although they are not therapist or medical professionals, if HRD professionals are aware of signs of postpartum depression symptoms, they can refer new mothers to get help.

Additionally, researchers advise that around the six and seven month mark postpartum women many begin to experience a decline in their overall health (Chatterji, Markowitz, \& Brooks-Gunn, 2013; McGovern et al., 1997). HRD professionals should be alerted to this finding so they will know to check in with new mothers around this time.

Findings related to maternity leave length were mixed. The studies presented in the literature review indicated that maternity leave over 12 weeks, especially around 15 weeks is associated with an increase in maternal mental health (Chatterji \& Markowitz, 2012; Chatterji et al., 2013; McGovern et al., 1997). However, studies on role quality emphasize that maternity leave length had little to no effect on maternal mental health when compared to role congruence (Dagher, et al., 2008; McGovern et al., 2007). 
High levels of coworker support was shown to promote better physical health (Dagher, et al., 2008; McGovern et al., 2007) especially in high urgency jobs (PerryJenkins et al., 2011). Better mental health was attributed at 5 and 11 weeks to perceived control over home and work (Dagher et al., 2012; Klein et al., 1998). Having some flexibility in home and work roles could also mitigate the effects of job stress (McGovern et al., 2007).

\section{Summary of the Study \#2}

The purpose of this study is to examine whether participation in online social support groups has an impact on the presenteeism and absenteeism of women with postpartum depression symptoms. The study was conducted to answer the following question for employed women with postpartum depression symptoms who engage in online support groups: To what degree is participation in online support groups related to work impairment?

The theoretical framework for this study is based on a combination of two theories: the stress-buffering hypothesis and the self-labeling theory. The stress-buffering hypothesis (Cohen \& Willis, 1985) was previously discussed in this section as the framework for study \#1. The self-labeling theory (Thoits, 1985) was developed to explain why mentally ill individuals sought social support voluntarily. The combination of theories is used to guide this study on how participation in online support groups can mitigate the effects of postpartum depression symptoms on work impairment.

This study was conducted using a survey. The survey consisted of questions related to postpartum depression symptoms, work impairment (measured as absenteeism and presenteeism), and perceived social support given on a Likert-scale. The survey 
includes questions about the employee's workplace organizations such as maternity leave policies and industry, and how the participant was recruited for the survey (i.e. an online forum, Facebook, through a clinician etc.). The survey had a total of 49 questions.

A sample of 153 women was recruited through online support groups, Facebook and Twitter posts, and clinicians personally known to the researcher. All participants were working mothers with children under the age of one. The participants were on average around 32 years old with their youngest child being seven months old. Majority of the participants were from the United States (86.9\%) and considered themselves White (62.7\%). Forty-one percent held a graduate degree and had a household income of $\$ 70,000$ or more (58.8\%). The majority worked in hospital or medical facilities, professional services (e.g. architect, police officer, lawyer), and for-profit services not including retail or restaurants (e.g. a bank) for anywhere between 40 and 49 hours per week (48\%). The women in this sample took 12.75 weeks of maternity leave on average (range 1 week to 52 weeks).

According to the EPDS, 55.6\% of the participants in this study were experiencing some type of postpartum depression symptoms. In terms of online support group participation, $52 \%$ of the participants were non-readers of online support groups and $47 \%$ were readers of online support groups. Overall, $82 \%$ of the participants agreed that participation in an online support group aided in coping with postpartum depression symptoms. There was a statistically significant difference in the absenteeism due to postpartum depression symptoms between the likely depressed $(M=2.38)$ and nondepressed groups $(M=.15, t(151)=3.31, p=.001)$. There was also a statistically significant difference between the effect of postpartum depression symptoms on percent 
of productivity impairment of the likely depressed group $(M=41.28)$ and the nondepressed group $(M=15.74, t(151)=.845, p=.000)$.

The hypotheses were: (a) that there exists a positive correlation between postpartum depression symptoms and overall work impairment, (b) there is a group difference between the participants who are experiencing postpartum depression symptoms and those who are not experiencing postpartum depression symptoms in terms of online support group participation, and (c) that participation in online support groups will moderate the effect of postpartum depression symptoms on work impairment. The first hypothesis of this study was supported. The more postpartum depression symptoms a woman is experiencing, the more likely she is to self-report diminished productivity at work. The second hypothesis was not supported. Members of both the likely depressed and non-depressed groups were equally likely to read and post message in online support groups. The third hypothesis of the study was also unsupported. There was not a moderating effect of postpartum depression symptoms on work impairment due to participation in online support groups.

\section{Findings Related to Overall Purpose of Collected Papers Dissertation}

The purpose of this collected papers dissertation was to investigate whether participation in online support groups is related to less work impairment for women with postpartum depression symptoms. The findings of the literature review, guided by the stress-buffering hypothesis, did find ample support for social support as a moderator for postpartum depression symptoms (Dagher, et al., 2008; McGovern et al., 2007; PerryJenkins et al., 2011). Although, these findings were not directly related to HRD practice nor were the primary purposes of these studies to research social support as moderators 
for postpartum depression symptoms. This substantiated a need for research directly related to HRD practices around employees experiencing postpartum depression symptoms, especially where social support opportunities exist.

For study \#1 the stress-buffering hypothesis was applicable as a means to help women with postpartum depression symptoms. By identifying potentially stressful events (such as returning to work after maternity leave or child care factors), HRD professionals can facilitate opportunities for social support interaction to prevent the stressors from snowballing into illness or illness behavior (such as depression). The question remained as to what types of social support made the biggest impact and also were the most feasible for HRD professionals to provide, both economically and within the scope of the profession.

The findings of the second study did not support participation in online support groups a viable moderator to the effect of postpartum depression symptoms on work impairment. However, the study did find that postpartum depression symptoms are correlated to self-reported measures of absenteeism and presenteeism. The difference between participants who were likely depressed and those who were not depressed was statistically significant in terms of absenteeism and presenteeism. These findings were supported by other studies that document the effect of depression in the workplace (Greenberg et al., 2003; Lerner et al., 2012).

\section{Implications for Theory, Research, and Practice}

There was a correlation between blaming oneself for things unnecessarily and reading postpartum depression support groups' postings. This is consistent with selflabeling theory that posits that an individual will first assess his or her actions and then, 
label him or herself. Subsequently, after labeling themselves (e.g., a mother who thinks she is a bad mother), the individual will then be more likely to seek support (Thoits, 1985). In this case, blame is a function of the labeling process and reading postpartum depression support groups is a mechanism by which a woman may begin to seek support. The self-labeling theory requires seems to apply to women experiencing postpartum depression symptoms.

The stress-buffering hypothesis could still serve as an applicable theory to guide research studies about social support for postpartum depression symptoms in the workplace. This study did not support online support groups as a method of social support that could moderate the effects of postpartum depression symptoms on work impairment, but there are many possible providers of social support that could be looked at such as family, co-workers, and supervisors. Additionally, social support is known to serve different functions. The four main functions of social support include: emotional, instrumental, informational and, within informational, appraisal (Cohen \& McKay, 1984; Thoits, 2011). Future studies around social support should not only focus on where the social support comes from, but also function of the support. HRD professionals should be prepared to provide the right type of support for each individual case. As the literature review revealed, there is not a one-size-fits-all solution. A woman who is concerned with issues of role congruence (Dagher, et al., 2008; McGovern et al., 2007) may need informational/appraisal support, while a woman who is experiencing issues with marital conflict (Perry-Jenkins et al., 2007) may need emotional support. HRD researchers can explore ways to offer different types of support under the various circumstances faced by women returning to work while experiencing postpartum depression symptoms. 
No research was found in HRD literature related to postpartum depression symptoms. This means that there is much yet to be learned in terms of how HRD professionals can help women experiencing postpartum depression symptoms at work. This research study and several others have found that experiencing postpartum depression symptoms has an impact on daily role function, including at work (Chatterji, Markowitz, \& Brooks-Gunn, 2013; Dagher et al., 2009; Hock and DeMeis, 1990; McGovern et al., 1997; McGovern et al., 2007).

Research around postpartum depression symptoms and work has generally consisted around the areas of leave time, maternal employment status, role congruence and role quality, physical and personal stressors, and work-related stressors. Of the 12 studies found for the literature review in this collected papers dissertation, two studies used data from the National Institute of Child Health and Human Development Study on Early Child Care (Chatterji, Markowitz, \& Brooks-Gunn, 2013; Usdansky et al., 2012), four studies used data from a 817 participant data set collected in Minnesota (Dagher et al., 2009; Dagher et al., 2011; McGovern et al., 2007; McGovern et al., 2011), one used secondary data from the Early Childhood Longitudinal Study - Birth Cohort (Chatterji \& Markowitz, 2012), and the remaining five used data sets that were collected by the researchers themselves and not used in any other studies in this literature review (Hock \& DeMeis, 1990; Klein, Hyde, Essex, \& Clark, 1998; McGovern et al., 1997; Perry-Jenkins et al., 2011; Perry-Jenkins et al., 2007). This shows that not only is there not a lot of research on the topic of postpartum depression symptoms at work, but even the research that exists, is not varied. Many of the same data sets are used across different studies; therefore, the sample populations are very similar. In the 12 studies examined in the 
literature review, all were predominately White, English speaking participants with a college education. The babies born to the women in this samples were all healthy and, in most cases, the first-born. Researchers need to diversify the sample populations in these studies. More research needs to be conducted with non-White women and women with more than one child. Special attention should also be put on women whose children are not healthy, or still-born. These women have unique postpartum depression circumstances that may need to be addressed differently by HRD professionals.

Additionally, the mean age for most of the sample populations, including the one in the empirical study in this collected papers dissertation is in the range of 28-30 years old. Understanding how age may play a factor in postpartum depression symptoms alongside work responsibility also needs to be understood. Presumably, a younger person will have fewer resources than an older person when she gives birth. Additionally, younger people may have less work experience than older people. The combination of having less work experience, and fewer resources, could possibly contribute to higher stress level upon returning to work. Age may also contribute to the types of social support that a person may need. A younger person may need more informational/appraisal support than an older person, especially if this is her first-born. An older person may require more emotional or instrumental support, especially if she has more than one child.

Future online researchers should also consider how the sample population could be diversified. In this study, many of the women were in the medical field, had a high degree of education, and a high socio-economic status. The results of this study may have been affected by these variables to the degree that women without medical background, and similarly with less education, may be less likely to know what resources are available 
to them. Lower earning women may also not have on-demand access to the Internet and therefore may be unable to use some of the online support groups presented in this study. Future research around online support groups should consider these variables.

It is the opinion of this researcher that an effort should first be made to find solutions that are low-cost and easy to implement. This could motivate HRD professionals to be proactive more quickly than a solution that requires a large-scale, high cost implementation (e.g. a change in employee mental health benefits). Simply having HRD professions that know the signs of postpartum depression symptoms is a step in the right direction. Beginning a conversation around how to offer social support to women who are suspected to be experiencing postpartum depression symptoms could be the next step. Eventually, research on this topic could lead to the development of training programs, return to work transition programs for new mothers, and formalized networks of social support within the organization (e.g. a group of mothers employed within the organization that offers to help a new mother upon her return to work). 


\section{REFERENCES}

Chatterji, P., \& Markowitz, S. (2013). Family leave after childbirth and the health of new mothers. Journal of Mental Health Policy and Economics, 15, 61-76.

Chatterji, P., Markowitz, S., \& Brooks-Gunn, J. (2013). Effects of early maternal employment on maternal health and well-being. Journal of Population Economics, 26, 285-301.

Cohen, S., \& Wills, T. A. (1985). Stress, social support, and the buffering hypothesis. Psychological Bulletin, 98, 310.

Dagher, R. K., McGovern, P. M., Alexander, B. H., Dowd, B. E., Ukestad, L. K., \& McCaffrey, D. J. (2009). The psychosocial work environment and maternal postpartum depression. International Journal of Behavioral Medicine, 16, 339346.

Dagher, R. K., McGovern, P. M., Dowd, B. E., \& Gjerdingen, D. K. (2012). Postpartum depression and health services expenditures among employed women. Journal of Occupational and Environmental Medicine, 54, 210-215.

Dagher, R. K., McGovern, P. M., Dowd, B. E., \& Lundberg, U. (2011). Postpartum depressive symptoms and the combined load of paid and unpaid work: A longitudinal analysis. International Archives of Occupational and Environmental Health, 84, 735-743.

Greenberg, P. E., Kessler, R. C., Birnbaum, H. G., Leong, S. A., Lowe, S. W., Berglund, P. A., \& Corey-Lisle, P. K. (2003). The economic burden of depression in the United States: how did it change between 1990 and 2000?. Journal of Clinical Psychiatry, 64, 1465-1475.

Hock, E. \& DeMeis, D. K. (1990). Depression in mothers of infants: The role of maternal employment. Developmental Psychology, 26, 285.

Klein, M. H., Hyde, J. S., Essex, M. J., \& Clark, R. (1998). Maternity leave, role quality, work involvement, and mental health one year after delivery. Psychology of Women Quarterly, 22, 239-266.

Lerner, D., Adler, D., Hermann, R. C., Chang, H., Ludman, E. J., Greenhill, A., \& Rogers, W. H. (2012). Impact of a work-focused intervention on the productivity and symptoms of employees with depression. Journal of Occupational and Environmental Medicine, 54, 128. 
McGovern, P., Dagher, R. K., Rice, H. R., Gjerdingen, D., Dowd, B., Ukestad, L. K., \& Lundberg, U. (2011). A longitudinal analysis of total workload and women's health after childbirth. Journal of Occupational and Environmental Medicine / American College of Occupational and Environmental Medicine, 53, 497-505.

McGovern, P., Dowd, B., Gjerdingen, D., Dagher, R., Ukestad, L., McCaffrey, D., \& Lundberg, U. (2007). Mothers' health and work-related factors at 11 weeks postpartum. Annals of Family Medicine, 5, 519-527.

McGovern, P., Dowd, B., Gjerdingen, D., Moscovice, I., Kochevar, L., \& Lohman, W. (1997). Time off work and the postpartum health of employed women. Medical Care, 35, 507-521.

Perry-Jenkins, M. (2011). Working-class jobs and new parents' mental health. The Journal of Industrial Economics, 59, 1117-1132.

Perry-Jenkins, M., Goldberg, A. E., Pierce, C. P., \& Sayer, A. G. (2007). Shift work, role overload, and the transition to parenthood. Journal of Marriage and the Family, 69, 123-138.

Usdansky, M. L., Gordon, R. A., Wang, X., \& Gluzman, A. (2012). Depression risk among mothers of young children: The role of employment preferences, labor force status and job quality. Journal of Family and Economic Issues, 33, 83-94. 


\section{Appendix}

\section{SURVEY QUESTIONS \& CONSENT}

Thank you for your interest in our study. Our research agenda is to establish a list of research-based best practices to guide Human Resource Development professionals in helping new moms transition back to work after maternity leave, cope with PPD symptoms at work, and foster social support in the workplace. Please answer the following questions to the best of your abilities make sure you are a good match for our study.

Please select your gender.

O Male (1)

Female (2)

Do you have a child who is 12 months old or younger?

Yes (1)

O No (2)

Are you currently working?

Yes (1)

No (2)

Answer If Are you currently working? No Is Selected Or Do you have a child who is 12 months old or younger? No Is Selected Or Please select your gender. Male Is Selected

Sorry, you are not a match for this study. Thank you for your time.

If Sorry, you are not a match ... Is Displayed, Then Skip To End of Survey

ADULT ONLINE CONSENT TO PARTICIPATE IN A RESEARCH STUDY

The Impact of Online Social Support on Workplace Absenteeism and Presenteeism in Women with Postpartum Depression Symptoms

PURPOSE OF THE STUDY

You are being asked to be in a research study. The purpose of this study is to investigate whether participation in online support groups is associated with higher work impairment in women with postpartum depression symptoms.

NUMBER OF STUDY PARTICIPANTS

If you decide to be in this study, you will be one of 150 people in this research study. 


\section{DURATION OF THE STUDY}

Your participation will require approximately 30 minutes of your time.

\section{PROCEDURES}

If you agree to be in the study, we will ask you to do the following things: 1 . Answer 49 questions related to your postpartum depression symptoms, work impairment, online support group participation, and demographic information.

\section{RISKS AND/OR DISCOMFORTS}

The following risks may be associated with your participation in this study: There are no known risks associated with participating in this study.

\section{BENEFITS}

The following benefits may be associated with your participation in this study: There are no known benefits associated with participating in this study.

\section{ALTERNATIVES}

There are no known alternatives available to you other than not taking part in this study. However, any significant new findings developed during the course of the research which may relate to your willingness to continue participation will be provided to you.

\section{CONFIDENTIALITY}

The records of this study will be kept private and will be protected to the fullest extent provided by law. In any sort of report we might publish, we will not include any information that will make it possible to identify a subject. Research records will be stored securely and only the researcher team will have access to the records. However, your records may be reviewed for audit purposes by authorized University or other agents who will be bound by the same provisions of confidentiality.

\section{COMPENSATION \& COSTS}

There will be not compensation associated with your participation in this study.

\section{RIGHT TO DECLINE OR WITHDRAW}

Your participation in this study is voluntary. You are free to participate in the study or withdraw your consent at any time during the study. Your withdrawal or lack of participation will not affect any benefits to which you are otherwise entitled. The investigator reserves the right to remove you without your consent at such time that they feel it is in the best interest. 


\section{RESEARCHER CONTACT INFORMATION}

If you have any questions about the purpose, procedures, or any other issues relating to this research study you may contact Dr. Thomas Reio at Reiot@fiu.edu.

\section{IRB CONTACT INFORMATION}

If you would like to talk with someone about your rights of being a subject in this research study or about ethical issues with this research study, you may contact the FIU Office of Research Integrity by phone at 305-348-2494 or by email at ori@fiu.edu.

\section{PARTICIPANT AGREEMENT}

I have read the information in this consent form and agree to participate in this study. I have had a chance to ask any questions I have about this study, and they have been answered for me. By clicking on the "consent to participate” button below I am providing my informed consent.

\section{O I agree. (1) \\ I disagree. (2)}

\section{If I disagree. Is Selected, Then Skip To End of Survey}

As you have recently had a baby, we would like to know how you are feeling.

Please check the answer that comes closest to how you have felt IN THE PAST SEVEN DAYS, not just how you feel today.

Here is an example, already completed.

I have felt happy:

$\square$ Yes, all of the time

$\otimes$ Yes, most of the time

No, not very often

No, not at all

This would mean: "I have felt happy most of the time" during the past week. Please complete the other questions in the same way.

In the past seven days, I have been able to laugh and see the funny side of things

As much as I always could (0)

Not quite so much now (1)

Definitely not so much now (2)

O Not at all (3) 
In the past seven days, I have looked forward with enjoyment to things

As much as I ever did (0)

Rather less than I used to (1)

Definitely less than I used to (2)

Hardly at all (3)

In the past seven days, I have blamed myself unnecessarily when things went wrong

Yes, most of the time (3)

Yes, some of the time (2)

Not very often (1)

No, never (0)

In the past seven days, I have been anxious or worried for no good reason

No, not at all (0)

Hardly ever (1)

O Yes, sometimes (2)

Yes, very often (3)

In the past seven days, I have felt scared or panicky for no very good reason

Yes, quite a lot (3)

Yes, sometimes (2)

No, not much (1)

No, not at all (0)

In the past seven days, things have been getting on top of me

Yes, most of the time I haven't been able to cope at all (3)

Yes, sometimes I haven't been coping as well as usual (2)

No, most of the time I have coped quite well (1)

No, I have been coping as well as ever (0)

In the past seven days, I have been so unhappy that I have had difficulty sleeping

Yes, most of the time (3)

Yes, sometimes (2)

Not very often (1)

No, not at all (0)

In the past seven days, I have felt sad or miserable 
Yes, most of the time (3)

Yes, quite often (2)

Not very often (1)

No, not at all (0)

In the past seven days, I have been so unhappy that I have been crying

Yes, most of the time (3)

Yes, quite often (2)

Only occasionally (1)

No, never (0)

In the past seven days, sometimes things (or life) have seemed a little too much for me.

Yes, most of the time (3)

Yes, quite often (2)

Only occasionally (1)

No, never (0)

The following questions ask about the effect of postpartum depression on your ability to work and perform regular activities. Please select an answer or fill in the blanks, as indicated. Are you currently employed (working for pay)?

Yes (1)

No (2)

During the past seven days, how many hours did you miss from work because of problems associated with postpartum depression symptoms? Include hours you missed on sick days, times you went in late, left early, etc., because of postpartum depression symptoms. Do not include time you missed to participate in this study.

During the past seven days, how many hours did you miss from work because of any other reason, such as vacation, holidays, time off to participate in this study?

During the past seven days, how many hours did you actually work?

During the past seven days, how much did postpartum depression symptoms affect your productivity while you were working? Think about days you were limited in the amount or kind of work you could do, days you accomplished less than you would like, or days you could not do your work as carefully as usual. If postpartum depression symptoms 
affected your work only a little, choose a low number. Choose a high number if postpartum depression symptoms affected your work a great deal.

\begin{tabular}{|c|c|c|c|c|c|c|c|c|c|c|c|}
\hline & $\begin{array}{c}\text { Postpartum } \\
\text { depression } \\
\text { symptoms } \\
\text { had no } \\
\text { effect on } \\
\text { my work. } \\
0 \text { (1) }\end{array}$ & $\begin{array}{c}1 \\
(2)\end{array}$ & $\begin{array}{c}2 \\
(3)\end{array}$ & $\begin{array}{c}3 \\
(4)\end{array}$ & $\begin{array}{c}4 \\
(5)\end{array}$ & $\begin{array}{c}5 \\
(6)\end{array}$ & $\begin{array}{c}6 \\
(7)\end{array}$ & $\begin{array}{c}7 \\
(8)\end{array}$ & $\begin{array}{c}8 \\
(9)\end{array}$ & $\begin{array}{c}9 \\
(10)\end{array}$ & $\begin{array}{c}\text { Postpartum } \\
\text { depression } \\
\text { symptoms } \\
\text { completely } \\
\text { prevented } \\
\text { me from } \\
\text { working. } \\
10(11)\end{array}$ \\
\hline $\begin{array}{c}\text { Consider } \\
\text { only how } \\
\text { much } \\
\text { postpartum } \\
\text { depression } \\
\text { symptoms } \\
\text { affected } \\
\text { productivity } \\
\text { while you } \\
\text { were } \\
\text { working. } \\
(1)\end{array}$ & 0 & 0 & 0 & 0 & $\bigcirc$ & 0 & 0 & 0 & 0 & 0 & 0 \\
\hline
\end{tabular}

During the past seven days, how much did your postpartum depression symptoms affect your ability to do your regular daily activities, other than work at a job? By regular activities, we mean the usual activities you do, such as work around the house, shopping, childcare, exercising, studying, etc. Think about times you were limited in the amount or kind of activities you could do and times you accomplished less than you would like. If postpartum depression affected your activities only a little, choose a low number. Choose a high number if postpartum depression symptoms affected your activities a great deal.

\begin{tabular}{|c|c|c|c|c|c|c|c|c|c|c|c|}
\hline & $\begin{array}{l}\text { Postpartum } \\
\text { depression } \\
\text { symptoms } \\
\text { had no } \\
\text { effect on } \\
\text { my work. } \\
0 \text { (1) }\end{array}$ & $\begin{array}{c}1 \\
(2)\end{array}$ & $\begin{array}{c}2 \\
(3)\end{array}$ & $\begin{array}{c}3 \\
(4)\end{array}$ & $\begin{array}{c}4 \\
(5)\end{array}$ & $\begin{array}{c}5 \\
(6)\end{array}$ & $\begin{array}{c}6 \\
(7)\end{array}$ & $\begin{array}{c}7 \\
(8)\end{array}$ & $\begin{array}{c}8 \\
(9)\end{array}$ & $\begin{array}{c}9 \\
(10)\end{array}$ & $\begin{array}{c}\text { Postpartum } \\
\text { depression } \\
\text { symptoms } \\
\text { completely } \\
\text { prevented } \\
\text { me from } \\
\text { working. } \\
10(11)\end{array}$ \\
\hline $\begin{array}{l}\text { Consider } \\
\text { only how }\end{array}$ & 0 & 0 & 0 & 0 & 0 & 0 & 0 & 0 & 0 & 0 & 0 \\
\hline
\end{tabular}




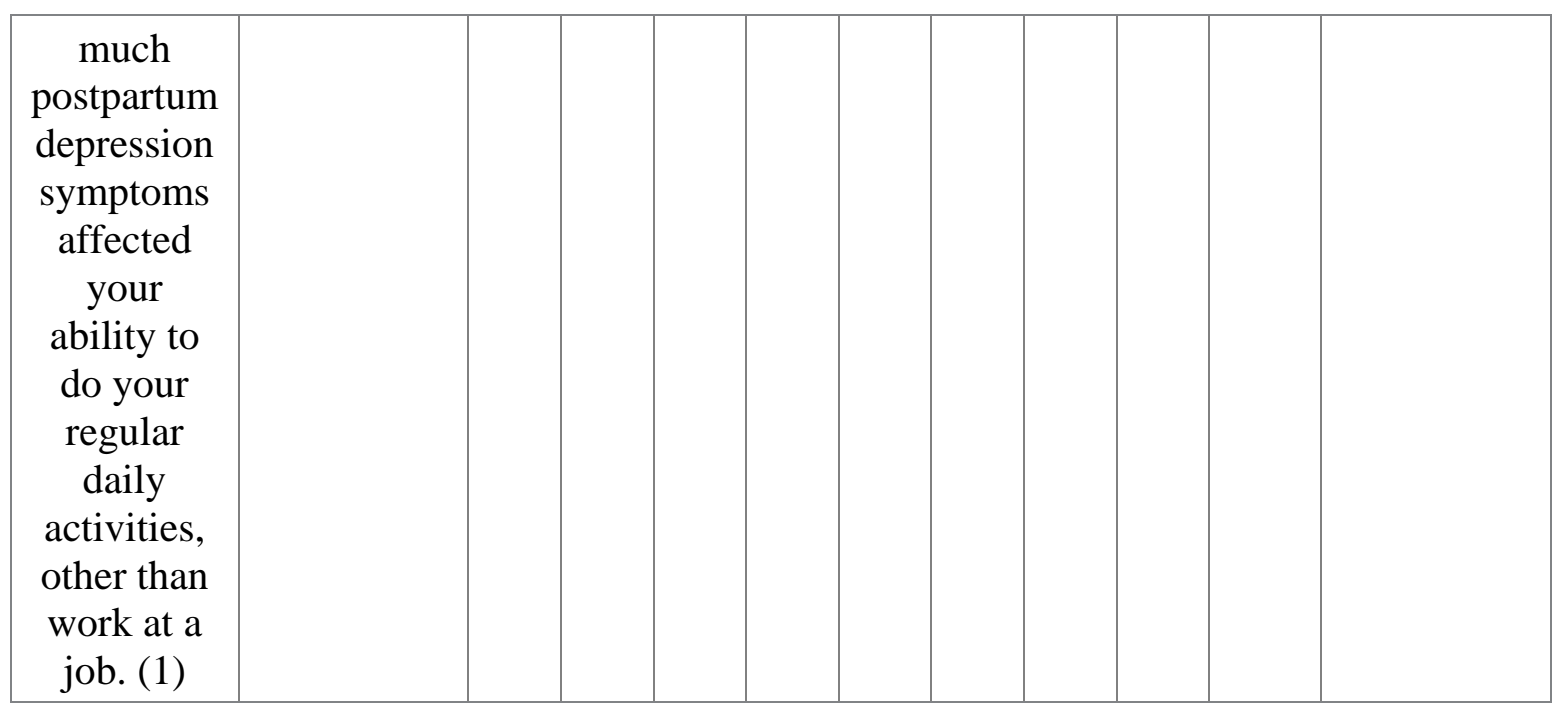

What is your current job title?

How many years of work experience do you have related to your current job?

During what month and year did you begin your current job?

How many hours per week do you work on average?
O $0-19(1)$
O $20-29(2)$
O $30-39$ (3)
O $40-49$ (4)
O 50 or more (5) 
What type of organization do you work for?

O retail (e.g., hardware store, clothing store) (1)

O manufacturing (2)

O government (military) (3)

government (non-military) (4)

non-profit service (non-government) (5)

O college or university (6)

O hospital or medical facility (7)

O restaurant (8)

for-profit service (besides retail or restaurant; e.g., a bank) (please specify) (9)

professional service (e.g., architect, police officer, lawyer) (please specify) (10)

Other (please specify) (11)

Have you ever read messages on an online support group related to postpartum depression?

O Yes (1)

O No (2)

If Yes Is Selected, Then Skip To The following questions will be about...If No Is Selected, Then Skip To Have you ever posted messages related...

Have you ever posted messages related to postpartum depression symptoms in an online support group?

Y Yes (1)

O No (2)

If Yes Is Selected, Then Skip To The following questions will be about...If No Is Selected, Then Skip To End of Block 
The following questions will be about your participation in online support groups. Please indicate your level of agreement with the statement.

\begin{tabular}{|c|c|c|c|c|}
\hline & $\begin{aligned} 1= & \text { disagree a } \\
& \text { lot }(1)\end{aligned}$ & $\begin{array}{c}2=\text { disagree a } \\
\text { little (2) }\end{array}$ & $\begin{array}{c}3=\text { agree a } \\
\text { little (3) }\end{array}$ & $\begin{array}{c}4=\underset{\text { agree } a \text { lot }}{\text { (4) }} \\
\text { (a) }\end{array}$ \\
\hline $\begin{array}{l}\text { I connected with } \\
\text { other people in } \\
\text { an online } \\
\text { support group } \\
\text { on topics other } \\
\text { than postpartum } \\
\text { depression. (1) }\end{array}$ & 0 & 0 & 0 & 0 \\
\hline $\begin{array}{c}\text { I never posted } \\
\text { messages in an } \\
\text { online support } \\
\text { group. (2) }\end{array}$ & 0 & 0 & 0 & 0 \\
\hline $\begin{array}{l}\text { I felt } \\
\text { comfortable } \\
\text { sharing private } \\
\text { or personal } \\
\text { thoughts with } \\
\text { other members } \\
\text { of an online } \\
\text { support group in } \\
\text { the public } \\
\text { forums. (3) }\end{array}$ & 0 & 0 & 0 & 0 \\
\hline $\begin{array}{l}\text { I felt } \\
\text { comfortable } \\
\text { sharing private } \\
\text { or personal } \\
\text { thoughts } \\
\text { through direct } \\
\text { messages to } \\
\text { individual } \\
\text { members of in } \\
\text { an online } \\
\text { support group. } \\
\text { (4) }\end{array}$ & 0 & 0 & 0 & 0 \\
\hline $\begin{array}{l}\text { By giving } \\
\text { advice to other } \\
\text { members of in } \\
\text { an online } \\
\text { support group, }\end{array}$ & 0 & 0 & 0 & 0 \\
\hline
\end{tabular}




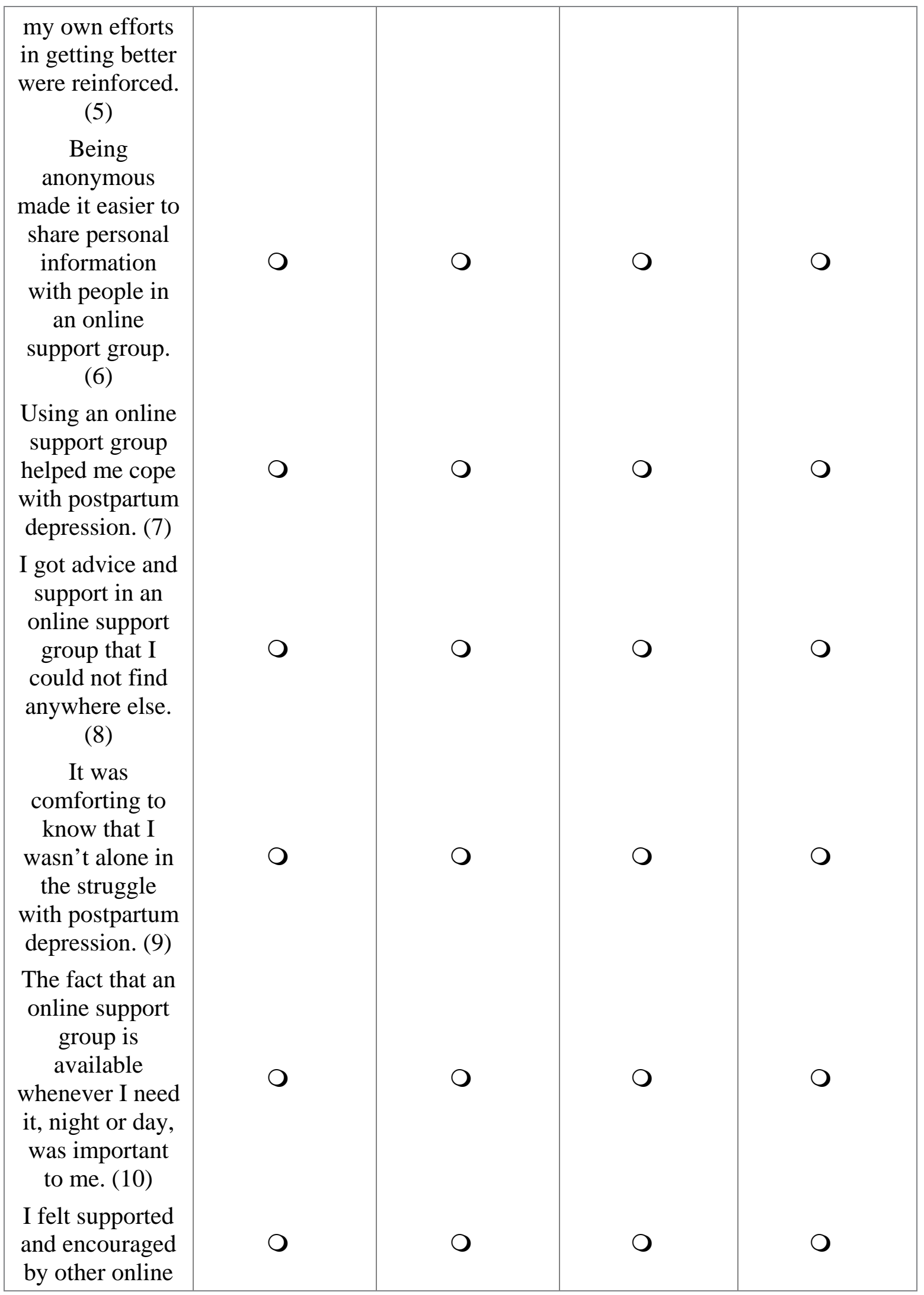




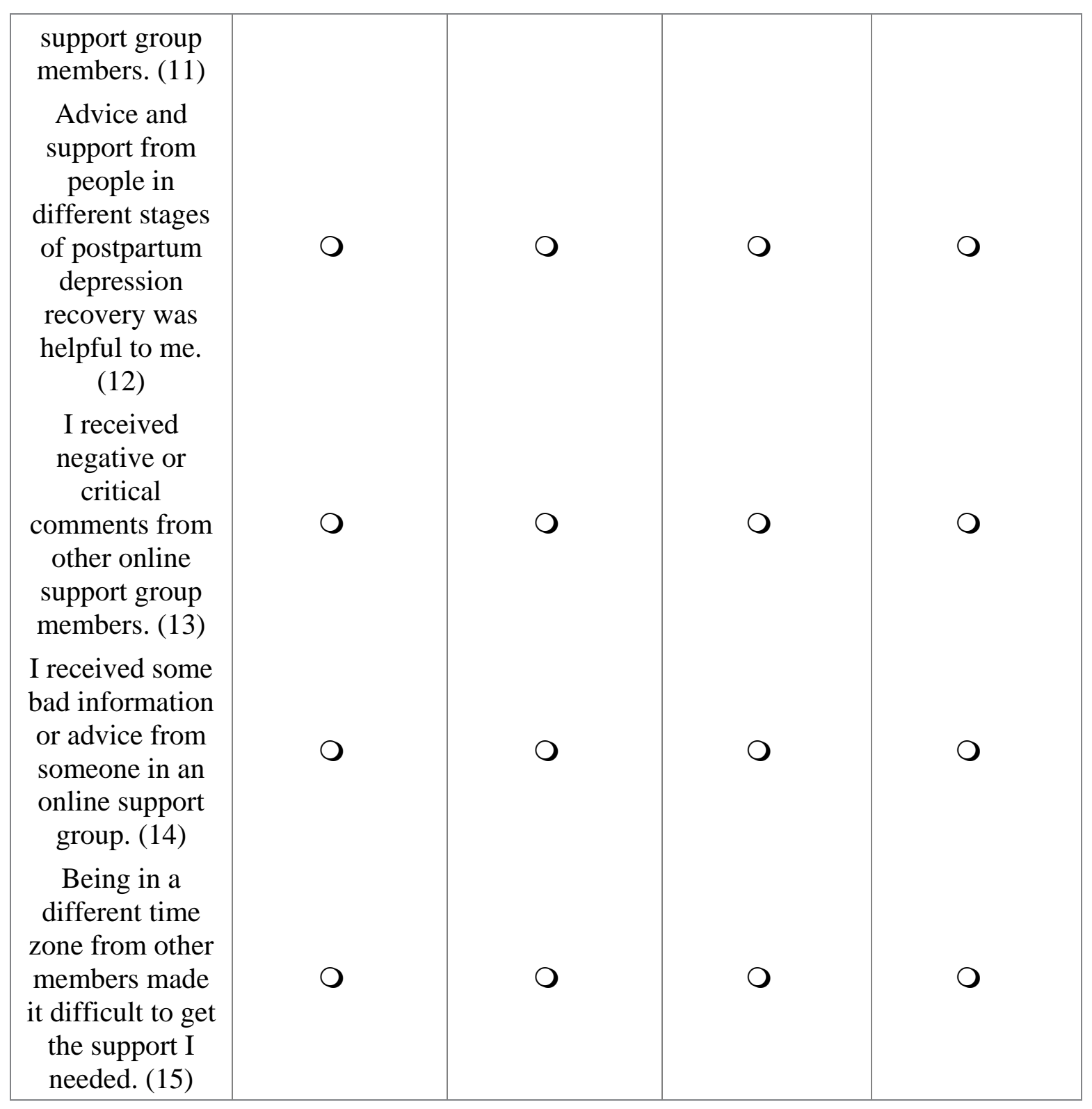

How much time per week do you spend reading or posting in postpartum depression online support groups? Indicate if time spent is in minutes or hours.

How long have you been participating in reading or posting in postpartum depression online support groups? Please indicate if time spent is in weeks, months or years.

What is your age?

How old is your youngest child (in months)?

How soon after the birth of your youngest child did you return to work? 
Were you eligible for leave through the Family Medical Leave Act (FMLA)?
O Yes (1)
O No (2)
O I don't know (3)

What is your total annual household income from all sources?
O less than $\$ 20,000(1)$
O $\$ 20,001-\$ 30,000(2)$
O $\$ 30,001-\$ 40,000(3)$
O $\$ 40,001-\$ 50,000(4)$
O $\$ 50,001-\$ 60,000(5)$
O $\$ 60,001-\$ 70,000(6)$
greater than $\$ 70,000$ (7)

What is your race/national origin?
O Asian (1)
O Black (2)
O Hispanic (3)
O White (4)
O Other (5)

What is the highest level of education you have achieved in school? 
less than high school (1)

O high school diploma or GED (2)

O some college (3)

Bachelor's degree (4)

Graduate degree (5)

In which country do you reside?

Afghanistan (1)

O Albania (2)

O Algeria (3)

O Andorra (4)

O Angola (5)

O Antigua and Barbuda (6)

Orgentina (7)

O Armenia (8)

Australia (9)

O Austria (10)

O Azerbaijan (11)

O Bahamas (12)

O Bahrain (13)

Bangladesh (14)

Barbados (15)

O Belarus (16)

Belgium (17)

Belize (18)

O Benin (19)

Bhutan (20)

O Bolivia (21)

Bosnia and Herzegovina (22)

Botswana (23)

Brazil (24)

O Brunei Darussalam (25)

O Bulgaria (26)

O Burkina Faso (27)

O Burundi (28)

O Cambodia (29)

O Cameroon (30)

O Canada (31)

O Cape Verde (32) 
Central African Republic (33)

O Chad (34)

O Chile (35)

O China (36)

O Colombia (37)

O Comoros (38)

O Congo, Republic of the... (39)

O Costa Rica (40)

O Côte d'Ivoire (41)

O Croatia (42)

O Cuba (43)

O Cyprus (44)

O Czech Republic (45)

O Democratic People's Republic of Korea (46)

O Democratic Republic of the Congo (47)

O Denmark (48)

O Djibouti (49)

O Dominica (50)

O Dominican Republic (51)

O Ecuador (52)

O Egypt (53)

O El Salvador (54)

O Equatorial Guinea (55)

O Eritrea (56)

O Estonia (57)

O Ethiopia (58)

O Fiji (59)

O Finland (60)

O France (61)

O Gabon (62)

O Gambia (63)

O Georgia (64)

O Germany (65)

O Ghana (66)

O Greece (67)

O Grenada (68)

O Guatemala (69)

O Guinea (70)

O Guinea-Bissau (71) 


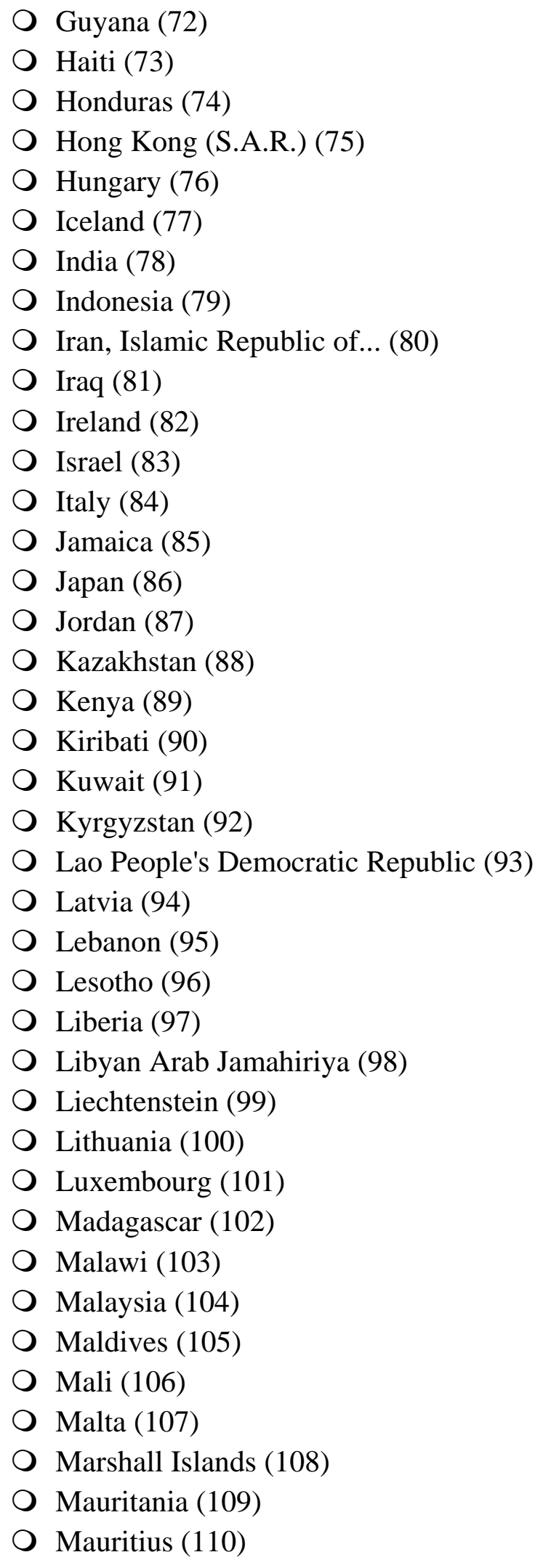


Mexico (111)

O Micronesia, Federated States of... (112)

O Monaco (113)

O Mongolia (114)

O Montenegro (115)

O Morocco (116)

O Mozambique (117)

O Myanmar (118)

O Namibia (119)

O Nauru (120)

O Nepal (121)

O Netherlands (122)

New Zealand (123)

O Nicaragua (124)

O Niger (125)

O Nigeria (126)

North Korea (127)

O Norway (128)

O Oman (129)

O Pakistan (130)

O Palau (131)

O Panama (132)

O Papua New Guinea (133)

P Paraguay (134)

P Peru (135)

Philippines (136)

O Poland (137)

O Portugal (138)

O Qatar (139)

O Republic of Korea (140)

O Republic of Moldova (141)

Romania (142)

O Russian Federation (143)

O Rwanda (144)

Saint Kitts and Nevis (145)

Saint Lucia (146)

O Saint Vincent and the Grenadines (147)

Samoa (148)

O San Marino (149) 
O Sao Tome and Principe (150)

O Saudi Arabia (151)

O Senegal (152)

O Serbia (153)

O Seychelles (154)

O Sierra Leone (155)

O Singapore (156)

O Slovakia (157)

O Slovenia (158)

O Solomon Islands (159)

O Somalia (160)

O South Africa (161)

O South Korea (162)

O Spain (163)

O Sri Lanka (164)

O Sudan (165)

O Suriname (166)

O Swaziland (167)

O Sweden (168)

O Switzerland (169)

O Syrian Arab Republic (170)

O Tajikistan (171)

O Thailand (172)

The former Yugoslav Republic of Macedonia (173)

O Timor-Leste (174)

O Togo (175)

O Tonga (176)

O Trinidad and Tobago (177)

O Tunisia (178)

O Turkey (179)

O Turkmenistan (180)

O Tuvalu (181)

O Uganda (182)

O Ukraine (183)

O United Arab Emirates (184)

O United Kingdom of Great Britain and Northern Ireland (185)

O United Republic of Tanzania (186)

O United States of America (187)

O Uruguay (188) 
O Uzbekistan (189)

O Vanuatu (190)

O Venezuela, Bolivarian Republic of... (191)

O Viet Nam (192)

O Yemen (193)

O Zambia (194)

O Zimbabwe (195)

How did you find out about this research study?

through an online support group (please specify) (1)

O through Facebook (2)

O through Twitter (3)

O through a Clinician or Doctor (4)

O through another participant or friend (5)

Thank you for your input. You may now exit this survey. 
VITA

\title{
CYNTIANNA C. LEDESMA ORTEGA
}

\author{
Miami, Florida
}

2003-2006

B.S. Journalism and Mass Communication

Florida International University

Miami, Florida

2006-2011

Language Arts Teacher

Miami Dade County Public Schools

Miami, Florida

2009-2010

M.S., Curriculum and Instruction

Florida International University

Miami, Florida

2011-2014

Instructional Designer 3

Florida International University

Miami, Florida

2011-2015

Doctoral Candidate

Florida International University

Miami, Florida

2013

Teaching Assistant

Florida International University

Miami, Florida

2014-Present

Senior Instructional Designer (Remote)

UnitedHealth Group

Minnetonka, Minnesota

\section{PUBLICATIONS AND PRESENTATIONS}

Thirunarayanan, M. O., Vilchez, M., Abreu, L., Ledesma, C., \& Lopez, S. (2010). A survey of video game players in a public, urban research university. Educational Media International, 47, 311-327.

Vilchez, M., Abreu, L., Ledesma, C., \& Lopez, S. (2010, April). A survey of video gamer players in a public, urban, research university. Paper presented at the International Conference on College Teaching and Learning. Orlando, FL. 
Reio, T. G., Jr., \& Ortega, C. C. L. (2013). Online learning: Demotivators and motivators of faculty online teaching participation. In V. Wang (Ed.), Handbook of research on teaching and learning in K-20 education (pp. 460-474). Hershey, PA

Ortega, C.C.L., \& Rojas, C. (2013, September). Making learning accessible: Strategies for working with students with disabilities. Presentation at the Florida Distance Learning Association Conference. Orlando, FL.

Ortega, C. C. L., \& Chavez, J. (2014, June). Minding the gap: Trending toward older online students. In S. M. Nielsen (Ed.), Proceedings of the $13^{\text {th }}$ annual South Florida Educational Research Conference 2014, (pp. 120-128), Miami, FL: FIU College of Education.

Ortega, C.C.L., \& Chavez, J. (2015, January). Minding the gap: Trending toward older online students. Paper presented at the South Florida Educational Research Conference. Miami, FL.

Ortega, C.C.L., \& Crockett, B. (2015, March). Writing objectives and critical path. Presentation at the annual UnitedHealth Group \#Design Different eLearning Conference. Virtual.

Reio, T. G., Jr., \& Ortega, C. C. L. (in press). Cyberbullying and its emotional consequences: What we know and what we can do. In S. Tettegah \& R. Ferdig (Ed.), Emotions and technology: Communication of feelings, for, with and through digital media. 